University of South Florida

DIGITAL COMMONS

@ UNIVERSITY OF SOUTH FLORIDA
Digital Commons @ University of

South Florida

$10-1-2008$

\title{
Programs That Match Seniors With Volunteer Drivers
}

CUTR

Follow this and additional works at: https://digitalcommons.usf.edu/cutr_nctr

\section{Recommended Citation}

"Programs That Match Seniors With Volunteer Drivers," National Center for Transit Research (NCTR) Report No. CUTR-NCTR-RR-2007-04, Center for Urban Transportation Research, University of South Florida, 2008.

DOI: https://doi.org/10.5038/CUTR-NCTR-RR-2007-04

Available at: https://scholarcommons.usf.edu/cutr_nctr/159

This Technical Report is brought to you for free and open access by the National Center for Transit Research (NCTR) Archive (2000-2020) at Digital Commons @ University of South Florida. It has been accepted for inclusion in Research Reports by an authorized administrator of Digital Commons @ University of South Florida. For more information, please contact digitalcommons@usf.edu. 


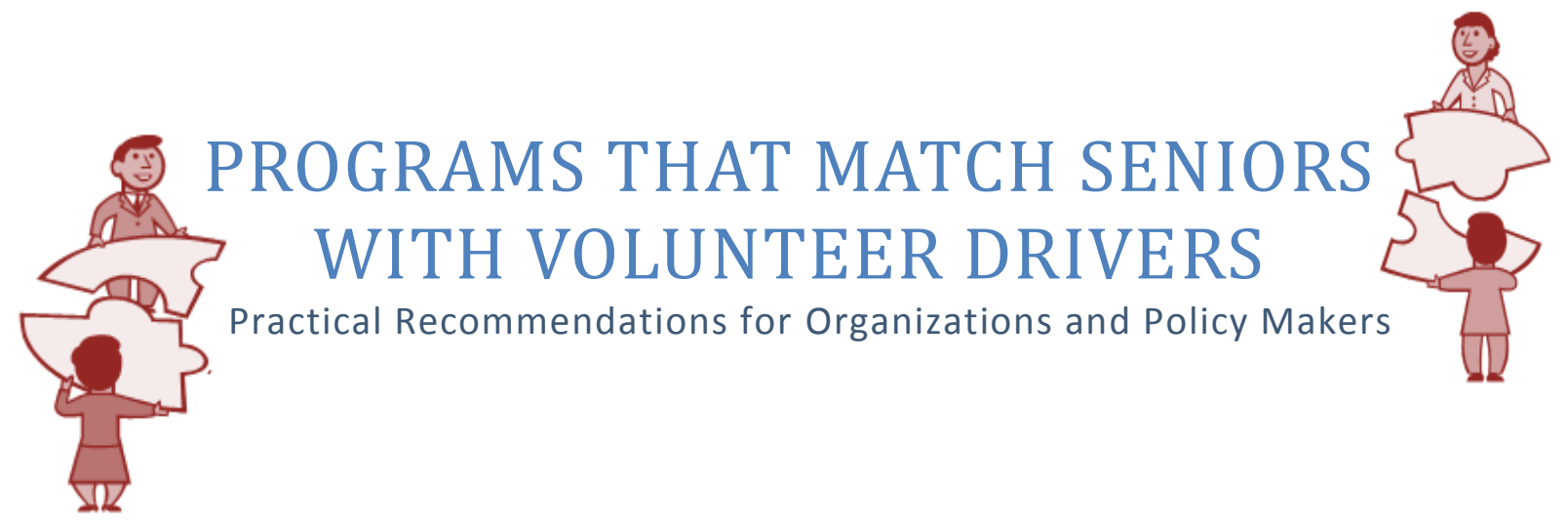

FDOT BD549 WO 41

Final Report
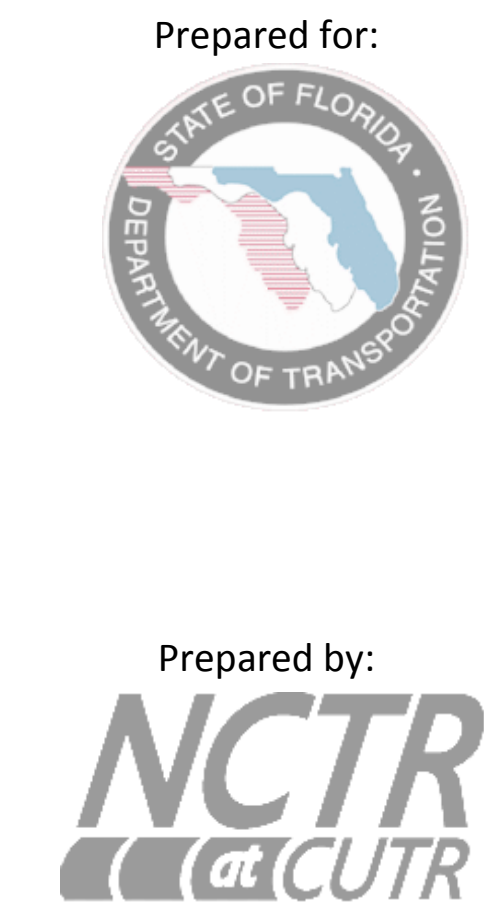

University of South Florida

4202 East Fowler Avenue, CUT100

Tampa, FL 33620-5375 
DISCLAIMER

The opinions, findings, and conclusions expressed in this publication are those of the author(s) who are responsible for the facts and accuracy of the data presented herein. The contents do not necessarily reflect the views or policies of the Florida Department of Transportation or the Research and Special Programs Administration. This report does not constitute a standard, specification, or regulation.

The report is prepared in cooperation with the State of Florida Department of Transportation and the U.S. Department of Transportation. 


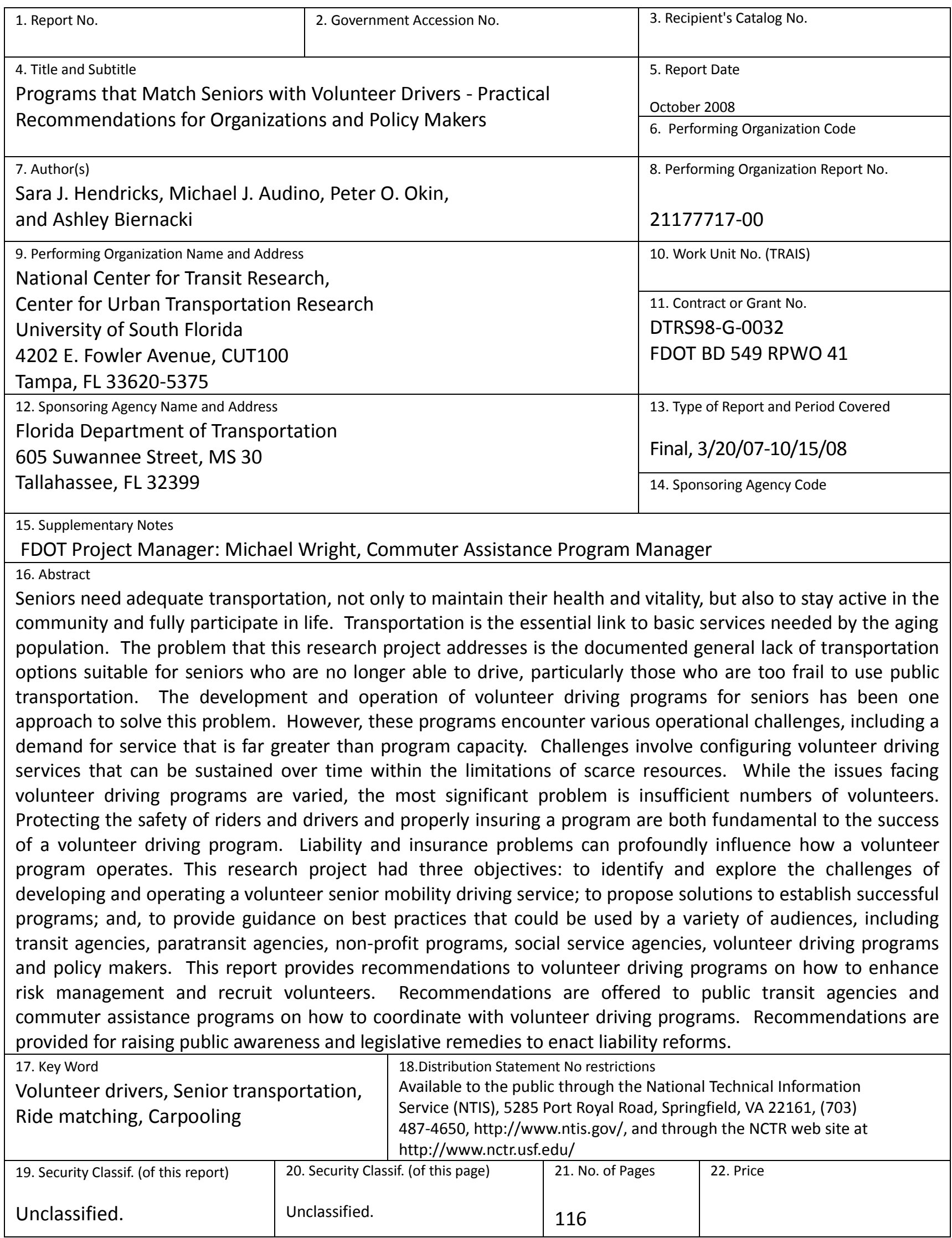




\section{ACKNOWLEDGEMENTS}

The Center for Urban Transportation Research developed this study in response to a research idea received through solicitation of problem statements from the transportation profession and the public. The problem statement was submitted by Lori Diggins, Chair of the Transportation Demand Management Institute of the Association for Commuter Transportation and Eric Schreffler, Chair of the Transportation Demand Management Committee of the Transportation Research Board of The National Academies. This research has been funded by the Florida Department of Transportation under the sponsorship of the National Center for Transit Research.

The authors gratefully acknowledge the assistance provided by members of an expert advisory panel, listed below. However, the opinions, findings, and conclusions expressed in this report, including any errors of fact or omission are solely those of the authors.

Liz Accles

Valerie Anderson

Fran Carlin-Rogers

Buddy Cloud

Jennifer Chandler-Hauge

Maureen Kelly

Denise Niese

Jackie Sims

Dennis Zegarac
Ride Provide, TransOptions, Cedar Knolls, New Jersey

Assistant Director of Patient Services, American Cancer Society, Florida Division Office, Tampa, Florida

President, ITNOrlando ${ }^{\circledR}$, Florida and Senior Transportation Consultant, Carlin Rogers Consulting, LLC Florida State Department of Elder Affairs, Tallahassee, Florida Senior Counsel and Director of Special Projects, Nonprofit Risk Management Center, Washington, D.C.

Executive Director, West Central Florida Area Agency on Aging, Tampa, Florida Executive Director, Wood County Committee on Aging, Bowling Green, Ohio Executive Director, Danville-Boyle County Gathering Place for Senior Adults, Danville, Kentucky, and delegate to the National Institute of Senior Centers Southeast lowa Area Agency on Aging, Burlington, lowa

The authors also thank those who provided valuable insight to this research effort, including:

Vicki Brooks
Neil Coppens
Laurie Coleman
Katherine Freund
Arizona Jenkins
Helen Kerschner, PhD
Ivan Maldonado
Chris Neal
Eileen O'Brien
Oliver Page
Bill Perkins
Tom Porter
Rene Robinson-Flowers
Marie-Helene Rousseau, PhD
Jean Barrett Teel
Cindy Zwart

Volunteers Insurance Service, The CIMA Companies, Inc. RidingTogether, Deltona, Florida

Volunteers Insurance Service, The CIMA Companies, Inc. Founder, President, ITNAmerica ${ }^{\circledR}$, Westbrook, Maine

President, New Horizons Support Group for Persons with Disabilities; Hillsborough Area Regional Transit, Americans with Disabilities Act Committee The Beverly Foundation, Pasadena, California Transit Operations Manager, Polk County Transit Services, Bartow, Florida Public Affairs Manager, State Farm, Florida Division Statewide Advocacy Coordinator, Florida Agency for Persons with Disabilities Assistant Research Scientist, Transportation Safety Analysis Division, University of Michigan Transportation Research Institute Instructor, Florida Association of Insurance Agents, Tallahassee, Florida ITNOrlando ${ }^{\circledR}$, Orlando, Florida EZride Program Manager, Neighborly Care Network, St. Petersburg, Florida The Beverly Foundation, Pasadena, California Executive Director, Faith In Action Caregivers-West Austin, Texas Transportation Manager, Senior Services, Seattle, Washington

Report photos used with permission from Cindy Zwart, Manager, Senior Services Transportation Program, King County, WA. 
Seniors need adequate transportation, not only to maintain their health and vitality, but also to stay active in the community and fully participate in life. Transportation is the essential link to basic services needed by the aging population. The problem that this research project addresses is the documented general lack of transportation options suitable for seniors who are no longer able to drive, particularly those who are too frail to use public transportation. One solution to this problem has been the development and operation of volunteer driving programs for seniors. However, these programs encounter various operational challenges.

The senior population is increasing, both in absolute numbers and as a proportion of total population. This shift is especially prominent in Florida. Seniors are living longer and many prefer to age in place. Seniors have generally not planned for their future transportation after driving cessation. The next generation of seniors, the "Baby Boomer" population, also is not planning for their future transportation needs. This study found that volunteer driving programs strive to meet the needs of a particular market of seniors. These seniors generally are on a fixed income, which limits their transportation options. Seniors represent a broad range of physical abilities and many develop disabilities in their later years. While travel generally decreases overall in later years, seniors have travel needs that still may include longer distance trips across jurisdictions. Many seniors have difficulty navigating the various available transportation options, and their associated eligibility, application, and advance reservation requirements to arrange a ride.

To meet the demand for transportation, many driving programs for seniors have been formed over the last several years and there are now several hundred such programs nationwide. As a result, various government and nonprofit agencies have created resource guides for the start-up and operation of volunteer driving programs for seniors. This report complements existing implementation guides by examining the challenges that remain and proposing actions for overcoming these challenges and strengthening programs. The National Center for Transit Research sponsored this research with funding through a grant from the Florida Department of Transportation Public Transit Office and the US Department of Transportation. The findings of this study concentrate on conditions in Florida but should have broad applicability to senior driving programs nationwide.

Community leaders lack general awareness of the magnitude of the problems faced by older seniors when they can no longer drive. The value of volunteer driving programs and the operational challenges these programs face are not on the "radar screens" of community leaders. The issues with which volunteer driving programs struggle include a demand for service that is far greater than program capacity. These challenges involve configuring sustainable volunteer driving services within the limitations of scarce resources. While the issues facing volunteer driving programs are varied, the problem that stands out is insufficient numbers of volunteers. This was the resounding drumbeat heard from every program examined. Secondly, while insurance and liability were cited as serious problems by only one program interviewed for this study, other previous studies conducted in Florida contained numerous references of problems faced by volunteers and volunteer driving programs nationwide with regard to obtaining insurance. As a result, this study also concentrated on liability and insurance. Protecting the safety of riders and drivers and properly insuring a program are both fundamental to the success of a volunteer driving program. Liability and insurance profoundly influence how a program operates.

Most importantly, providing quality transportation through volunteer driving programs for the growing number of seniors who need it will require the collaboration of transit agencies, commuter assistance programs, Area Agencies on Aging, the volunteer driving programs and community leaders. Support at the state and federal levels will further advance volunteer driving programs for seniors. Generally, communities that put the resources of interested organizations together can address liability and find more volunteers. 
The available evidence suggests that most volunteer driving programs for seniors have excellent safety records. The programs interviewed demonstrate strict attention to detail in managing risk. Regardless, insurers are influenced by perception of risk, specifically that volunteer drivers may lack training, and that riders are an especially vulnerable group. In fact, seniors are much more likely to sustain serious injuries in an auto accident than are younger people. Therefore, the concern by insurers may be less the frequency of accidents and more the potential for any one accident to have severe consequences.

This study examined volunteer driving programs nationwide and identified several main service delivery models. The selection of an appropriate service model constitutes one of several best practices in tailoring a program structure that most closely matches; (1) the nature of the seniors' transportation needs; (2) the aim that a program and its volunteers wish to accomplish; and (3) the combined resources (or lack thereof) of the seniors and the program. Each service model places priority on a different service or operational characteristic.

This report provides recommendations to volunteer driving programs for enhancing risk management, recruiting volunteers and supporting their organizations. Figure ES-1 outlines the recommendations for each stakeholder group and is further explained in the report. Recommendations are also offered to public transit agencies and commuter assistance programs on how to coordinate with volunteer driving programs as well as help seniors postpone their need to use volunteering driving services. Several recommendations are offered to Area Agencies on Aging, including the need to raise public awareness. Lastly, this report presents several options for action by policy makers, including legislative remedies to enact liability reforms.

For those who run volunteer driving programs or who are considering the development of a program, handy information is provided in Appendix A, Volunteer Driving Program Resources and References; Appendix B, the Volunteer Driver Turnkey Kit@ and the Senior Friendliness Calculator@; Appendix C, Examples of Volunteer Driving Program Types; and Appendix D, A Risk Pool Example. For Area Agencies on Aging and policy makers, Appendix E contains a legal analysis of risk associated with volunteer driving programs. Written by an attorney with expertise in public health, this provides the important background and rationale for several of the legislative remedies recommended in this report. Lastly, policy makers will be interested in Appendix F, which contains examples of state safety requirements for transportation for vulnerable populations. These examples contain ideas to consider as part of potential administrative and operational reforms that could set the stage for reducing the liability of volunteer drivers and volunteer driving programs.

Community leaders may feel hesitance toward establishing volunteer driving programs due to the various issues identified in this study. However, the hundreds of volunteer driving programs in operation across the nation demonstrate that these issues are manageable. Volunteer driving programs address a critical transportation need. This report proposes an agenda for action to bolster volunteer driving programs and the important transportation services they provide. 


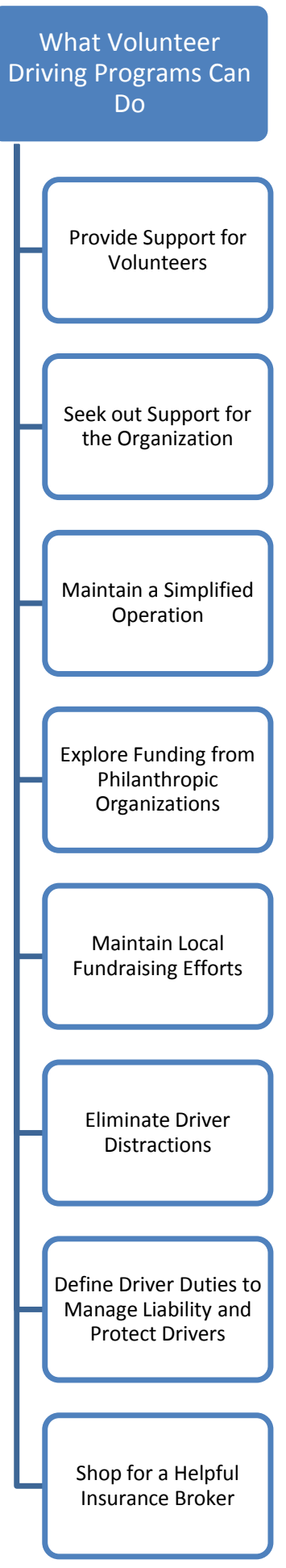

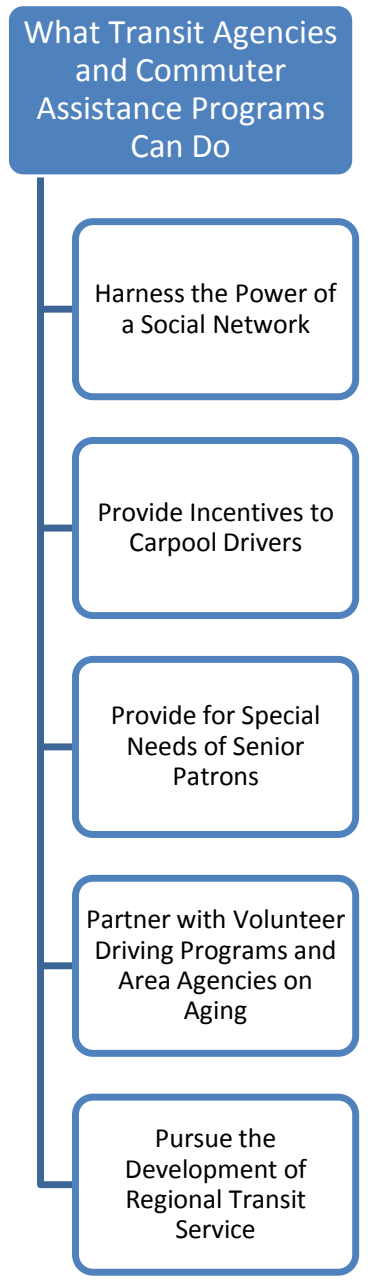
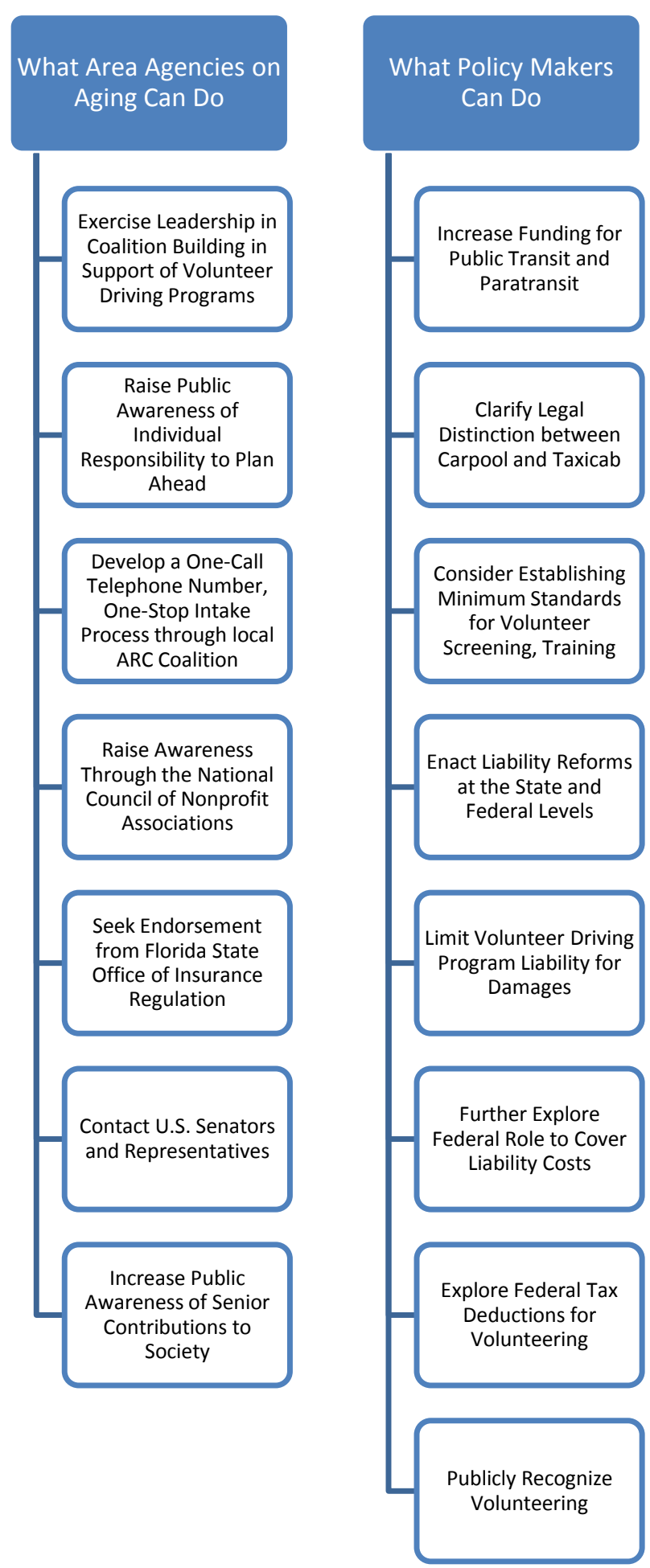

Develop a One-Call

Telephone Number

One-Stop Intake

Process through local ARC Coalition

Raise Awareness Through the National Council of Nonprofit Associations

Seek Endorsement from Florida State Office of Insurance Regulation

Contact U.S. Senators and Representatives

Increase Public Awareness of Senior Contributions to Society

Figure ES-1: Outline of Recommendations to Stakeholders 


\section{TABLE OF CONTENTS}

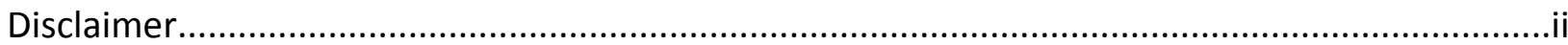

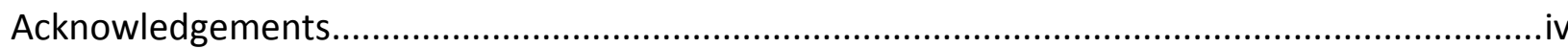

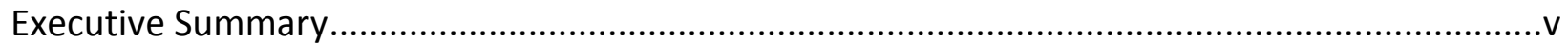

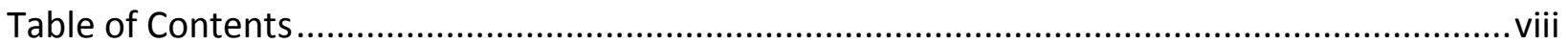

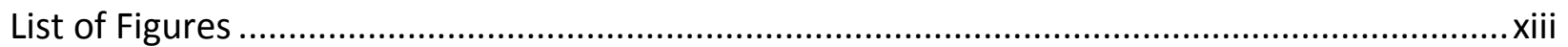

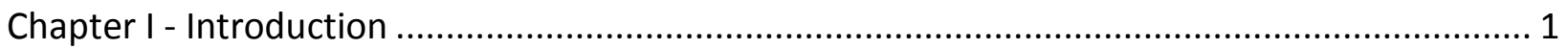

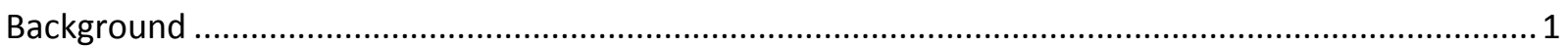

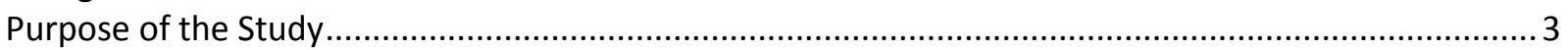

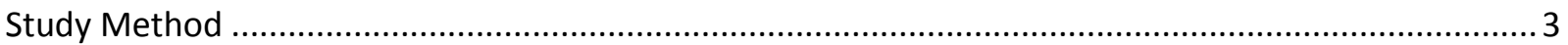

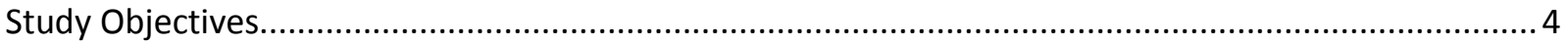

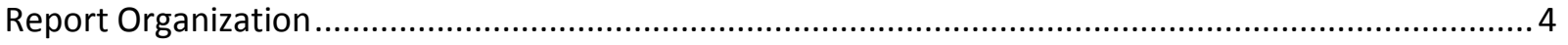

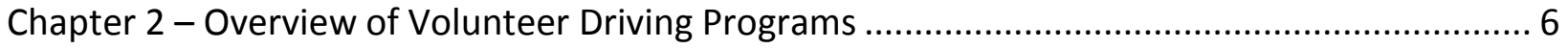

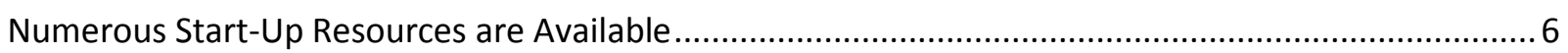

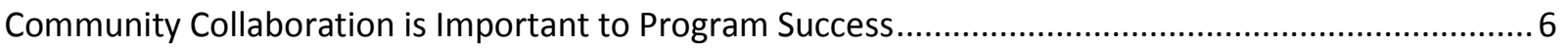

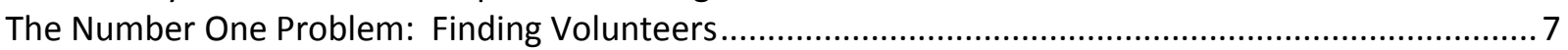

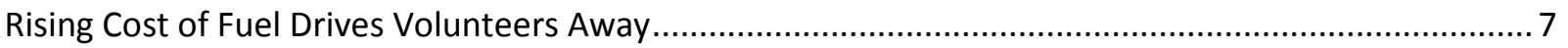

There are Many More Volunteer Recruitment Challenges................................................................ 8

Program Managers Trade Service Features to Manage Risk .............................................................. 8

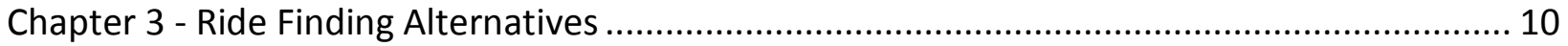

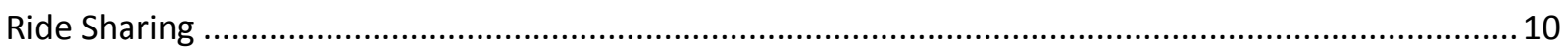

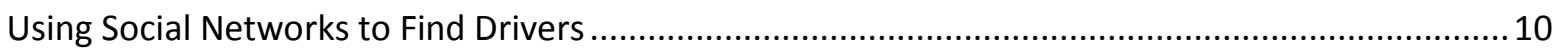

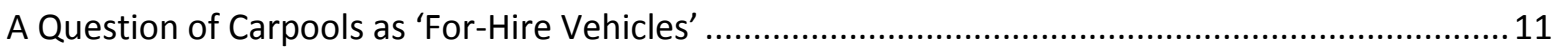

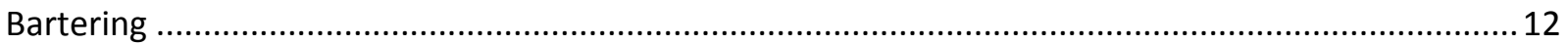

Volunteer Driving Program “Menu” of Options: Service Models ......................................................... 12

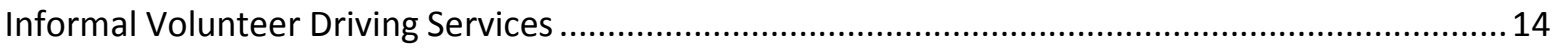

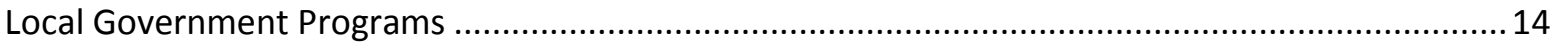

Social Service Programs Focusing on Particular Senior Market Segments..................................... 15

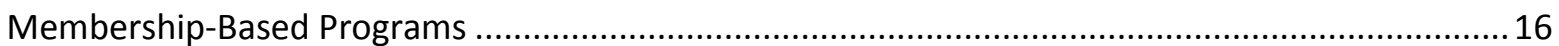

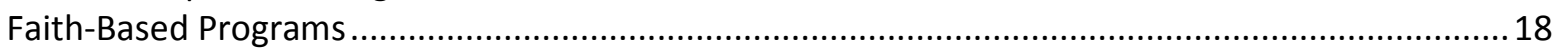

Chapter 4 - Coordination with Other Transportation Services ............................................... 23

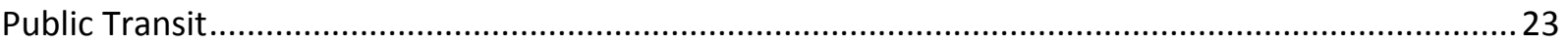

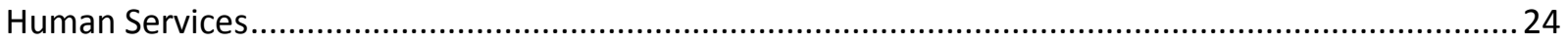

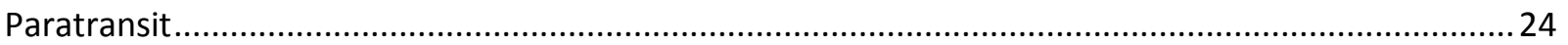

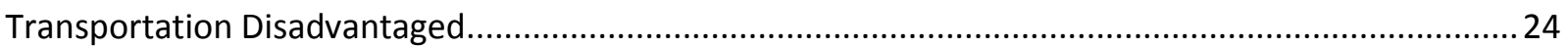

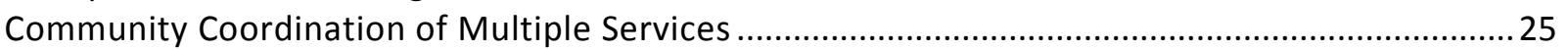

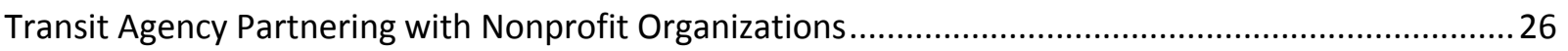

Chapter 5 - Risk, Liability, Risk Management, and Insurance ................................................ 28

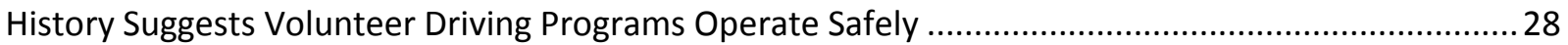

Loss/Claims Data for Volunteer Driving Programs are Not Publicly Available .....................................28

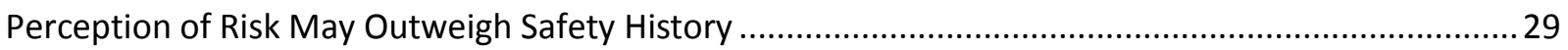

Volunteers Assume Risk and Liability ............................................................................................... 29

Thomas Muster v. General Motors Corp. et al. Uncovers Additional Essential Risk Management

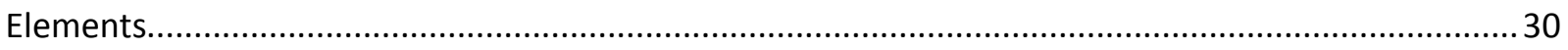




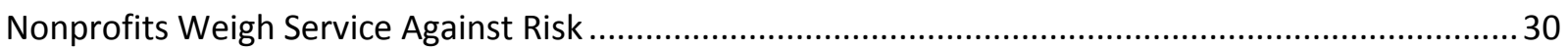

Government Programs Have the Capacity for Adequate Insurance Coverage ...................................30

Identifying and Eliminating Driver Distractions Need Emphasis.......................................................... 31

Formal Volunteering Alters the Placement and Magnitude of Liability .............................................. 31

Federal and State Volunteer Protection Acts Provide Minimal Protection to Volunteer Drivers .......... 31

Charging Fares and Hiring Paid Drivers Increase Liability to a Program .............................................. 32

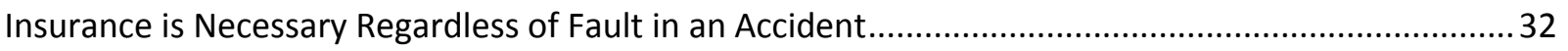

Volunteer Driving Programs Rely on the Volunteer's Personal Auto Insurance....................................32

Questions Remain Regarding Extent that Personal Auto Insurance is Available to Volunteer

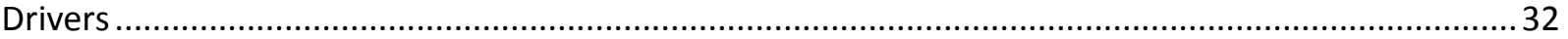

Driving More Miles Increases Exposure to Risk But Premiums Might Not Reflect This .........................34

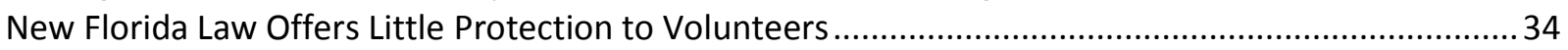

Personal No-Fault Insurance Provides Limited Protection Only ...................................................... 34

Parameters for Commercial Hired and Non-Owned Auto Insurance are Changing .............................. 35

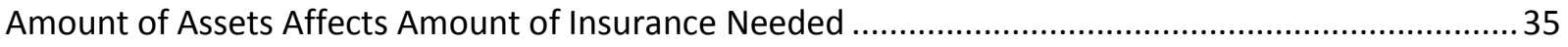

Adequate Insurance Coverage Requires the Services of a Diligent Broker ............................................35

A Legal Analysis of Risk Associated with Volunteer Driving Programs Uncovers Gaps .........................36

Minimum Requirements for Risk Management Would Set Stage for Liability Reforms ....................37

Contracts between the Volunteer Driving Program and the Rider are Recommended But

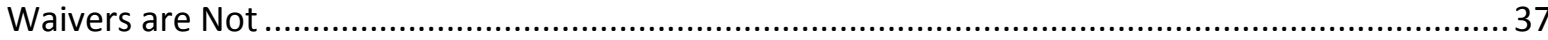

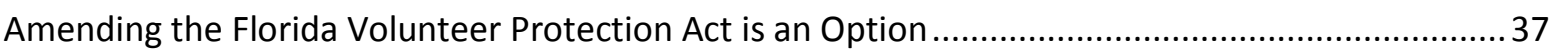

Amending the Federal Volunteer Protection Act is Another Option.............................................. 38

There are Several Options for Limiting Damages ......................................................................... 38

Chapter 6 - Conclusions and Recommendations for Action ................................................. 39

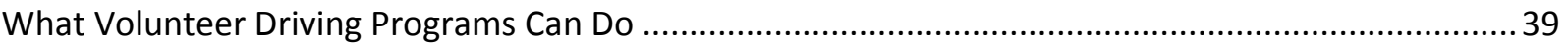

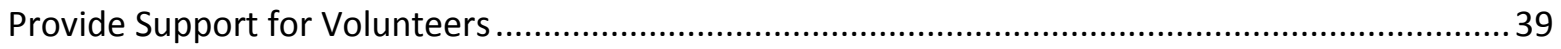

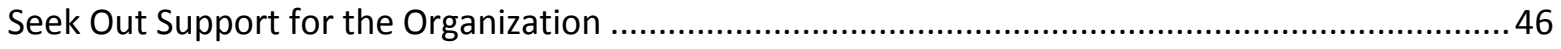

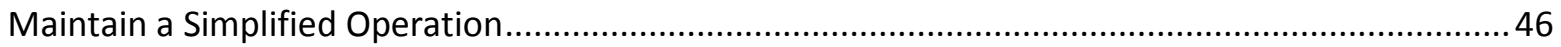

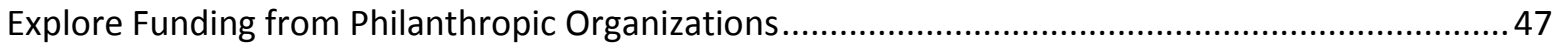

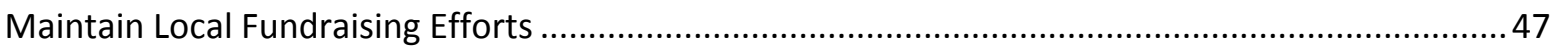

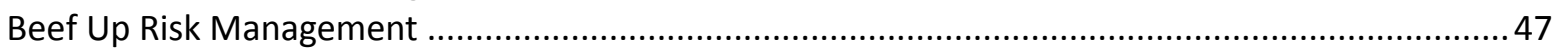

Define Driver Duties to Manage Liability and Protect Drivers..................................................... 48

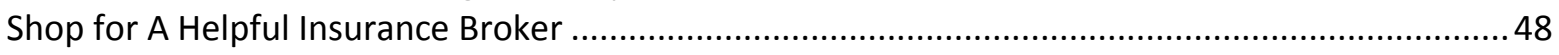

What Transit Agencies and Commuter Assistance Programs Can Do ..................................................49

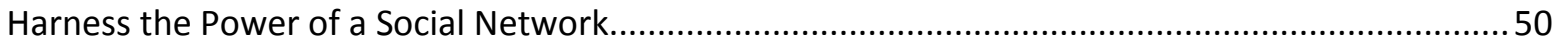

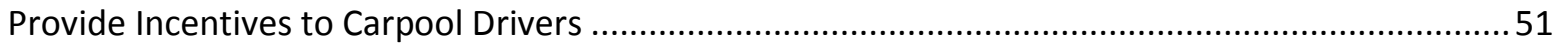

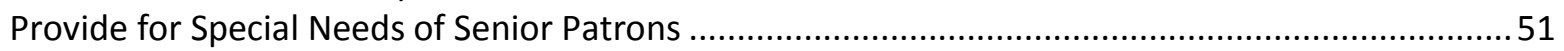

Partner with Volunteer Driver Programs and Area Agencies on Aging ......................................... 51

Pursue Development of Regional Transportation Service......................................................... 52

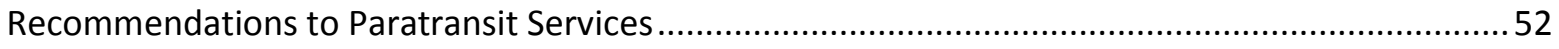

What Area Agencies on Aging Can Do to Support Volunteer Driving Programs .................................53

Collaborate with Public Transit Agencies on Information Campaigns.............................................5 54

Develop a One-Call Telephone Number, One-Stop Intake Process.............................................5 54

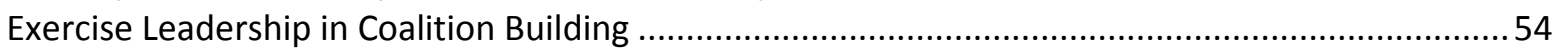

Raise Awareness Through the National Council of Nonprofit Associations .................................... 54

Seek Endorsement from Florida State Office of Insurance Regulation ............................................55 


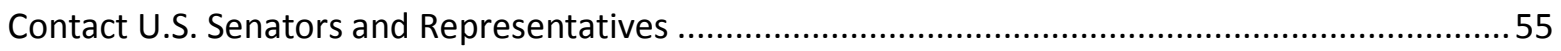

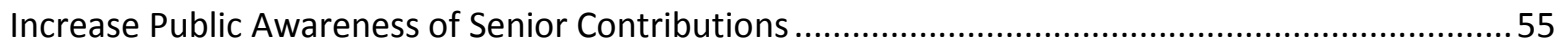

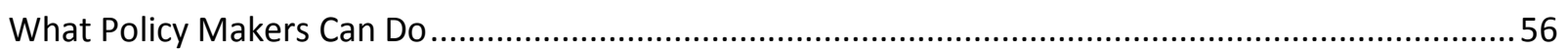

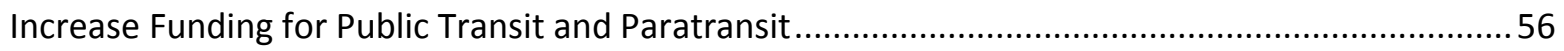

Promote and Support Regional Transportation Service Development ...........................................56

Consider Establishing Minimum Standards for Volunteer Screening, Training ................................56

Enact Liability Reforms at the State and Federal Levels ..............................................................56

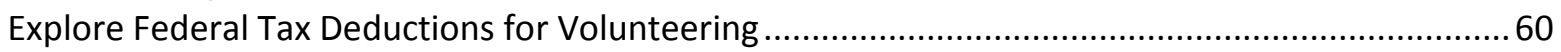

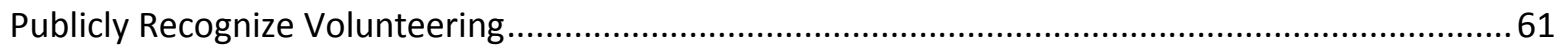

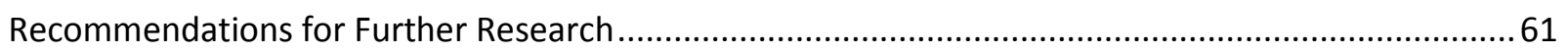

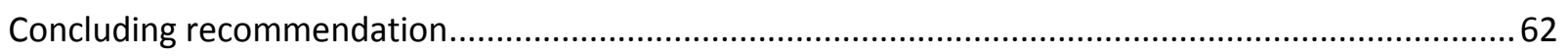

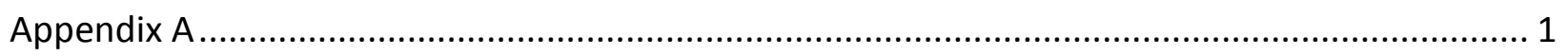

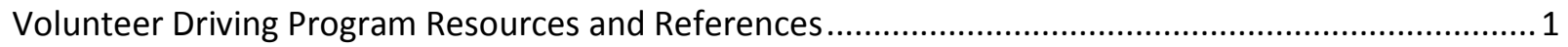

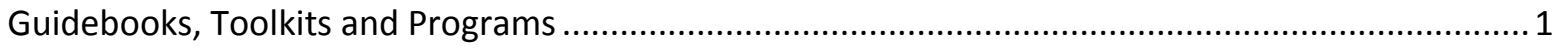

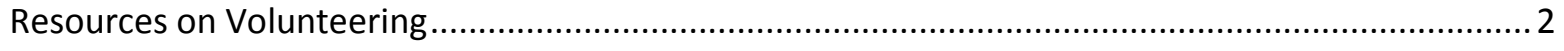

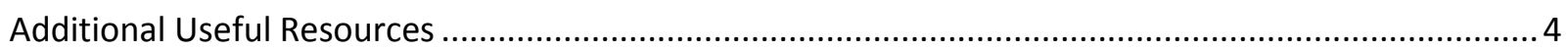

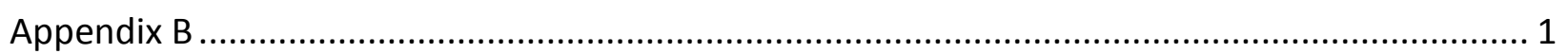

Volunteer Driver TurnKey Kit $@$ and Senior Friendliness Calculator $₫$................................................. 1

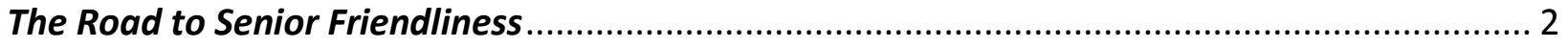

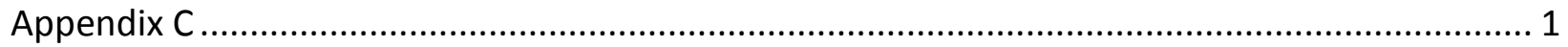

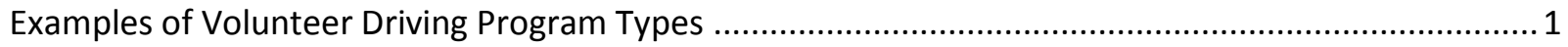

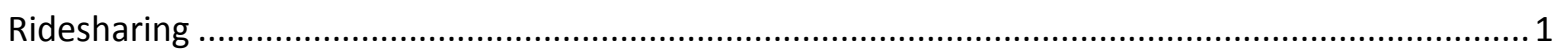

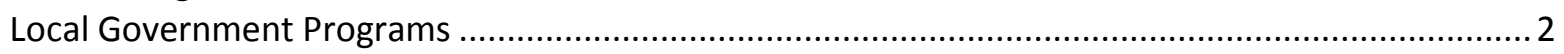

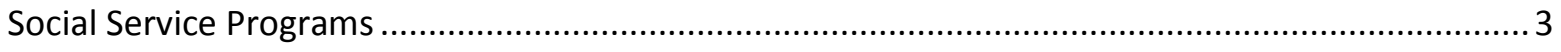

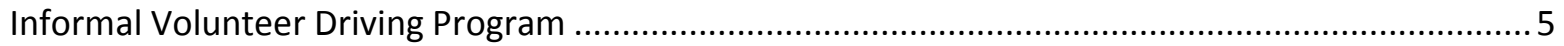

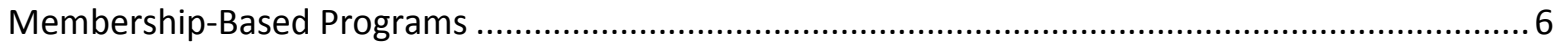

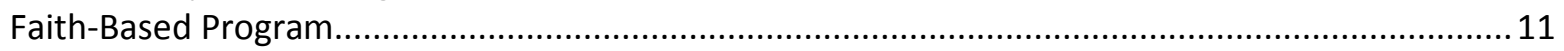

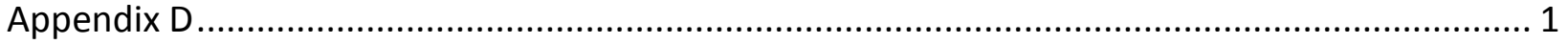

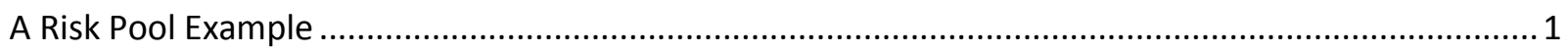

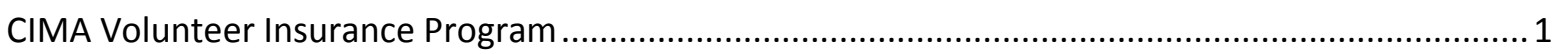

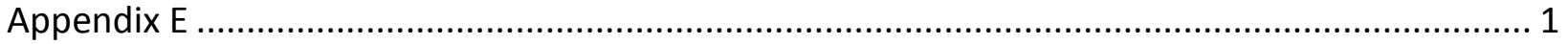

A Legal Analysis of Risk Associated with Volunteer Driving Programs ................................................ 1

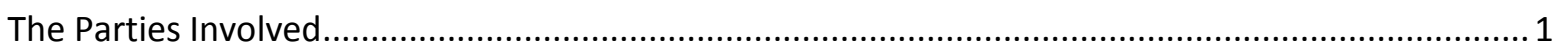

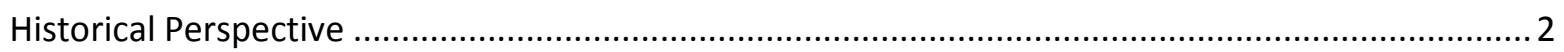

The Current Volunteer Liability Situation in Florida .................................................................. 5

Recommendation: Place Priority Protection on Vulnerable Clients ............................................... 7

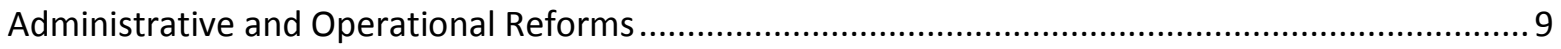

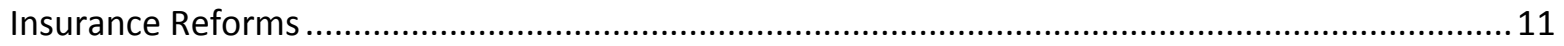

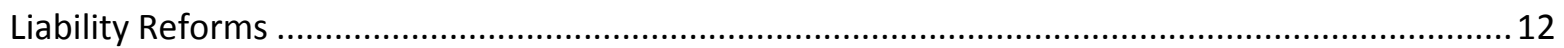

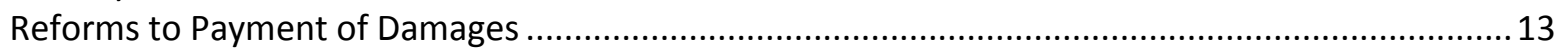

Liability of Public Sector Programs Engaging Volunteers ............................................................ 15

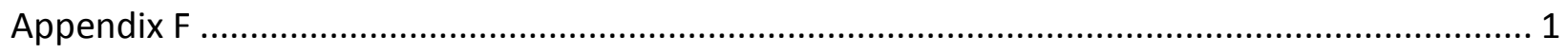

Examples of State Safety Requirements for Transportation for Vulnerable Populations ...................... 1 


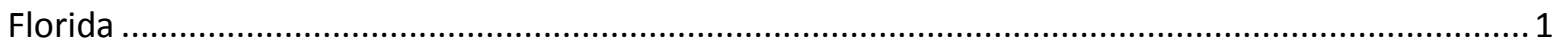

Tennessee

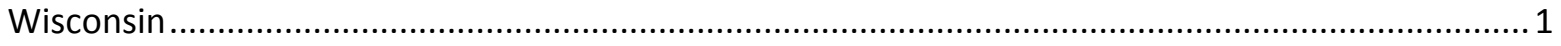

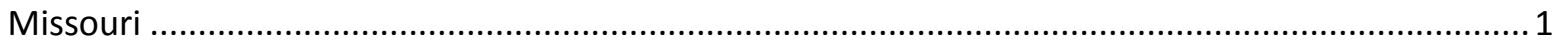

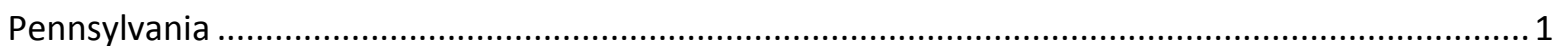




\section{LIST OF TABLES}

Table 1 - Percent of Persons 65 Years of Age and Older by Florida County ........................................... 1

Table 2 - General Qualities of Informal Volunteer Driving Services ..................................................... 14

Table 3 - General Qualities of Local Government Driving Programs ...................................................... 15

Table 4 - General Qualities of Social Service Programs.................................................................... 16

Table 5 - General Qualities of Membership-based Programs................................................................ 18

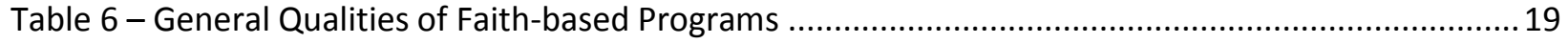

Table 7 - Volunteer Driving Programs that Serve any Trip Purposes.....................................................20

Table 8 - Volunteer Driving Programs that Serve Only Targeted Purposes .............................................21 
Figure 1 - Five Building Blocks of Interfaith Volunteer Caregiver Program .......................................... 18

Figure 2 - Outline of Recommendations to Volunteer Driving Programs ............................................. 41

Figure 3 - Outline of Recommendations to Transit Agencies and Commuter Assistance Programs ........ 50

Figure 4 - Outline of Recommendations to Area Agencies on Aging ...................................................5

Figure 5 - Outline of Recommendations for Policy Makers ...................................................................5 5 
For most rural areas and low density suburban areas in Florida and across the United States, there are few transportation options if one does not drive a personal automobile. The elderly in the United States generally outlive their ability to drive by six years for men, and by ten years, for women. ${ }^{1}$

\section{BACKGROUND}

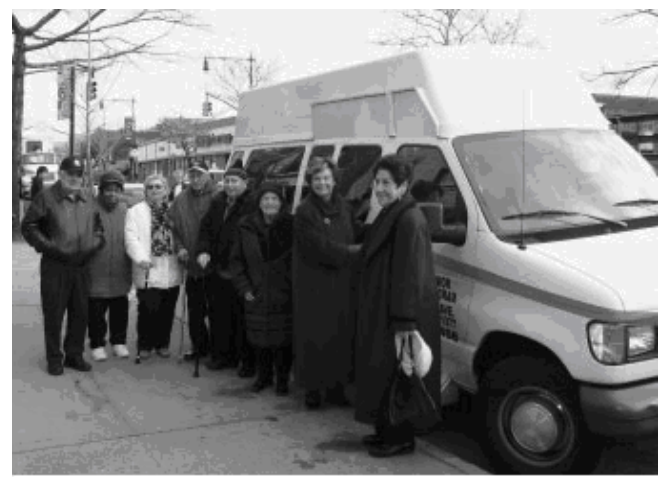

The population known as "senior" is defined variously by different organizations. For example, the American Association of Retired Persons (AARP) defines their senior constituency as those of age 50 and older. In the U.S., the most common convention has been age 65 and older. The population of interest to this study is those seniors who, because of issues associated with advanced age, are no longer able to drive safely. Table 1 below lists the percentage of persons out of total Florida County populations who are age 65 years and older, according to U.S. Bureau of the Census data from year 2000. Census population forecasts for the year 2025 indicate not only a total increase in persons age 65 years and older, but also an increase in the proportion of seniors in the population. One in every five Americans will be age 65 years or older by 2025 nationally.

Table 1 - Percent of Persons 65 Years of Age and Older by Florida County

\begin{tabular}{|l|l|l|l|l|}
\hline $\mathbf{7 . 5} \%-11.4 \%$ & $12 \%-14.8 \%$ & $15.7 \%-19.9 \%$ & $22.1 \%-27.4 \%$ & $28.2 \%-34.7 \%$ \\
\hline Alachua & Bay & Brevard & Collier & Charlotte \\
\hline Baker & Bradford & Broward & Lake & Citrus \\
\hline Clay & Calhoun & Desoto & Lee & Flagler \\
\hline Duval & Columbia & Dixie & Marion & Hernando \\
\hline Hamilton & Escambia & Franklin & Palm Beach & Highlands \\
\hline Hendry & Gadsden & Glades & Pasco & Indian River \\
\hline Leon & Gilchrist & Gulf & Pinellas & Martin \\
\hline Liberty & Hardee & Levy & St.Lucie & Sarasota \\
\hline Manatee & Hillsborough & Okeechobee & Sumter & \\
\hline Orange & Holmes & Polk & Volusia & \\
\hline Osceola & Jackson & Putnam & & \\
\hline Santa Rosa & Jefferson & St. Johns & & \\
\hline Seminole & Lafayette & Suwannee & & \\
\hline Union & Madison & Walton & & \\
\hline Wakulla & Miami-Dade & Washington & & \\
\hline & Monroe & & & \\
\hline & Nassau & & & \\
\hline & Okaloosa & & & \\
\hline & Taylor & & & \\
\hline
\end{tabular}

\footnotetext{
${ }^{1}$ Foley, Daniel, J., Harley K. Heimovitz, Jack M. Guralnik, and Dwight B. Brock, "Driving Life Expectancy of Persons Aged 70 Years and Older in the United States", American Journal of Public Health, Vol. 92, No. 8, 2002, pp. 12841289.
} 
The onset of problems that makes driving unsafe will occur at different ages for different people. Usually, the reasons why seniors stop driving are the same reasons that they cannot use regular public transit service: general physical frailty, slower reflexes, and limited vision and hearing. ${ }^{2}$ Therefore, even in urban areas with good public transit services, many seniors are without basic transportation, regardless of location.

In Florida, one in every four citizens will be age 65 years and older. As a result, the number of seniors lacking basic transportation is expected to increase. As seniors advance in age, their ability to continue living independently in the community depends on being able to access essential services.

There are various transportation services available in communities everywhere, of which some seniors can access. First, for those who still drive, there are programs available that strive to extend the time that seniors can drive safely, such as CarFit, DriveWell, 55 Alive, Florida GrandDriver ${ }^{\circledR}$ and FDOT's Safe Mobility for Life Program. ${ }^{3}$ Second, as seniors approach the time that they should stop driving, there are efforts by transit agencies nationwide to introduce regular transit service to seniors. Such efforts include travel training, targeted advertising, discounts, easy-to-read maps and schedules, and flexible routing. ${ }^{4}$ Third, when use of public transit becomes unfeasible, seniors most often find car rides through their personal network of family, neighbors and church friends. Fourth, for those who cannot count on a social network for transportation, there is paratransit provided by public transit authorities for seniors who can demonstrate that they have a disability that prevents them from using regular bus service. In Florida, there is Transportation Disadvantaged (TD) services for those who qualify based on income. There is medical transportation for those who qualify for Medicaid. There are some nonprofit organizations that transport seniors to and from meal sites and other social services. In these cases, the transportation is only incidental to the main services provided. For those who can afford it, seniors can pay for taxi service or pay for a professional caregiver who can provide them with transportation.

While there is a multitude of transportation options, especially in urban areas, there are just as many reasons why seniors may find themselves ineligible for these transportation services. For many seniors, their trip origins and destinations fall outside the public transit service area; therefore, they cannot use ADA-sponsored paratransit. Many seniors have too much money to qualify for TD service but too little money to afford private taxi service on a routine basis. Some seniors who fall ill may need transportation service on an immediate but temporary basis. In these cases, lengthy application processes and waiting periods render some transportation services useless. The different applications and eligibility requirements are overwhelming to many seniors. Some transportation is for specific trip purposes only, such as Medicaid for doctor appointments. As most communities are experiencing, there is a gap in basic transportation service for seniors. Essentially, transportation options for non-

\footnotetext{
${ }^{2}$ Firestone, Lauren and Paulette Geller. “Florida's Volunteers: The Driving Force for Senior Mobility: Identifying Barriers and Enabling Change", Winter Park Health Foundation. Issue Brief, December 2006, p. 2. Found at http://www.wphf.org/pubs/briefpdfs/Transportation.pdf

${ }^{3}$ Carfit is a program of the American Society on Aging in collaboration with the American Association of Retired Persons (AARP), American Automobile Association, and the American Occupational Therapy Association. CarFit assesses an individual's needed car adjustments and adaptations for safer driving. 55 Alive is a driver safety program of AARP. DriveWell provides older driver safety and wellness resources and was developed by the American Society on Aging and the National Highway Traffic Safety Administration. Florida GrandDriver ${ }^{\circledR}$ is an education and awareness program of the Florida Department of Highway Safety and Motor Vehicles. Safe Mobility for Life is a program of the Florida Department of Transportation with the mission to improve safety, access, and mobility for seniors.

${ }^{4}$ Florida Transit Planning Network, Professional Development Workshop, "Attracting Elderly Drivers to Public Transportation", presentation given jointly by the Center for Urban Transportation Research, University of South Florida, and the Lehman Center for Transportation Research, Florida International University, June 4, 2008.
} 
medical needs are limited to non-existent. Over half of all non-drivers age 65 and over stay home on any given day. This rate is three times higher than for drivers. Non-drivers make fewer trips because they are dependent on others to meet their personal mobility needs. They make fewer trips in all categories, including trips for medical/dental purposes. ${ }^{5}$

Volunteer driving programs have sprung up in many communities as a result. This study is about the opportunities and challenges of operating volunteer driving programs for seniors.

\section{PURPOSE OF THE STUDY}

The number of supplemental senior transportation programs that engage volunteer drivers is numerous and growing nationwide. These programs are generally much less expensive to operate than programs employing paid drivers. Many volunteer driving programs strive to be financially selfsustaining. These programs generally operate on a very small scale, with a service radius of about 15 miles and providing anywhere from a few rides per week to over 40 rides per day. ${ }^{6}$ The main mission of most of these programs is to provide transportation for any trip purpose. Volunteer driving programs extend public transportation dollars as well as save social service dollars. Not only do these programs provide the critical link for seniors to all other needed services, they also enable seniors to continue to participate and contribute to society. Many seniors who are customers of volunteer driving programs are enabled to serve as volunteers in other ways.

However, there are challenges to starting, operating and sustaining volunteer driving programs. The responses to these challenges have resulted in a wide spectrum of program structures, operational characteristics and markets served by the many volunteer driving programs in existence today. The purpose of this study has been to examine this variety of response and to investigate the barriers that still stand in the way of these programs to provide transportation. Additionally, this study has examined the opportunities that volunteer driving programs take advantage of to provide transportation to a segment of our society that sorely needs it. The aim of study results is to provide practical recommendations to help volunteer driving programs thrive. This report also aims to lay out some options for policy makers to remove barriers experienced by these programs.

This research is sponsored by the National Center for Transit Research at the Center for Urban Transportation Research at the University of South Florida with funding from the Florida Department of Transportation (FDOT) Public Transit Office. In pursuit of its mission to "identify, support, advance and manage cost effective, efficient and safe transportation systems and alternatives to maximize the passenger carrying capacity of surface transportation facilities," the FDOT Public Transit Office recognizes the value of the volunteer driving program model as a means to extend service to a growing segment of the population that cannot use public transit and that would otherwise have no transportation. The audience for this report includes transit agencies, paratransit programs, nonprofit agencies and social service agencies that operate volunteer driving programs for seniors or those who wish to start a program. Other interested parties include policy makers, elected officials and government leaders who are confronting the issue of transportation needs of seniors and are looking for solutions.

\section{STUDY METHOD}

\footnotetext{
${ }^{5}$ Bailey, Linda. “Aging Americans: Stranded Without Options". Surface Transportation Policy Project, 2004. http://www.transact.org/library/reports_html/seniors/aging.pdf (last accessed 08/04/08)

${ }^{6}$ For example, one of the larger and better known programs is Independent Transportation Network ${ }^{\circledR}\left(\right.$ ITN $\left.^{\circledR}\right)$, started in 1995 in Portland, Maine. ITNPortland ${ }^{\circledR}$ now provides on average 41 trips per day. This makes it one of the largest volunteer driver operations. ITN ${ }^{\circledR}$ uses a combination of paid drivers and volunteer drivers.
} 
This study includes an extensive review of volunteer driving programs and available resources for program start-up. The study was guided by an advisory panel representing various kinds of organizations, expertise, and locations to provide guidance on problem identification, perspective on specific issues, and feedback on recommendations. Research and interviews with experts in the insurance profession focused upon risk management and key elements of volunteer driver liability.

Legal issues associated with volunteer driving programs for seniors were examined, especially those relating to the liability risks posed by those programs. For analytical purposes, the perspectives of the several principal parties involved: the volunteer driving program (non-profit or government agency), the volunteers, the clients, and third parties were considered as they sometimes have divergent legal interests. This examination included an assessment of society's interest to protect powerless injured persons, while not discouraging volunteerism, since these social goals might conflict at times. A good volunteer driving program policy needs to balance these interests. The focus of this analysis was upon the scenario in which a volunteer driver injures a client or a third party (e.g., pedestrian or other motorist) while acting within the "scope of his/her duties" for the volunteer driving program. This can lead to personal liability for the volunteer and "vicarious liability" for the volunteer driving program. Past and present federal and state statutes were reviewed, in addition to administrative code provisos, court cases, and law review articles that are related to this scenario.

Finally, this research included in-depth interviews with six volunteer driving programs, selected for their varying characteristics of location, organizational structure and operations.

\section{STUDY OBJECTIVES}

This research project had three objectives. The first objective was to identify and explore the challenges of developing and operating a volunteer senior mobility driving service. This is addressed in Chapter 2, Overview of Volunteer Driving Programs; Chapter 4, Coordination with Other Transportation Services which includes a discussion of the nature of the service gap left by other existing transportation services; and Chapter 5, Risk, Liability, Risk Management and Insurance.

The second objective was to propose solutions to establish successful programs. This is addressed in Chapter 6, Conclusions and Recommendations for Action identified for volunteer driving programs, transit agencies, commuter assistance programs, Area Agencies on Aging, and policy makers. Highlights of situations and circumstances under which practices and solutions are effective are described in Chapter 3, Ride Finding Alternatives; and in Appendices E and F, which contain a detailed legal analysis and examples.

The third objective was to provide guidance on best practices that could be used by a variety of audiences, including transit agencies, paratransit agencies, non-profit programs, social service agencies, volunteer driving programs and policy makers. This is addressed in a discussion of service models in Chapter 3; a discussion of the potential role of public transit in Chapter 4, and various resources in the Appendices. These include a reference list of useful guides, handbooks and checklists in Appendices A and B, and profiles of several volunteer driving programs in Appendix C.

\section{REPORT ORGANIZATION}

The next chapter summarizes the literature review and the interviews with representatives of both volunteer driver programs and research organizations that support volunteer driver programs. Prior to discussing different kinds of emerging volunteer driving program models, Chapter 3 presents ridesharing options that may develop more potential in the future, especially as computer literate Baby Boomers approach the age of driving cessation. Chapter 4 characterizes transportation gaps left by community transportation services that volunteer driving programs are created to fill. Chapter 5 
identifies risk and liability issues associated with volunteer driving programs. This chapter also summarizes the conclusions of a legal analysis of risk (discussed in detail in Appendix E) associated with volunteer driving programs. Based upon study findings, the last chapter in this report presents recommendations for action to various audiences that have a stake in the success of volunteer driving programs. These stakeholders include staff of volunteer driving programs, transit agencies, commuter assistance programs, Area Agencies on Aging, and policy makers. 
This chapter identifies and explores the primary challenges of developing and operating volunteer driving programs for seniors. These findings were derived from an extensive literature search and interviews with representatives of volunteer driving programs, research organizations that support volunteer driving programs, government agency representatives, insurance professionals, and discussions with an advisory panel of experts.

\section{NUMEROUS START-UP RESOURCES ARE AVAILABLE}

Hundreds of volunteer driving programs for seniors exist nationwide.

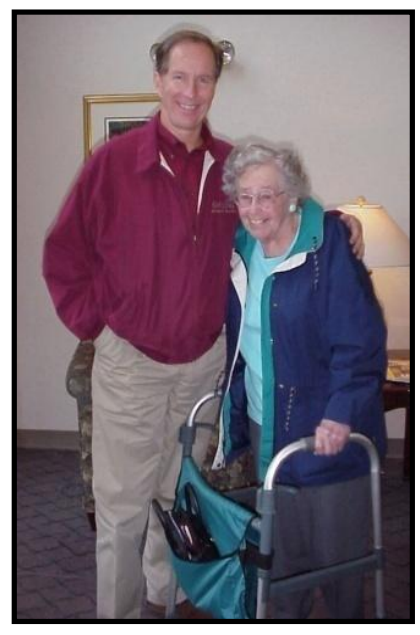

There are many service models of programs that have sprung up to meet the unique needs of the communities they serve with the resources available to them. There is an online database of volunteer driving program profiles nationwide, that is available from the Beverly Foundation, known as Supplemental Transportation Programs for seniors (STPs) and found at http://www.STPexchange.org

There are several excellent resources available to help individuals and organizations start a volunteer driving program. These are listed in Appendix A. The Beverly Foundation and the Transportation Reimbursement and Information Project (TRIP) ${ }^{7}$ have established a set of criteria, the "Five A's," which characterize transportation needed by seniors and which serves as a planning and evaluation checklist for volunteer driving programs for seniors. The Five A's include availability, accessibility, adaptability, acceptability, and affordability. ${ }^{8}$ The Senior Friendliness Calculator for Volunteer Driving Programs(C) is reprinted with permission from the Beverly Foundation and provided in Appendix B.

\section{COMMUNITY COLLABORATION IS IMPORTANT TO PROGRAM SUCCESS}

Volunteer driving programs often spring from the communication and coordination of multiple organizations and government agencies concerned about the transportation needs of seniors in their community. ${ }^{9}$ Assembling the right organizations and individuals to discuss the issue, identify resources and solve logistical problems can often result in the development of a service that fits the community. These organizations often include:

- Local restaurant council

- Local business leadership networks

- Local retail association

- Veterans groups

- Shriners

- Rotary clubs

- Churches

\footnotetext{
${ }^{7}$ Transportation Reimbursement and Information Project (TRIP), Independent Living Partnership, Riverside County, CA, found at http://www. living partnership.org/Transportation. htm is a program that reimburses volunteers who provide rides to seniors.

${ }^{8}$ Volunteer Driver TurnKey KitC, A Five A's “Senior Friendliness" Evaluation Strategy for Volunteer Driver Programs, developed by Beverly Foundation, Pasadena, CA and TRIP, Riverside, CA, revised November 2006.

9 "Partnering to Promote Healthy Aging: Creative Best Practice Community Partnerships", The National Council on Aging, Washington, D.C., http://www.ncoa.org See also "Seniors Benefit from Transportation Coordination Partnerships-A Toolbox", Administration on Aging, U.S. Department of Health and Human Services.
} 
- Area Agency on Aging

- State DOT

- Transit agency

- County/city council members

- AARP local chapter

- Junior League and other women's groups

- Local government human services department

Public transit agencies potentially are a tremendous resource for the creation of volunteer driving programs. Public transit agencies are in a position to help marshal the community leadership needed to develop a volunteer driving program. One Florida example is described later in this report.

\section{THE NUMBER ONE PROBLEM: FINDING VOLUNTEERS}

The biggest problem faced by volunteer driving programs is recruiting and retaining volunteers. Existing volunteer driving programs that serve the general public usually do not have the capacity to provide rides for all those who request them. Demand for rides exceeds the number of volunteers available to provide rides. Even for programs that serve specific trip

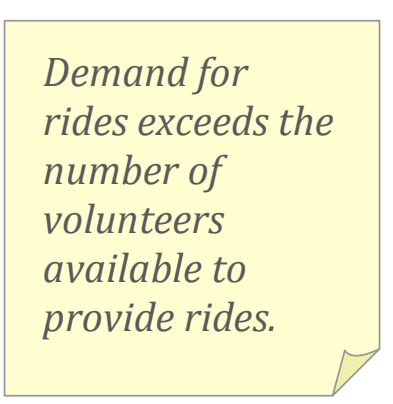
purposes for narrowly defined markets, there are problems finding volunteers. For example, the American Cancer Society's (ACS) Road to Recovery Program is a national volunteer driving program specifically designed to transport cancer patients and family members to treatment centers. A focus upon recruiting cancer survivors to serve as volunteer drivers has helped boost their numbers of volunteers. The Road to Recovery Program in Tampa, Florida has been able to provide for 100 percent of the trip requests in their area. ${ }^{10}$ Interestingly, this Road to Recovery Program has a "safety valve" sister program, called LifeLine, which provides taxis and transit transportation to cancer patients. If a patient's needs cannot be served through Road to Recovery, then the secondary program Lifeline steps in. This program in the Tampa area has secured sufficient volunteers through the work of a full-time paid volunteer recruiter and coordinator. However, there are other ACS Road to Recovery volunteer programs that are struggling to keep up with the demand, such as those serving Broward and Miami-Dade Counties. The approximately 100 volunteers currently providing rides in these two counties are insufficient. This area of Florida not only has a large number of seniors who make up a significant percentage of cancer patients, but also there are many who live alone and have no nearby family to help them. ${ }^{11}$

\section{RISING COST OF FUEL DRIVES VOLUNTEERS AWAY}

The most pressing current challenge of recruiting volunteer drivers is the rising cost of fuel. Many programs rely on not only the volunteers donating their time to drive, but also donating the expense of personal vehicle operation, including fuel. To make matters worse, in accordance with federal income tax law, volunteers are allowed to claim a deduction on the mileage they drive for a charity, but at the rate of only 14 cents per mile. This is a charitable rate set by statute (Taxpayer Relief Act of 1997, P.L. 105-34) but is fixed under Section 170(i) of the Internal Revenue Code of 1986 . This charitable deduction rate is much less than the current standard business mileage rate of 58.5 cents used to calculate the deductible cost of operating an automobile for business purposes. The business rate also is not fixed by statute but is variable and can be changed-that is, raised over time-by the IRS.

\footnotetext{
${ }^{10}$ Valerie Anderson, American Cancer Society, Florida Division, telephone interview., March 20, 2008.

${ }^{11}$ Robindson, Andrea. "Drivers wanted to help cancer patients", Miami Herald, April 2, 2008.
} 
Some volunteer driving programs reimburse volunteers for some portion of these expenses; however, federal income tax law requires each volunteer driver to fill out an IRS 1099 Form and treat as taxable income any mileage reimbursements by the charity in excess of 14 cents per mile. As of this writing (08/12/08), Senator Charles Schumer (D-NY) and three co-sponsors introduced S. 3429, the Giving Incentives for Volunteers Everywhere (GIVE) Act of 2008. The Act would amend Sec. 170(i) of the Internal Revenue Code by raising the volunteer standard deduction rate from 14 cents per mile to 70 percent of the standard business mileage deduction rate. That would raise the volunteer rate to 41 cents per mile and allow the rate to be adjusted annually. Furthermore, the Act would exempt from taxable income, reimbursements from charities for mileage travelled by a volunteer up to the business rate and exempt the reporting requirement. This bill was introduced on August 1, 2008 and Congress has referred it to the Committee on Finance.

\section{THERE ARE MANY MORE VOLUNTEER RECRUITMENT CHALLENGES}

Many others who might otherwise volunteer to drive are discouraged by the prospect of having to drive in traffic congestion. Many volunteers come from certain population groups that move on after a time, such as "snowbirds," teenagers and college students. Another source of volunteers is retired individuals. However, many individuals of retirement age are choosing to extend their careers, either by choice or by necessity. Jon Roberts points out in his analysis of U.S. Bureau of Labor Statistics data that due to the differences in the numbers of individuals of different age cohorts, there will be a drop in the number of total workers as Baby Boomers begin to retire. ${ }^{12}$ As a result, there may be added incentive for individuals of retirement age to postpone retirement. As a result, would-be volunteers of retirement age may still be working full-time. Finally, volunteer driving programs compete with the many other good causes that attract volunteers. All these factors cut into the pool of potential volunteers.

\section{PROGRAM MANAGERS TRADE SERVICE FEATURES TO MANAGE RISK}

The expense to volunteers of personal vehicle operation includes the burden of personal liability in the case of an accident and the cost of personal auto insurance. Safety, liability, and the cost of program insurance weigh heavily on the minds of many volunteer program administrators. The liability burden varies based upon program configuration; therefore, administrators can control liability to some degree based upon how the volunteer driving service is operated. For example, some volunteer driving programs limit exposure to risk and liability by the restrictions they put on their services:

- Time of day of operation: avoiding congested times as well as night driving

- Days of the week of operation: avoiding weekends

- Requiring seniors to be ambulatory

- Restrictions, such as prohibiting the driver from leaving the car to escort passengers to and from the car

... lessening

liability also may mean eliminating service features, which are valuable to the riders served by these programs.

However, lessening liability may mean eliminating service features, such as those above, which are valuable to the riders served by these programs. As a volunteer driving program grows, providing more rides and engaging more volunteers, there is a point at which the operation becomes so complex that paid staff is a necessity. In an effort to meet the demand for rides despite the shortage

${ }^{12}$ Roberts, Jon. "The Hunt for Talent", TIP Strategies, Inc. Austin TX, July 2006. Found at http://www.tipstrategies.com/The\%20Hunt\%20for\%20Talent.pdf 
of volunteers, some program administrators decide to employ paid drivers. At that point, raising sufficient money to cover the cost of program operations, including increased insurance premiums, often becomes a difficult challenge. 
Prior to discussing the different kinds of emerging volunteer driving program models, it should be noted that there are a few other ride-finding options available for everyone, including seniors. These options are for those who are computer savvy and/or are willing and able to find rides on their own and deal directly with potential drivers without the "go-between" assistance of a program. These options may develop more potential in the future, especially as computer literate Baby Boomers approach the age of driving cessation.

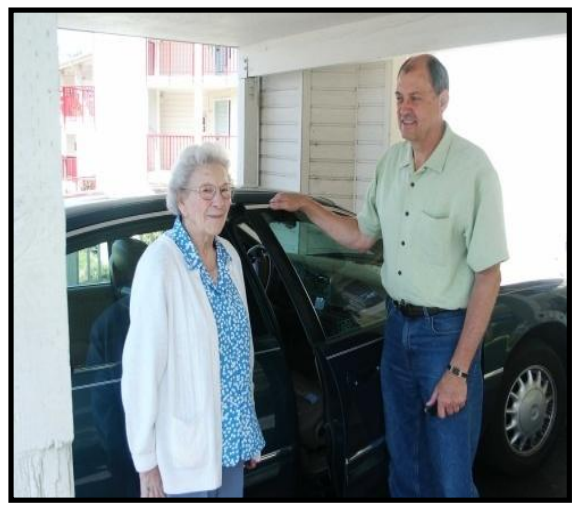

\section{RIDE SHARING}

A ridesharing arrangement may be described as when the driver is already planning to go to some destination regardless of having a passenger. The driver agrees to share the ride with someone who also happens to be going to the same destination. In this case, the rider might receive the ride at no charge, or might pay some portion of the driver's expense of operating the motor vehicle in exchange for sharing the ride. In Florida and nationwide, commuter assistance programs, sponsored by state departments of transportation and other agencies, have been in place for many years. These programs are primarily aimed at matching commuters of a particular region to share work trips but the services are available for anyone and for any trip purpose. Typically, the ride matching databases of commuter assistance programs are populated with many who seek a ride but far fewer of those who have a car and seek passengers. With the rising price of fuel, this may begin to change. Nonetheless, the challenge with ridesharing programs remains finding enough drivers who are seeking passengers.

\section{USING SOCIAL NETWORKS TO FIND DRIVERS}

When applying this ride-matching model to seniors, the same issue of how to find enough willing drivers would need to be addressed. It may be that organizations at the local level, such as those listed above in the preceding section, should consider launching incentives programs, such as NuRide ${ }^{\circledR}$ described in Appendix C, to promote the creation of personal ridesharing networks. Present-day drivers would be participating in these ridesharing networks to receive short-term rewards but with the understanding that at some point in the future, they may likely be the riders. As public awareness begins to increase among persons approaching retirement, that they must plan for their future transportation needs now before they actually need alternative services to driving, this might be a good way to involve them.

GoLoco $^{\text {TM }}$ is an example of a more formalized on-line ride matching service that also arranges for expense sharing by keeping track of individual accounts, in which each passenger agrees to pay the driver for their fair share of the costs. In the case of GoLoco ${ }^{\mathrm{TM}}$, it is suggested that the driver is not actually a volunteer in the same sense as those who volunteer to drive for volunteer driving programs. A volunteer is someone who is willing to go out of his or her way to help another without expectation of compensation in return. Alternatively, the
A volunteer is someone who is willing to go out of their way to help another without expectation of compensation in return. ridesharing arrangement provided by GoLoco ${ }^{\mathrm{TM}}$ is more of an exchange or mutually beneficial arrangement. There are other programs that fit this model, such as eRideShare.com and NuRide ${ }^{\circledR}$, which provide a computerized matching service but stop short of 
actually arranging rides between riders and drivers. Importantly, these programs are distinguished by the characteristic that program registrants can create their own personal networks of trusted family, friends and associates, within which rides are matched. Both GoLoco $^{\mathrm{TM}}$ and NuRide ${ }^{\circledR}$ are further described in Appendix C.

As with any ride matching arrangement, it is a self-serve approach that requires the rider to find his or her ride and accept the risks associated with ridesharing. The GoLoco ${ }^{\mathrm{TM}}$ program, like conventional commuter assistance ride matching programs, merely provides information. It is up to the carpooler to select with whom he or she wants to travel. Likewise, the senior would be personally responsible

the senior would be personally responsible for checking the driving credentials of the driver as well as the driver's insurance coverage. for checking the driving credentials of the driver as well as the driver's insurance coverage. According to GoLoco ${ }^{\mathrm{TM}}$, in the event of an accident, passengers ordinarily are covered by the driver's personal auto insurance policy if the passenger is paying no more than his or her fair share of the costs of the trip. This is sometimes known as a "share-the-expense car pool arrangement." Nonetheless, it is incumbent upon the rider to ask the driver for details of what the driver's insurance policy covers in the event of an accident. GoLoco ${ }^{\mathrm{TM}}$ does not check driver's insurance and does not represent that drivers are insured. ${ }^{13}$

A QUESTION OF CARPOOLS AS 'FOR-HIRE VEHICLES'

As the Winter Park Health Foundation earlier found, it is also important to note what Florida law includes in its definition of a 'for-hire vehicle' as "....any motor vehicle, ...offered or used to provide transportation for persons solicited through personal contact ... on a "share-expense" basis. ${ }^{14}$ No references in the Florida Statutes could be found that distinguished any difference between a 'for-hire vehicle' and a taxicab. Sec. 450.28(3), F.S. defines a carpool narrowly as transportation serving commuter trips within the context of "Farm Labor Contractor Registration Law" and does not address liability and insurance of the carpool driver. ${ }^{15}$ As the definition for a 'for-hire vehicle' is

... Any driver of a carpool who accepts money to help pay for gas can be liable for damages to the same extent as a taxi driver, from any bodily injury to a passenger... indistinguishable from a taxicab, a number of disturbing conditions apply to a motor vehicle used to provide transportation for persons solicited through personal contact on a 'share-expense' basis. This includes Sec. 627.733(1)(b), F.S., which requires a higher level of auto insurance, as specified in Sec. $324.032(1)$ (a). Florida law requires the owner of any for-hire passenger transportation vehicles to hold a motor vehicle liability policy with minimum limits of $\$ 125,000 / 250,000 / 50,000 .{ }^{16}$ This is higher than the minimum limits for personal auto insurance policies. It also removes the protection of a tort exemption of the Florida Motor Vehicle No-Fault Law from persons who provide transportation on a 'share-expense' basis. Any driver of a carpool who accepts money to help pay for gas can be liable for

\footnotetext{
${ }^{13}$ For more information, go to http://www.goloco.org/help

${ }^{14}$ Sec. 320.01(15)(a), F.S. See also Firestone, Lauren and Paulette Geller, "Florida's Volunteers: The Driving Force for Senior Mobility: Identifying Barriers and Enabling Change", Winter Park Health Foundation, Issue Brief December 2006, p. 4.

${ }^{15}$ Sec. 450.28 (3), F.S. defines a carpool as “....an arrangement made by the workers using one worker's own vehicle for transportation to and from work and for which the driver or owner of the vehicle is not paid by any third person other than the members of the carpool."

${ }^{16}$ Sec. 324.032(1)(a), F.S.
} 
damages to the same extent as a taxi driver, from any bodily injury to a passenger. Clarification in Florida state law is needed to distinguish a taxicab from a carpool for non-commute trips and should provide protection to carpool drivers.

\section{BARTERING}

An arrangement of potential value to seniors is a barter or trade. This may differ from a ridesharing arrangement in that the driver may agree to go out of his or her way to provide a ride that he or she would not have ordinarily taken, in exchange for some other good or service. A barter might include a senior informally agreeing with someone, for example, to do their ironing in exchange for rides. In this case, the senior might work out this arrangement with a friend or there might be a central bulletin board, either real or virtual, in which people of a community advertise their offerings and connect with one another to exchange goods and services. ${ }^{17}$ The barter arrangement addresses two issues. First, most seniors who have lived independently all their lives hate to ask for the favor of a ride from family and friends. Once a senior stops driving, they suddenly find themselves in the position of repeatedly having to ask for rides. This aversion to asking for favors is so great for many seniors that they decide to start foregoing essential trips, such as doctor appointments. It is easier to ask for a ride if they can give something in return. Second, many seniors are on a limited income and may not have cash to give. A trade may enable a senior to give something else of value. No examples of transportation bartering arrangements were found. This is likely an arrangement that exists informally among seniors and their network of family and friends.

Something close to a barter arrangement is the Senior Services Homesharing Program in Seattle, Washington. This is a nonprofit intergenerational housing program that matches elderly who live alone with younger tenants looking for a place to live and willing to do some chores in return for reduced rent. In this case, the barter arrangement is aided by a "go-between" organization.

No law references were found specifically with regard to a trade arrangement between a rider and driver but it is possible that bartering would fall under the Florida State definition of a 'for-hire vehicle'. As such, the driver would be held to a higher standard of duty similar to a ridesharing arrangement in which there is sharing of expenses.

\section{VOLUNTEER DRIVING PROGRAM “MENU” OF OPTIONS: SERVICE MODELS}

There are a number of different models of volunteer driving programs for seniors. These are distinguished from the ride matching options above in that the programs provide a "go between" service that finds a driver on behalf of the senior who needs a ride. While many rides for seniors are provided by immediate family and friends ${ }^{18}$, many seniors would welcome a ride provided as more of a business arrangement. These models address that preference and generally tend to differ based upon four basic decisions that program organizers are faced with in the development of a program.

(1) Whether to use all volunteers or also some paid drivers. Using paid drivers ensures a greater likelihood that a driver is available to respond to the trip needs of a rider. However, programs incur the added expenses of salaries and administration as well as greater liability.

\footnotetext{
17 Jennifer Salmon, Ph.D., Aging Research Group, phone conversation, October 10, 2007.

${ }^{18}$ L.P. Kostyniuk and J.T. Shope, "Reduction and cessation of driving among older drivers: Focus groups" (Rep. No. UMTRI-98-26), The University of Michigan Transportation Research Institute, Ann Arbor, MI, 1998.
} 
(2) Determining how large the geographic service area can be and still keep the program operation manageable. The larger the service area, the more likely that a rider's travel needs are met and that more riders are served. However, this means longer trips and stretching scarce volunteer resources thin.

(3) Providing rides to seniors free of charge or charging a fare. Charging a fare increases administrative duties as well as increases the liability of the volunteer driving program; however, it also provides a reliable source of income.

(4) Limiting exposure to risk versus providing better service. The more helpful that a volunteer driving program tries to be, such as the driver helping to carry groceries into the rider's house, the more that volunteer drivers and volunteer driving programs are exposed to risk and the associated liability.

Volunteer driving programs must weigh the advantages of providing more or less driving against the implications for assuming risk, liability, added expense, and most crucially, added requests of time and effort on the part of volunteers. Examples of service elements that make a volunteer driving service highly desirable but for which finding enough volunteers is a challenge, are the following:

- Providing for regional trips

- Providing rides 24 hours per day, seven days per week

- Being able to reserve a ride on very short notice, such as on the very day of the trip

- Allowing the rider to link trips, such as transporting the rider to the hairdresser, then to the grocery

- Having the volunteer driver wait for the rider, to provide the return trip

- Allowing pets aboard

- Including a caregiver or spouse along on the trip for less than double the fare

- Providing personalized assistance before and after the ride

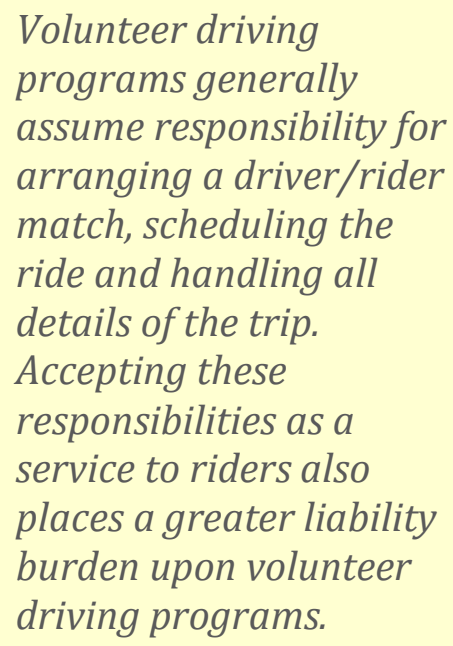

Volunteer driving programs generally assume responsibility for arranging a driver/rider match, scheduling the ride and handling all details of the trip. Accepting these responsibilities as a service to riders also places a greater liability burden upon volunteer driving programs.

Volunteer driving programs that provide premium service must make decisions regarding pricing the ride. Programs break down the various costs in any number of ways as follows:

- Free (donations accepted)

- One-time initial registration fee

- Annual membership fee

- Ride pick-up fee, one-way or round-trip

- Fee per mile

- Short advance notice fee

- Linked trip fee

Service limitations to manage risk exposure might include requiring all riders to be ambulatory and ride in the back seat of the vehicle only. Examples of service additions for which risk exposure and liability increase might include escorting the rider to his or her front door or carrying packages inside the house for the rider. 
Volunteer driving programs generally assume responsibility for arranging a driver/rider match, scheduling the ride and handling all details of the trip. Accepting these responsibilities as a service to riders also places a greater liability burden upon volunteer driving programs.

The types of insurance coverage generally needed by any type of nonprofit organization, including a volunteer driving program are general liability insurance, personal property insurance and director's and officer's insurance. In addition, for a volunteer driving program, the sponsoring organization should have a commercial liability policy for the organization. This is called "hired and non-owned auto" insurance. This coverage is used after the limits of the volunteer driver's personal auto insurance have been exhausted, but may not cover volunteer driving activities, as discussed later in this report. The sponsoring organization should also purchase excess auto liability coverage or an umbrella policy, also to be used after the limits of the volunteer driver's personal auto insurance have been exhausted. In addition, volunteer drivers should have personal auto liability coverage, accident coverage and personal liability coverage.

The volunteer driving program models, based upon the four decision points, are outlined below, with names of examples for which profiles can be found in Appendix $C$. These program models are not exclusive of each other as many volunteer driving programs have overlapping characteristics that could place them in more than one model category. Nonetheless, the identification and description of models helps to outline the many options and differences among programs.

INFORMAL VOLUNTEER DRIVING SERVICES

Some volunteer driving services can be arranged outside the framework of a formal organization. This might include a network of people representing different agencies who informally agree to work together outside the formalized operation of a nonprofit. These agencies might draw up a memorandum of understanding that defines a cooperative relationship. An established example of a network was not found; however, exploratory discussions have been held in Polk County, Florida, in which such a network has been considered. This is further described in a later section of this report on the role of public transit. Another informal program type is exemplified by the pilot project, PasRide (Pasadena Area Seniors Ride), which employed the Volunteer Friends service model, developed and piloted by the Beverly Foundation. ${ }^{19}$ PasRide is described in Appendix C.

LOCAL GOVERNMENT PROGRAMS

Some county or municipal governments will employ volunteers to provide services under their Transportation Disadvantaged Program. The Human Services Department of Charlotte County, Florida and the Gulfport Extended Mini-bus Service (GEMS) in Gulfport, Florida are examples described in Appendix C. These transportation services are usually provided in vans or small buses rather than private passenger cars.

\footnotetext{
${ }^{19}$ The information provided on the Volunteer Friends model was taken from the Beverly Foundation, "PasRide: A Pilot Low Cost/Low Maintenance Supplemental Transportation Program for seniors (STPs), Part 1. Program Planning, White Paper 3.1, prepared for the STPs Mobilizer Project.
} 
Table 2 - General Qualities of Informal Volunteer Driving Services

\begin{tabular}{|l|l|}
\hline $\begin{array}{l}\text { Volunteers vs. paid } \\
\text { drivers }\end{array}$ & Only volunteer drivers are used. \\
\hline $\begin{array}{l}\text { Small vs. larger service } \\
\text { area }\end{array}$ & No set boundaries are required. \\
\hline Free vs. fares & $\begin{array}{l}\text { Rides are free. } \\
\text { Safeguards that are used by the Volunteer Friends model to control } \\
\text { exposure to risk and acquire sufficient insurance include: } \\
\text { Riders recruit their own drivers, placing the responsibility on } \\
\text { the rider to recruit a safe driver. } \\
\text { Minimizing liability vs. }\end{array} \quad \begin{array}{l}\text { Travel reimbursement is provided directly to the riders and not } \\
\text { the drivers. This would minimize the organization's liability } \\
\text { expanding services }\end{array}$ \\
$\begin{array}{l}\text { since the driver is a volunteer for the rider and not for the } \\
\text { organization. } \\
\text { Volunteer drivers were screened using an approved checklist of } \\
\text { the Nonprofits' Alliance of California (NIAC), which then } \\
\text { qualified the program for hired and non-owned auto coverage. } \\
\text { Riders would sign an agreement releasing the sponsoring } \\
\text { organization from legal liability. }\end{array}$
\end{tabular}

Table 3 - General Qualities of Local Government Driving Programs

\begin{tabular}{|l|l|}
\hline $\begin{array}{l}\text { Volunteers vs. paid } \\
\text { drivers }\end{array}$ & $\begin{array}{l}\text { Volunteer drivers are essentially unpaid employees who may receive the } \\
\text { same training and share the same duties as paid drivers. }\end{array}$ \\
\hline $\begin{array}{l}\text { Small vs. larger service } \\
\text { area }\end{array}$ & $\begin{array}{l}\text { Under a local government, the service area is generally defined as the } \\
\text { government's jurisdictional boundaries. }\end{array}$ \\
\hline Free vs. fares & $\begin{array}{l}\text { A fare is ordinarily charged for rides provided by a local government } \\
\text { entity, although there may be discounts to those meeting eligibility } \\
\text { requirements. }\end{array}$ \\
\hline $\begin{array}{l}\text { Minimizing liability vs. } \\
\text { expanding services }\end{array}$ & $\begin{array}{l}\text { Under a local government, the volunteer's performance is held to the } \\
\text { same standard of care expected of paid drivers; however, the volunteers } \\
\text { are ordinarily covered by umbrella insurance provided by the local } \\
\text { government. Volunteers working for a local government are also } \\
\text { covered by sovereign immunity, which is discussed in detail in Appendix } \\
\text { E. }\end{array}$ \\
\hline
\end{tabular}

SOCIAL SERVICE PROGRAMS FOCUSING ON PARTICULAR SENIOR MARKET SEGMENTS

Social service programs, as a model, are nonprofit organizations that generally provide some other type of primary service, such as meals to seniors. The transportation is either a secondary support service to enable the senior to access the main service or just one of an array of services provided. The transportation is only provided for particular trip purposes. For example, Meals on Wheels is known nationally as a network of nutrition programs. These programs often receive government grant funding. While Meals on Wheels transports meals to homebound seniors, Manatee County Meals on Wheels Plus in Florida uses volunteer drivers to transport seniors to daytime social functions. 
Table 4 - General Qualities of Social Service Programs

\begin{tabular}{l|l|}
\hline Volunteers vs. paid drivers & Drivers are primarily volunteers. \\
\hline \multirow{5}{*}{$\begin{array}{l}\text { Small vs. larger service } \\
\text { area }\end{array}$} & $\begin{array}{l}\text { Tunding sources but does not necessarily follow jurisdictional } \\
\text { boundaries if government funding is not used. For some programs, } \\
\text { transcending jurisdictional boundaries is part of the service, as seniors } \\
\text { may need to travel outside their jurisdiction of residence to accomplish } \\
\text { the trip purpose. However, keeping the operation manageable may } \\
\text { rely on matching seniors with nearest available volunteers to minimize } \\
\text { total travel distance. In the case of national programs with local or } \\
\text { regional service divisions, the geographic boundaries of these divisions } \\
\text { may be determined in part by where the concentrations of clients are } \\
\text { located and their primary destinations. The geographic division may be } \\
\text { drawn to encompass these origin-destination pairs. }\end{array}$ \\
\hline Free vs. fares & $\begin{array}{l}\text { Rides are usually free. } \\
\text { The social service provided is very specifically defined, including trip } \\
\text { purpose. This means that the scope of duties of the volunteer driver is } \\
\text { narrower, thus limiting exposure to risk. Programs of a national scale } \\
\text { expanding services }\end{array}$ \\
\hline may easily have the financial means to provide umbrella insurance \\
coverage.
\end{tabular}

The American Cancer Society's Road to Recovery Program is another example. This program provides transportation to and from medical treatment for all cancer patients who need it. A majority of cancer patients are seniors. ${ }^{20}$ In this case, the target market is specific and the trip purpose is specific. Senior Services Transportation Program of King County, Washington targets lower income persons over the age of 75 and those with limited English speaking ability. Senior Services provides rides for any trip purpose. These three programs are described in Appendix C. A fourth example of a target market is disabled veterans. The Disabled American Veterans Transportation Network is a nationwide program of over 5,000 volunteers who provide rides for disabled veterans.

MEMBERSHIP-BASED PROGRAMS

Most transportation services for seniors focus upon a specific senior market to provide for a specific trip purpose, for example, a ride to a medical appointment for a low-income senior. The least available service is the type for any senior for any trip purpose. This is where membership-based services fill a need.

Some senior driving programs that engage volunteer drivers set up the service as a membership organization. These are highly organized programs that often strive to provide a higher level of service, giving seniors some measure of consumer choice. In many cases, there is an initial application and registration fee, an annual member fee, and fares charged per trip and per mileage. Independent Transportation Network ${ }^{\circledR}$ is an example of a senior driving program that is a membership organization, described in Appendix C.

\footnotetext{
${ }^{20}$ Lewis, Joy H., Meredith L. Kilgore, Dana P. Goldman, Edward L. Trimble, Richard Kaplan, Michael J. Montello, Michael G. Housman, José J. Escarce. "Participation of Patients 65 Years of Age or Older in Cancer Clinical Trials", Journal of Clinical Oncology, Vol. 21, Issue 7, April 2003, pp. 1383-1389.
} 
The Independent Transportation Network ${ }^{\circledR}$ or ITNAmerica ${ }^{\circledR}$ provides a service model for offering high quality volunteer driving services to those seniors who are able and willing to pay for it. A ride from an ITN $^{\circledR}$ affiliate is less than the price of a taxi. While for-profit businesses will sell franchises to expand their operations, the non-profit counterpart to franchising is scaling, in which affiliate ITN ${ }^{\circledR}$ programs start an operation in a locality for a fee in exchange for technical support from ITNAmerica ${ }^{\circledR}$. The general start-up cost to an ITN ${ }^{\circledR}$ affiliate is approximately $\$ 125,000$ for licensing, training software and capital expenses. One such ITN ${ }^{\circledR}$ program has recently started operating in Orlando. A number of other communities in Florida are exploring starting an ITN ${ }^{\circledR}$ affiliate. Sarasota was recently awarded the opportunity to start an ITN ${ }^{\circledR}$ program.

ITN ${ }^{\circledast}$ began several years ago with one program in Portland, Maine and the program model has now spread to several urban communities throughout the United States. Each ITN ${ }^{\circledR}$ is incorporated as a separate $501(\mathrm{c})(3)$ organization. Factors that determine likelihood of a successful ITN ${ }^{\circledR}$ affiliate include the demographics of the area, population density and the presence of a host of agencies and organizations ready and willing to collaborate to make the program a success.

To avoid the conditions attached to public dollars that might jeopardize the longer-term sustainability and service mission of the operation; the ITN ${ }^{\circledR}$ service model does not accept government funding. Alternatively, ITN ${ }^{\circledR}$ staff concentrates on finding private funding with the belief that there is ample private money, such as foundation grants and business partnerships, and that ITN ${ }^{\circledR}$ just needs to be marketed properly to find it. ITN ${ }^{\circledR}$ also looks from within its membership as a source of assets. For example, riders can donate their cars in exchange for rides. Riders pay some portion of the cost of the trip; however, those who cannot pay are not turned away. There is a "Roads Scholarship" program to which donors can contribute rides for seniors who cannot pay.

ITN $^{\circledR}$ affiliates rely on the private automobile insurance of the volunteer drivers. Drivers paid by ITN ${ }^{\circledast}$ usually get paid minimum wage and receive insurance through ITN ${ }^{\circledR}$. Paid drivers use ITN ${ }^{\circledR}$ cars that have been donated by charity or have been donated by customers for ride credits. ITN ${ }^{\circledR}$ affiliates strive to operate $24 / 7$, with no restrictions or value judgment placed upon the ride type. ITN ${ }^{\circledR}$ serves clients of age 65 and over as well as those with visual impairments. The cost of an ITN ${ }^{\circledR}$ ride is the approximate actual cost of the ride or about half the cost of a taxi ride. In general, ITN ${ }^{\circledR}$ clients are older than 75 years and volunteer drivers are between the ages of 55 and 74 . Volunteer drivers can earn credits for their service to redeem rides later for their own use.

In addition to ITN ${ }^{\circledR}$, other examples of membership programs include EZride in Pinellas County, Florida, and RidingTogether, in Deltona, Florida, also described in Appendix C. The approach with the use of memberships is to enable planning in advance of the ride needs of the members by registering them in advance. Membership in a program provides an added sense of security to riders and may promote a more vested interest in keeping the program going by its members. Membership fees and fares provide a more certain source of steady income to cover program expenses. However, there are challenges with charging fares, including questions raised about competing with private taxi services, especially for those volunteer programs that also receive government funds. Another issue is increased liability of the volunteer and the volunteer driving program because the expected standard of care increases for a program that charges fares. 
Table 5 - General Qualities of Membership-based Programs

\begin{tabular}{|l|l|}
\hline Volunteers vs. paid drivers & $\begin{array}{l}\text { These programs often must supplement their volunteer driving } \\
\text { corps with paid drivers. }\end{array}$ \\
\hline Small vs. larger service area & $\begin{array}{l}\text { There are usually geographic service boundaries on the scale of } \\
\text { serving a 10-15-mile radius from the center of a service area. }\end{array}$ \\
\hline Free vs. fares & $\begin{array}{l}\text { There can be both membership fees as well as a set schedule of } \\
\text { fares per ride. This may include a pick-up fee plus additional } \\
\text { charges per mile. }\end{array}$ \\
\hline $\begin{array}{l}\text { Minimizing liability vs. } \\
\text { expanding services }\end{array}$ & $\begin{array}{l}\text { Liability tends to be greater as membership-based programs } \\
\text { usually offer higher levels of service as well as charge fares. } \\
\text { Liability is borne first by the volunteer driver. Vicarious liability is } \\
\text { borne by the volunteer driving program. }\end{array}$ \\
\hline
\end{tabular}

FAITH-BASED PROGRAMS

Faith organizations often provide rides to members of their own organizations. These rides are usually provided by a church member for transportation to and from religious services and church activities as well as personal trips needed by the congregant. However, some organizations with a community service mission seek to assist any member of the community. Faith organizations can partner with other member organizations in their larger community or they may join a network or coalition of diverse organizations that may share a similar service mission. One such network is "Faith in Action" or the Interfaith Volunteer Caregivers (IVC). IVC has provided a model of care and operation that has been adopted by faith coalitions in many communities across the nation. ${ }^{21}$ IVC is community-based and community-supported. The IVC model development was funded by the Robert Wood Johnson Foundation with technical support provided by the Wake Forest University School of Medicine in North Carolina. While the National Program Office in Winston-Salem, North Carolina, closed on June 30, 2008, local programs are continuing to function in their communities. Currently, there are several hundred programs throughout the nation, all slightly different to meet the unique needs of their communities. They are based upon the Interfaith Volunteer Caregiver program model of five building blocks, Figure 1:
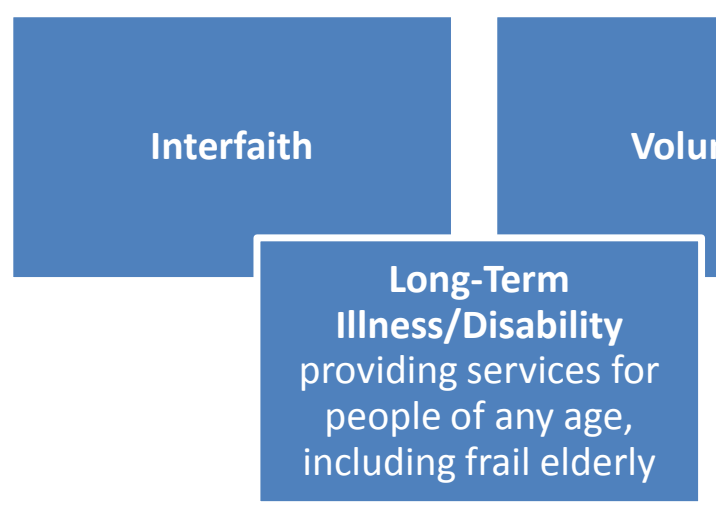

Volunteer

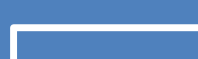

Homebased

serving people where

they live in the

community at large

\section{Figure 1 - Five Building Blocks of Interfaith Volunteer Caregiver Program}

The service focus is any nonmedical care of the individuals who need assistance. The care is not necessarily the provision of transportation. Caregivers take a holistic approach to addressing the

${ }^{21}$ Found at http://www.faithinactioncaregivers.org/about_fiac.php 
needs of the person. However, Faith in Action has found that a very large number of individuals needing assistance ask for transportation; therefore, transportation is often integrated into the total care provided to the person. The West Austin Caregivers in Texas is featured in Appendix C. In Florida, there is Faith in Action for Strength Together (FAST), which is a coalition of 30 churches in Pinellas County, Florida. There is also a Faith in Action organization in Hillsborough County, called Seniors in Service. They currently provide no transportation, as their challenges include no start-up infrastructure, both institutional and physical, such as vehicles. There also is a Faith in Action of Greater Winter Haven, Florida. It serves an area composed of urban, suburban, and rural communities. It provides transportation with a menu of services. It serves 425 seniors, as well as people with disabilities or dementia, children and others, with 2 paid staff. Its 100 volunteer drivers use their own vehicles and program-owned vehicles to provide transportation with a high level of assistance and support. It provides rides at all times (24/7), does not charge fees, but does accept rider donations. Its current annual operating budget is $\$ 4225 .^{22}$

\section{Table 6 - General Qualities of Faith-based Programs}

\begin{tabular}{|c|c|}
\hline $\begin{array}{l}\text { Volunteers } \\
\text { vs. paid } \\
\text { drivers }\end{array}$ & $\begin{array}{l}\text { Only volunteer drivers are used and, in concept, a ready source of volunteers is } \\
\text { available from each of the memberships of the participating faith based } \\
\text { organizations. }\end{array}$ \\
\hline $\begin{array}{l}\text { Small vs. } \\
\text { larger service } \\
\text { area }\end{array}$ & $\begin{array}{l}\text { Faith based programs may provide some of the most flexible transportation service } \\
\text { because the focus is on the total care of the individual. As a result, the objective is } \\
\text { to do whatever it takes to provide for the individual. For example, this may include } \\
\text { cross-county or longer distance rides to specialized medical facilities. }\end{array}$ \\
\hline Free vs. fares & Rides are free. \\
\hline $\begin{array}{l}\text { Minimizing } \\
\text { liability vs. } \\
\text { expanding } \\
\text { services }\end{array}$ & $\begin{array}{l}\text { The individual volunteer often bears the liability burden. Faith organizations often } \\
\text { operate on a "shoestring" and insurance coverage may not entirely cover the } \\
\text { activities of congregants. Additionally, volunteers for faith-based organizations may } \\
\text { see their service as a religious calling and as a duty to help another despite the risks } \\
\text { and personal liability burden associated with providing assistance. In addition, many } \\
\text { faith-based volunteers may not fully understand or even be aware of the liability } \\
\text { risks. }\end{array}$ \\
\hline
\end{tabular}

The various program configurations according to service features of interest to seniors are summarized in Tables 7 and 8 according to the combinations of characteristics discussed in this report. The characteristics of interest to seniors include who is eligible, what trip purposes are served, what service area is covered and the cost of the ride.

The focus of Table 7 is on the programs that serve any trip purpose while Table 8 focuses on programs that only serve targeted trip purposes. For example, in Table 7, West Austin Caregivers serve a special senior market determined through an eligibility process. The agency serves any trip purpose to any destination and the ride is provided free. Table 7 provides additional information regarding the use of volunteer drivers. The shaded cells of the table indicate service configurations that tend to provide the most flexible transportation to seniors (any senior, any trip purpose, and any destination) but also the greatest responsibility on the rider. The service configuration that would likely incur the greatest liability to the volunteer driving program is noted in the cell with italicized text. The cell represents a program type that would employ paid drivers in addition to volunteers, and charge a fare while setting the fewest limitations on transportation service provided.

${ }^{22}$ Source: 2007 STAR Search/Awards Report. Beverly Foundation. 
Table 7 - Volunteer Driving Programs that Serve any Trip Purposes

\begin{tabular}{|c|c|c|c|c|c|}
\hline \multirow[b]{2}{*}{$\begin{array}{l}\text { Serves any } \\
\text { trip purpose }\end{array}$} & \multicolumn{2}{|l|}{ Serves any senior } & \multicolumn{2}{|c|}{ Serves special senior market } & \multirow[b]{2}{*}{ Cost to senior } \\
\hline & $\begin{array}{l}\text { Engages volunteer } \\
\text { drivers only }\end{array}$ & $\begin{array}{l}\text { Employs some } \\
\text { paid drivers }\end{array}$ & $\begin{array}{l}\text { Engages } \\
\text { volunteer drivers } \\
\text { only }\end{array}$ & $\begin{array}{l}\text { Employs } \\
\text { some } \\
\text { paid } \\
\text { drivers }\end{array}$ & \\
\hline \multirow{4}{*}{$\begin{array}{l}\text { Serves any } \\
\text { trip } \\
\text { destination }\end{array}$} & $\begin{array}{l}\text { GoLoco }^{\mathrm{TM}} \text {, NuRide }{ }^{\circledR} \text {, and } \\
\text { eRideShare.com }\end{array}$ & & $\begin{array}{l}\text { West Austin } \\
\text { Caregivers TX }\end{array}$ & & Free to seniors \\
\hline & $\begin{array}{l}\text { GoLoco }^{\mathrm{TM}}, \mathrm{NuRide}^{\circledR} \text {, and } \\
\text { eRideshare.com }\end{array}$ & & & & $\begin{array}{l}\text { Expense sharing } \\
\text { is a customary } \\
\text { option }\end{array}$ \\
\hline & $\begin{array}{l}\text { Informal barter } \\
\text { arrangement, } \\
\text { sometimes with aid of } \\
\text { physical or electronic } \\
\text { bulletin board }\end{array}$ & & & & $\begin{array}{l}\text { Seniors trade } \\
\text { goods/services in } \\
\text { exchange for a } \\
\text { ride }\end{array}$ \\
\hline & & $\begin{array}{l}\text { Service } \\
\text { configuration of } \\
\text { greatest liability }\end{array}$ & & & $\begin{array}{l}\text { Seniors pay fare } \\
\text { and/or other fees }\end{array}$ \\
\hline \multirow{4}{*}{$\begin{array}{l}\text { Serves a } \\
\text { defined } \\
\text { service area } \\
\text { only }\end{array}$} & $\begin{array}{l}\text { Informal network or } \\
\text { coalition of like-minded } \\
\text { organizations }\end{array}$ & & $\begin{array}{l}\text { PasRide pilot } \\
\text { program, } \\
\text { Pasadena, CA } \\
\text { and } \\
\text { Senior Services of } \\
\text { King County, WA }\end{array}$ & & Free to seniors \\
\hline & & & & & $\begin{array}{l}\text { Expense sharing } \\
\text { is customary } \\
\text { option }\end{array}$ \\
\hline & $\begin{array}{l}\text { Similar in concept to } \\
\text { Senior Services of King } \\
\text { County, WA } \\
\text { Homesharing Program }\end{array}$ & & & & $\begin{array}{l}\text { Seniors trade } \\
\text { goods/services in } \\
\text { exchange for a } \\
\text { ride }\end{array}$ \\
\hline & $\begin{array}{l}\text { RidingTogether, Deltona, } \\
\text { FL }\end{array}$ & $\begin{array}{l}\text { ITNOrlando }{ }^{\circledR} \text {, and } \\
\text { EZride, Pinellas } \\
\text { County, FL }\end{array}$ & & & $\begin{array}{l}\text { Seniors pay fare } \\
\text { and/or other fees }\end{array}$ \\
\hline
\end{tabular}

Comparatively, the cells shaded in Table 8 indicate those service configurations that tend to provide the most limited transportation service to seniors (special eligibility required, specific trip purposes only and within a defined service area). The service configuration that would likely incur the least liability to the volunteer driving program relative to the other programs is noted in the cell with bold text. This represents a program type that would engage only volunteer drivers, provide rides for at no cost and provide limited transportation service to control risk, among other reasons. 
Table 8 - Volunteer Driving Programs that Serve Only Targeted Purposes

\begin{tabular}{|c|c|c|c|c|c|}
\hline \multirow{2}{*}{$\begin{array}{l}\text { Serves a } \\
\text { targeted trip } \\
\text { purposes only }\end{array}$} & \multicolumn{2}{|c|}{ Serves any senior } & \multicolumn{2}{|c|}{ Serves special senior market } & \multirow[b]{2}{*}{ Cost to senior } \\
\hline & $\begin{array}{l}\text { Engages } \\
\text { volunteer } \\
\text { drivers only }\end{array}$ & $\begin{array}{l}\text { Employs } \\
\text { some paid } \\
\text { drivers } \\
\end{array}$ & $\begin{array}{l}\text { Engages volunteer } \\
\text { drivers only }\end{array}$ & $\begin{array}{l}\text { Employs some } \\
\text { paid drivers }\end{array}$ & \\
\hline \multirow{4}{*}{$\begin{array}{l}\text { Serves any trip } \\
\text { destination }\end{array}$} & & & $\begin{array}{l}\text { ACS Road to } \\
\text { Recovery }\end{array}$ & & Free to seniors \\
\hline & & & & & $\begin{array}{l}\text { Expense sharing is } \\
\text { a customary } \\
\text { option }\end{array}$ \\
\hline & & & & & $\begin{array}{l}\text { Seniors trade } \\
\text { goods/services in } \\
\text { exchange for a ride }\end{array}$ \\
\hline & & & & & $\begin{array}{l}\text { Seniors pay fare } \\
\text { and/or other fees }\end{array}$ \\
\hline \multirow{4}{*}{$\begin{array}{l}\text { Serves a defined } \\
\text { service area only }\end{array}$} & & & $\begin{array}{l}\text { Manatee County } \\
\text { Meals on Wheels } \\
\text { Plus, FL } \\
\text { Service configuration } \\
\text { of least liability }\end{array}$ & & Free to seniors \\
\hline & & & & & $\begin{array}{l}\text { Expense sharing is } \\
\text { customary option }\end{array}$ \\
\hline & & & & & $\begin{array}{l}\text { Seniors trade } \\
\text { goods/services in } \\
\text { exchange for a ride }\end{array}$ \\
\hline & & $\begin{array}{l}\text { Gulfport } \\
\text { GEMS, FL }\end{array}$ & & $\begin{array}{l}\text { Charlotte } \\
\text { County Human } \\
\text { Services Dept., } \\
\text { FL }\end{array}$ & $\begin{array}{l}\text { Seniors pay fare } \\
\text { and/or other fees }\end{array}$ \\
\hline
\end{tabular}

Illustrating the range of many potential service concepts, Tables 7 and 8 are intended to help readers locate an example of a volunteer driving program that provides a service configuration similar to a potential program being considered.

In summary, each service model places priority on different services or operational characteristics.

Informal ride sharing arrangements, as a service model, are effective for seniors who have an active social network to draw upon and who can make the ride arrangements on their own.

Bartering, as a model, is effective for seniors who want to find rides through a business transaction but who lack cash. Instead, seniors can offer goods (such as dinner casseroles) and services (such as tutoring, ironing, recordkeeping) in exchange for rides.

Informal volunteer driving programs, as a service delivery model, are those that seek to provide all the essential elements of a driving program while minimizing administrative costs and liability.

Local governments, as a model, seek to extend their existing driver corps through the engagement of volunteers, to provide government-funded transportation. 
Social services programs, as a model for the delivery of volunteer rides, seek to assist a targeted market and/or provide a ride in order to deliver some other primary service. These are often wellestablished programs or local affiliates of national programs.

Membership-based programs, as a model, serve paying customers with a higher level of transportation service.

Faith-based programs, as a service model, start with an individual person needing help and apply a holistic approach to providing for the total care of that individual. Based upon the needs of each individual, transportation is usually but not always part of the regimen of care.

The development of these models has come about in practice through the intersection of three elements: (1) the nature of the senior's need, (2) the aim that a program and its volunteers want to accomplish, and (3) the combined resources (or lack thereof) of the seniors and the program. The exercise of categorizing volunteer driving programs into generalized service models helps to identify which model features might be useful to consider in starting a new volunteer driving program, or strengthening an existing one. 
The purpose of this chapter of the report is to better characterize the transportation "gap" left by other available community transportation services, which volunteer driving programs are created to fill. Examining this context is useful in order to consider, (1) how volunteer driving programs can better fill the gap, (2) coordinate with these other services to create greater efficiencies and better service for seniors, and (3) help identify what can be done to make the gap smaller, so as

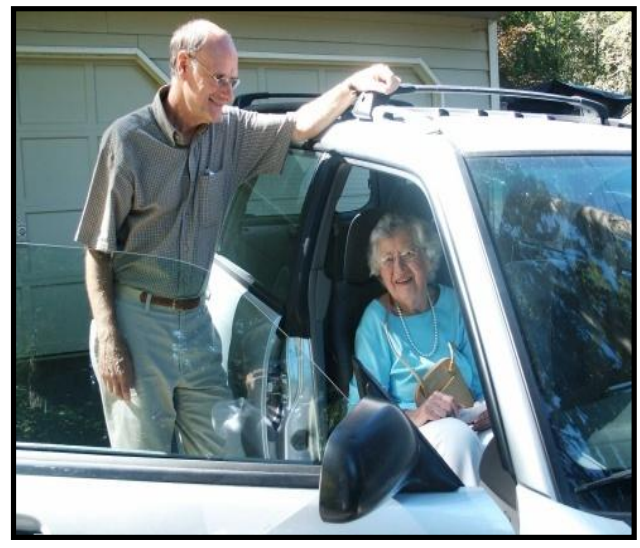
to minimize seniors' reliance on volunteer driving programs that must compete for a limited number of community volunteers. These other transportation services include regular fixed route public transit, paratransit, local government human service programs, Transportation Disadvantaged services, transportation from service providers under contract with Area Agencies on Aging and Medicaid-provided transportation.

\section{PUBLIC TRANSIT}

The more that public transit can serve seniors, the less need there would be for volunteers to give seniors rides. In Florida, bus services are becoming fully accessible with low-floor buses and equipment enabling people in wheelchairs or motorized scooters to board. Transit systems want riders to use regular bus service whenever feasible and are encouraging more use of transit by seniors through targeted advertising, travel training using other seniors as teachers, easy-to-read maps and schedules, flexible routing and senior discounts. Transit agencies even provide a linking service for those who cannot get to the nearest bus stop, due to either disability or some kind of geographic or man-made physical barrier. This service will pick the individual up at their front door and transport them to the bus stop. Still, there are a number of limitations. AARP reports that less than 50 percent of suburban households are within $1 / 2$ mile of transit service and less than 12 percent of rural households are served by transit. ${ }^{23}$ Some seniors may have a trip destination that is just a mile or two away; however, if the trip crosses a jurisdictional boundary, some public transit systems may not be able to serve them. This is beginning to change. For example, Pasco County Public Transportation provides connections to transit in Pinellas and Hillsborough Counties. However, in many areas in Florida, finding public transportation options that cross-jurisdictional boundaries continues to be a problem. ${ }^{24}$ Seniors tend to be frail, are more sensitive to weather, safety and security concerns, and often cannot wait for long periods. Standard buses do not have seat belts. From time to time, the bus must make an emergency stop. Research shows that seniors have a higher rate of fatalities and injuries in traffic accidents than younger people. ${ }^{25}$ If seniors were to be thrown from their seats, they would tend to suffer more serious injuries than others would.

\footnotetext{
${ }^{23}$ Straight, Audrey and Steven R. Gregory. "Transportation: The Older Person's Interest”. AARP Public Policy Institute. 2002.

${ }^{24}$ Hillsborough Seniors on the Move. Transportation Meeting discussion. West Central Florida Area Agency on Aging, Inc., May 22, 2008.

${ }^{25}$ Yee, W. Y., P. A. Cameron and M. J. Bailey. "Road Traffic Injuries in the Elderly", Emergency Medicine Journal, Vol. 23, 2006, pp. 42-46.
} 
Aside from public transit, there are usually other transportation options available to seniors in communities throughout Florida, provided through either local government human services programs or the Area Agency on Aging (AAA). There are eleven AAA planning and service areas (PSA) in Florida. AAA is funded through the State of Florida Department of Elder Affairs to serve seniors of age 60 years and older and who meet eligibility requirements as established by the Federal Older Americans Act (OAA). However, transportation services through AAA are usually targeted for certain types of trips only, such as to nutrition/meal sites. There is Medicare, a national health insurance program for eligible seniors age 65 years and older, which covers emergency transportation services only. There is also transportation for non-emergency purposes paid for by Medicaid, a health care program for lowincome persons. Medicaid covers the cost of transportation if the senior has no other means of transportation to an appointment. By Florida Statute, Medicaid is required to purchase transportation services through the Community Transportation Coordinator (CTC) through the Transportation Disadvantaged (TD) Program. Seniors must be Medicaid clients to be eligible for this service. If a senior is not eligible for Medicaid or for the TD Program, chances are poor that the CTC will be able to help.

\section{PARATRANSIT}

Some seniors might qualify for paratransit service due to a disability. In Florida, transit agencies usually are the providers of paratransit service, per requirements of the federal Americans with Disabilities Act (ADA). To be eligible to use paratransit, a person must have a disability that prevents them from using standard fixed route service. Paratransit service is available during the same hours and days of operation as for fixed route service. Paratransit serves any trip purpose with origin and destination falling within $3 / 4$ mile of regular fixed routes. For those seniors who live beyond the area served by fixed route transit, they will not be able to use paratransit. Use of paratransit requires a greater level of personal organization that may become challenging as seniors with disabilities get older, especially if they have never used public transit before. Determination of eligibility usually requires filling out a multi-page application, an interview, a doctor's note, and a wait period before an eligibility determination is made. The rider must know the exact street address of where he or she wants to go. He or she may bring no more than two bags onto the vehicle. Using the example of one paratransit service in Florida, riders must request each ride at least 24 hours in advance but no earlier than three days in advance. Seniors may find themselves not up for a trip they scheduled the day before. If it is too late to cancel, the senior rider may incur a "no show" penalty on their patron record. An accumulation of three "no shows" in a month may disqualify a rider from paratransit service. In order to provide the best service to the most patrons under a limited budget, these eligibility processes and operation procedures are necessary. However, the many gradual changes associated with advanced age, such as general weakness and ability to stand for only short periods, are not recognized as disabilities per se, which puts paratransit out of reach for many seniors.

\section{TRANSPORTATION DISADVANTAGED}

There is also a Transportation Disadvantaged Program, sponsored by the State of Florida Transportation Disadvantaged Trust Fund and administered by the Commission for the Transportation Disadvantaged. This program assigns a Community Transportation Coordinator (CTC) for each county to assist those who qualify as transportation disadvantaged. In 2005, seniors made up approximately 35 percent of all passenger trips provided by the Florida Transportation Disadvantaged Program. ${ }^{26}$ To

${ }^{26}$ Florida Department of Transportation. 2006 Trends and Conditions Report: Transit and Transportation Disadvantaged. Public Transit Office. May 2006. Pg. 11. 
be eligible to use TD services, a senior must be able to demonstrate that they have no other means of transportation. This might include submitting proof of income and/or a medical verification form that describes a disability, which has been completed by their doctor. TD services are also available to seniors who live in a rural area that has no other form of public transportation. Seniors must have no other family or friends who could provide them with rides. Often, seniors do have some family members or friends who can transport them, but these trips are only an option when family or friends are available and willing to help.

\section{Community Coordination of Multiple Services}

Communities that already offer multiple service options for seniors are dealing with coordination issues. For example, in urban areas where there are large senior populations and multiple service options, different information and computer technologies used by various service organizations may be incompatible. This incompatibility obstructs sharing of data that would enable cooperation.

Another challenge has been to create and refine a one-stop intake process to remove redundancies when seniors apply for transportation service eligibility. The need is for the senior to go through an application process just once, with the end result that the senior is signed up for all services that he or she is eligible for, and the senior has enough information to know how to access and select those services. While there are online resources that can explain a senior's eligibility, those seniors who are not computer literate may need to talk to a knowledgeable and considerate staff member who listens and provides one-on-one assistance. Another need that would advance a one-stop intake process is a "one-call" telephone number, but a major hurdle is getting the word out to the

The goal is for the senior to go through an application process just once, with the end result that the senior is signed up for all services that he or she is eligible for, and the senior has enough information to know how to access and select those services. community that a one-call phone number exists. There is a need to put a system in place to track such calls, and conduct follow-up to make sure requests for assistance have been met in a timely manner. Where there is a one-call number, there must be enough knowledgeable staff to field calls in a timely manner, without putting someone on hold for long periods. Finally, a system is needed to accurately count and document those requests for assistance that could not be served.

In Florida, the concept of Aging Resource Centers (ARC) was developed through the amendment of Chapter 430, F.S. The Aging Resource Center for each service area corresponding to an Area Agency on Aging, is tasked with integrating information and coordinating multiple service providers to make it easier for seniors to find the services they need. As part of this process, local ARC Coalition Work Groups have been formed. For example, the ARC Coalition for the Miami-Dade and Monroe Counties developed a strategic plan to address these issues. Goals and objectives include the development of an integrated management information system and electronic referral network shared by the service community and accessible to the general public. Goals and objectives also address the need for community outreach, ARC services user training, and tracking of client screening, referrals and service delivery. ${ }^{27}$

Public transportation strives to provide the most transportation using very limited public dollars. It appears that many seniors fall somewhere in between the regular public transit services designed for

\footnotetext{
${ }^{27}$ 2007-2010 Strategic Plan, Aging Resource Center (ARC) Coalition. Alliance for Aging. Prepared by Health Council of South Florida, Inc., June 27, 2007.
} 
the general able-bodied population and the other services designed for the neediest. Many seniors are too frail to use regular public transit safely, but perhaps are not "poor enough" or do not meet criteria for being disabled or are not isolated enough, either geographically or socially, or their immediate needs are not considered urgent enough. The middle gray area is where volunteer driving programs attempt to bridge the gap for seniors

\section{TRANSIT AGENCY PARTNERING WITH NONPROFIT ORGANIZATIONS}

Presently, many seniors may not be able or eligible to use the available public transportation options for some or all of their trips, due to some combination of physical inabilities (or abilities), trip purpose, location, income or other eligibility requirements. By serving in the role of mobility manager, some public transit agencies are going beyond offering traditional transit service to provide more to seniors. For example, Polk County Transit Services (PCTS) has been investigating options for providing more transportation to seniors who do not drive.

In December 2007, PCTS held a day-long summit with over 170 stakeholders to identify unmet needs and priorities. This was part of a process to develop a coordinated human services transportation plan in order to be eligible, under SAFETEA-LU, for certain federal funds. These funding opportunities include Section 5310 - Elderly Individuals and Individuals with Disabilities, Section 5316 - Job Access and Reverse Commute, and Section 5317 - New Freedom Initiative. In response to problems identified, PCTS formed the Polk County Human Service Transportation Network. Part of the Network's charge is to improve and increase transportation services for seniors. In collaboration with the Network, PCTS has planned to investigate the possibility of new services like a volunteer transportation program for seniors. PCTS had initially investigated conducting its own program but the County legal services department counseled against it.

PCTS held a Volunteer Coordination Workshop in June 2008. The purpose of the meeting was to gather all those with an interest in senior transportation and to identify resources and collaborative opportunities to provide for the need. PCTS hoped to find a nonprofit organization willing to take the lead and partner with PCTS to implement a volunteer driving program. As a partner, PCTS could provide driver training and background checks, potential resources for the purchase of vehicles or the borrowing of vehicles from other programs, funding to reimburse volunteer drivers for their cost of fuel, and program administrative services, such as handling all recordkeeping required of organizations that receive federal

... Some public transit agencies are attempting to go beyond the more traditional transit service offerings to provide more to seniors.

funds. PCTS could provide customer service staff to help schedule the rides. PCTS could collect data on all trips provided and other reporting required of agency funders. PCTS could also provide computer hardware and TRAPEZE ${ }^{\mathrm{TM}}$ RidePro, scheduling software to organize rides. The use of scheduling software could potentially eliminate duplication among various programs, such as transportation provided through Medicaid, veterans' hospitals and churches.

There were several nonprofit human service agencies who participated in the June Volunteer Coordination Workshop but none initially offered to provide a volunteer driving service. The main reason is that existing nonprofit agencies, which answer to their boards of directors, ordinarily have narrowly focused missions with regard to service area, target population, and services provided. Operating on shoestring budgets, staff of nonprofit organizations must remain highly focused on their missions. It is unlikely that organization boards would agree to divert scarce resources to provide an additional service, especially if it does not directly advance the organizational mission. Under 
circumstances where federal grants are awarded, nonprofits express wariness of federal monitoring and auditing, even though PCTS asserts that they could assume the role of accountable officer.

It was concluded that the issue of developing a volunteer driving program for seniors was not a funding issue, as most every agency or organization has some kind of transportation budget to serve their members. The barrier to a nonprofit taking the lead was an issue of mission that cannot justify providing the coordination function. The meeting ended with discussion about the possibility of either starting a new nonprofit to provide volunteer driving services to seniors or starting a consortium of cooperative agencies tailored after the organizational model used by the Homeless Coalition.

The Homeless Coalition, of which there are several offices statewide, facilitate the coordination and collaboration among service organizations in a particular area and conduct strategic planning to maintain services. The PCTS meeting ended with a call to identify organization representatives with decision-making power to serve on a steering committee to lead the exploration of forming a coalition. An organizational model such as a coalition could bring together businesses, agencies, service providers and faith organizations to expand the community capacity to provide volunteer rides for seniors. 
Non-profit organizations, including those that provide volunteer drivers to give rides to seniors, are exposed to various types of risk in the course of routine activities. Risk is the likelihood of loss or injury. In addition to various types of risk, such as traffic accidents, risk also varies according to the degree of severity of potential incidents as well as the frequency with which they occur. Liability has to do with who is responsible if something goes wrong. Liability describes the degree of responsibility that an individual or organization

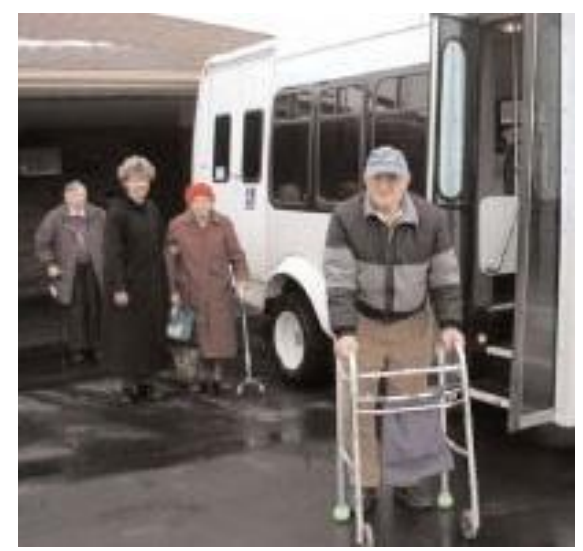
holds. Liability is preassigned by federal and state law and as interpreted and applied by the courts. Based upon the nature, severity, and frequency of risk and liability associated with routine activities, organizations rely upon various types and amounts of insurance coverage to protect the organization's assets and operations in the event of involvement in an incident in which a claim is filed. Insurance is one necessary element of an organization's plan to manage the risks taken in the course of doing business and providing services.

\section{HISTORY SUGGESTS VOLUNTEER DRIVING PROGRAMS OPERATE SAFELY}

What is the safety record of volunteer driving programs? During interviews with staff of volunteer driving programs for this study, staff reported that throughout the history of their collective operations, one minor claim had been filed. Most volunteer driving programs are relatively new but a few of these programs have operated for decades. The Beverly Foundation has concluded that volunteer driving programs are safe. ${ }^{28}$ These programs share many of the same risk management elements. All programs interviewed for this research appeared to emphasize risk management. This is due, primarily, to the program staff's concern for the safety of riders and volunteer drivers. Secondly, the program staff members of most but not all programs are generally aware of liability considerations. Risk management programs usually include a volunteer application, a volunteer criminal background check, a motor vehicle record check, reference checks, an interview, driver training, and vehicle inspection.

\section{LOSS/CLAIMS DATA FOR VOLUNTEER DRIVING PROGRAMS ARE NOT PUBLICLY AVAILABLE}

The Florida Office of Insurance Regulation (OIR) reported no problems regarding liability issues of volunteer driving programs. OIR has received no complaints or grievances. The OIR is aware of no court cases in which the Florida Volunteer Protection Act was cited with regard to a volunteer driving program. ${ }^{29}$ While insurance providers consider how past claims under similar circumstances are decided in court, this body of information does not include the cases settled out of court. Research staff attempted to find loss/claims data regarding frequency, severity and costs of motor vehicle accidents involving volunteer drivers for nonprofit organizations. However, insurance carriers that

\footnotetext{
${ }^{28}$ The Beverly Foundation surveyed 225 Faith in Action volunteer driving programs in 2007 and reported a collision liability of 3 percent in the previous 5-year period and concluded that the "low number of collisions that result in legal liability in Faith in Action transportation programs appears to be consistent with other volunteer driver program data. It is believed that such experience results from the fact that volunteer drivers are either safe drivers or that they use especially safe driving methods when driving older people or people with disabilities." 2007 STAR Search Survey \& STAR Awards for Excellence, 2007 Report, pp. 6-7. The Beverly Foundation, Pasadena, CA, July 2007. Found at http://www.beverlyfoundation.org/awards/2007star_search_report_final.pdf

${ }^{29}$ Jack McDermott, Florida Office of Insurance Regulation. Interview, November 8, 2007.
} 
underwrite policies do not share their loss/claims data. Furthermore, nonproprietary loss/claims data regarding volunteer drivers were not available from the Insurance Information Institute or other public information sources.

Even if insurance carriers did provide claims histories, it is likely that the data could not be disaggregated to isolate only those claims involving volunteer drivers. Any available claims/loss data from the insurance industry would likely address claims under a commercial insurance coverage known as hired and non-owned auto. ${ }^{30}$ This is carried by organizations and covers accidents of an employee or volunteer using his or her own private vehicle while conducting business on behalf of the organization. Examples of business might be going to the bank or running errands. As a result, the claims data would encompass more than accidents involving volunteer drivers.

Risk management programs usually include a volunteer application, a volunteer criminal background check, a motor vehicle record check, reference checks, an interview, driver training, and vehicle inspection.

\section{PERCEPTION OF RISK MAY OUTWEIGH SAFETY HISTORY}

Despite the fact that the history of volunteer driving programs indicates they are safe, the necessity of insurance recognizes that the consequences of just one accident could be devastating to not only the individuals involved, and their families, but to the volunteer driving program. There may be obstacles experienced by start-up volunteer driving programs to receiving adequate insurance coverage. Even though some volunteer driving programs have been in operation since the 1980's, these programs still represent a relatively new social service concept. Insurance carriers and underwriters may refuse to issue policies to volunteer driving programs, not because they have sufficient data on claims histories to calculate a reliable probability of risk, but because they may have very little data. As a result, the perception of risk by the underwriter is what counts. From the underwriter's point of view, volunteer driving programs present more than one "red flag." ${ }^{13}$ These include a service for a vulnerable population that suffers more severe injuries than others in the event of an accident. Secondly, the service is carried out by volunteers who may be perceived as those with inadequate training. It is easy to get and keep a driver license. The real concern for most volunteer driving programs is about validating a volunteer driver's driving abilities and judgment.

\section{VOLUNTEERS ASSUME RISK AND LIABILITY}

Informal volunteer driving relationships, such as a neighbor driving a friend to the grocery, is easy for an insurance underwriter to deal with. The law does not expect an individual to perform to some higher standard while transporting a neighbor or friend. However, the consequences of a claim upon an informal volunteer can also be severe as evidenced by the 1994 case of Thomas Muster v. General Motors Corporation et al. in Miami. Austrian professional tennis player Thomas Muster was being driven in a tournament car to the Miami downtown by a volunteer, Linda Boyd. She stopped her car at Bayside Shopping Center to drop off Muster. As he was retrieving items from the trunk of Boyd's car, a drunk driver, Robert Sobie, collided with Boyd's car, knocking Muster to the ground. Muster sustained injuries and filed a claim for damages in the millions. Sobie was found to be 90 percent responsible and the other three co-defendants, Lipton International Players Championships, General Motors, and Boyd, were found to be 10 percent responsible. Boyd was found to be "an incompetent driver" because the location where she dropped off Muster was not a designated stop for

\footnotetext{
30 Jennifer Chandler-Hauge, Nonprofit Risk Management Institute, email communication, November 28, 2007.

${ }^{31}$ Chandler-Hauge, ibid.; and Bill Perkins, Florida Association of Insurance Agents, Tallahassee, FL, email communication, December 4, 2007.
} 
disembarking from vehicles. Florida law, as with federal law, limits the liability on pain and suffering damages to the percentage of responsibility imposed against each defendant but makes all defendants equally responsible for the economic damages in a lawsuit. ${ }^{32}$

THOMAS MUSTER V. GENERAL MOTORS CORP. ET AL. UNCOVERS ADDITIONAL ESSENTIAL RISK MANAGEMENT ELEMENTS

Staff of volunteer driving programs can exert some degree of control over this issue. First, staff should develop and implement a rigorous risk management program that identifies and addresses all the major points. These include ensuring that every driver is licensed and has at least the state minimum required personal auto liability insurance coverage. It also includes ensuring that every driver has no record of driving while under the influence of alcohol and has no moving violations within a reasonable period. Resources for developing sound risk management programs are listed in Appendix A. The lesson learned from Thomas Muster v. General Motors Corp. et al. is for volunteer driving organizations to provide driver training to avoid accidents with claims of driver "gross negligence" or incompetence. This includes strict adherence to laws and street signage concerning motor vehicle operation. It should include carefully considered procedures established by the volunteer driver program with regard to how and where a volunteer driver picks up and drops off a rider. Such guidance could help avoid accidents and claims filed against both the driver and the volunteer driving program.

NONPROFITS WEIGH SERVICE AGAINST RISK

Nonprofit organizations assume "vicarious liability" for the actions of their volunteers. Nonprofit service programs vary in their capacity to insure their operations. They vary in the level of service they seek to provide, which directly affects the level of risk the program assumes. They also vary in their willingness to "stick their necks out" to accomplish the service mission of their organization despite that they may not have adequate risk management procedures and insurance coverage in place. Generally, the smaller programs that serve smaller communities show more flexibility and willingness to do what it takes to provide the needed rides and support services to help the seniors. In their good intentions, this also makes these programs more vulnerable. As programs grow in the number of riders they serve, become more formalized, serve more urbanized communities, and accept various types of grant funds, the programs tend to become much more risk averse. The available resources enabling program expansion allow a more detailed and formalized risk management program and better attention to the necessary insurance coverage. However, it also can mean a much less flexible approach to providing service, especially less of the more personalized and individualized combinations of support services that seniors tend to need as part of the ride. In a sense, the more formalized a program becomes, the more it may resemble a public transit service.

\section{GOVERNMENT PROGRAMS HAVE THE CAPACITY FOR ADEQUATE INSURANCE COVERAGE}

Appendix $E$ includes an analysis on protection from liability for government agencies who engage volunteer drivers. Known as the doctrine of sovereign immunity, it is concluded that sovereign immunity law in Florida likely would not give public agencies protection if one of their volunteers (or

${ }^{32}$ Thomas Muster v. Lipton Sports, Inc.: Thomas J. Lipton, Inc.; General Motors Corporation; Robert Sobie; and Linda Boyd. $11^{\text {th }}$ Judicial Court of Florida, Miami-Dade County. Clerk's File No. 1994 R 285066. See also Dunnigan, Pat,

“Tennis player injured in car accident awarded \$2.5 million by jury", Miami Daily Business Review, June, 1994. 
paid drivers) causes an accident. Any service sponsored by a public entity must pass muster with a formal risk management program that ensures the legitimacy of volunteer drivers and sufficient insurance coverage. Generally, programs affiliated with government agencies or larger nonprofits have the means to manage risk adequately. However, local governments may be reluctant to assume the risk, as in the case of Polk County Transit Services discussed earlier. Government agencies in Florida are permitted to extend insurance to cover volunteer drivers. Furthermore, Section 430.204(3), F.S. calls for maximizing use of volunteers to serve functionally impaired elders to prevent premature institutionalization. The Department of Elder Affairs or their contracting agency may provide excess automobile liability protection for volunteers.

\section{IDENTIFYING AND ELIMINATING DRIVER DISTRACTIONS NEED EMPHASIS}

Although media attention in recent years has highlighted research that indicates cell phone use as a dangerous distraction from driving, other more mundane but no less dangerous distractions include spilling coffee, eating, map reading and even conversing with passengers. Driver distractions are among the most frequent culprits for automobile accidents. In response, a good risk management program for volunteer driving programs should include driving procedures that reduce as many distractions as possible. Special consideration should be given, in the development of risk management procedures and driver training to managing conversation while driving. Social conversation has been identified as among one of the most important elements of volunteer driving, for both the rider and the driver. Conversation may actually be critical to some riders, such as cancer patients for whom social support may play an important role in the patient's recovery. ${ }^{33}$ Personal conversation is one of those attributes of the volunteer driving program that make it

Volunteer drivers are covered by Florida's Volunteer Protection Act but liability protection is minimal. especially valuable and different from other options, such as a cab ride.

FORMAL VOLUNTEERING ALTERS THE PLACEMENT AND MAGNITUDE OF LIABILITY

In comparison with a neighbor volunteering a ride, a volunteer driver program complicates the insurance issue because a formal relationship spreads the liability from the arena of personal to the arena of commercial. Any type of "agreement" between a sponsoring agency and a volunteer driver creates a different legal standard, which, in turn, creates a different risk of claims for the insurance company. "Working" (unpaid) for an organization creates new standards of duty and increased obligation on the part of the driver.

FEDERAL AND STATE VOLUNTEER PROTECTION ACTS PROVIDE MINIMAL PROTECTION TO VOLUNTEER DRIVERS

With regard to volunteer liability, the Federal Volunteer Protection Act (FED-VPA) excludes motor vehicle accidents from VPA protection; however, the FED-VPA also allows states to pass laws that provide greater protection to volunteers. This is discussed in detail in Appendix E. Volunteer protection laws are different, state-by-state. ${ }^{34}$ The laws of many states also specifically exclude any motor vehicle accident from state VPA protection, whether a volunteer driver for a senior driving program or anyone else. According to the Nonprofit Risk Management Institute, this is because these states have no-fault insurance laws for automobile accidents in general, to avoid the flood of costly

${ }^{33}$ Goodwin, Jerry, MD, Director, Sylvester Cancer Center, Miami, Florida, as reported by Andrea Robinson. "Drivers wanted to help cancer patients", Miami Herald, April, 2, 2008.

${ }^{34}$ Sundeen, Matt, and Nicholas Farber, "Volunteer Driver Liability and Immunity: A 50-State Survey". National Conference of State Legislatures, December, 2006. 
court fights regarding whose fault it was. ${ }^{35}$ While Florida requires licensed drivers to carry no-fault insurance protection, Florida is one of 15 states with volunteer protection acts, in which motor vehicle drivers (volunteer drivers included) are not explicitly mentioned. In the absence of a court case outcome that interprets otherwise, this means volunteer drivers are covered by the Florida Volunteer Protection Act (FL-VPA). However, the actual protection provided to a volunteer driver under the FLVPA would be minimal, for reasons discussed later in this report.

\section{CHARGING FARES AND HIRING PAID DRIVERS INCREASE LIABILITY TO A PROGRAM}

ITN ${ }^{\circledR}$ represents a service model in which liability insurance may be more difficult to obtain, due to charging fares to riders as well as hiring paid drivers. Difficulty obtaining insurance may be exacerbated by the present condition of the insurance industry in Florida. For example, as of March 1 , 2008, State Farm, the second largest property insurer in Florida no longer writes commercial policies in Florida, which would include umbrella policies that non-profit organizations purchase to provide excess coverage beyond that provided by the volunteer's personal auto insurance.

\section{INSURANCE IS NECESSARY REGARDLESS OF FAULT IN AN ACCIDENT}

In the event of any incident in which a suit is filed, there is the potential expense involved in hiring an attorney, even if the volunteer driving program and its volunteer is not at fault. Attorneys must be paid to get a case dismissed. This situation could be especially onerous for small programs and well worth the added attention to preventing incidents.

VOLUNTEER DRIVING PROGRAMS RELY ON THE VOLUNTEER'S PERSONAL AUTO INSURANCE

The volunteer driving programs interviewed for this study that do not charge fares and do not have paid drivers, indicated that the availability and cost of insurance was not a barrier. The insurances carried by each volunteer driving organization differ in both types and amounts. There does not appear to be a commonly accepted standard for amounts, nor does there appear to be a common language with regard to different types of insurance. Different groups call the insurance products by different names. However, what the volunteer driving programs all have in common is that they all rely on the volunteer's personal auto insurance as the first line of defense in the event of a claim. Some but not all volunteer driving programs carry excess coverage or an umbrella policy to cover the remaining claim amounts after the volunteer's insurance limits are reached. This raises the question, what entity should appropriately bear the risk and burden of liability, relating to the provision of volunteer rides for seniors? If the liability burden remains primarily on the individual volunteers, and secondarily on the volunteer driving programs, then it is reasonable to assume that it will remain difficult to find volunteers willing to provide a public service for free and it will remain difficult for volunteer driving programs to afford the administration of the public service that is either free or very low cost to seniors.

QUESTIONS REMAIN REGARDING EXTENT THAT PERSONAL AUTO INSURANCE IS AVAILABLE TO VOLUNTEER DRIVERS

Some volunteer driving programs in Florida have reported that their volunteers have had difficulty obtaining personal auto liability insurance when it became known that they were volunteer drivers. Furthermore, where personal auto insurance has been made available, studies cite instances in which

35 Jennifer Chandler-Hauge, Nonprofit Risk Management Center, Washington, D.C. Telephone conference, June 2, 2008. 
the premiums of some volunteer drivers have been raised to unaffordable levels. ${ }^{36}$ However, interviews with five out of six volunteer driving program managers contacted for this study indicated that obtaining insurance and insurance affordability has not been a problem for their volunteers or for the program. The one program that did cite a problem identified difficulty obtaining commercial insurance (hired and non-owned auto) for the program itself and not personal auto liability insurance of volunteers.

A number of things could explain the difference between the problems documented by other studies and what this study has found.

(1) This study may not have interviewed enough programs to uncover the problem. The primary goal in the selection of volunteer driving programs for this study was to identify different service models.

(2) The one program that cited difficulty is a special type of membership program that hires paid drivers and charges fares to riders. This added liability may figure into the further difficulty obtaining insurance for the program.

(3) The specific problem cited by the membership program was related to hired and non-owned commercial insurance, which is a special type of insurance with narrowly defined application. Issues relating to this type of insurance are further discussed below.

(4) Managers of volunteer driving programs who were interviewed for this study may not be fully aware of any difficulties experienced by their volunteers, and especially problems anticipated by persons who may have considered volunteering but decided against doing so.

(5) For those individuals who have, in the past, experienced difficulty obtaining personal auto insurance and who have claimed it is due to volunteer status, it is not fully known whether there may have been other legitimate reasons why the insurance carriers denied coverage.

(6) Insurance carriers vary widely in the manner in which they judge risk. There is no standardized formula used in the auto insurance industry. One carrier may deny coverage while another may determine acceptable risk and write a policy.

(7) Especially for volunteers living in rural areas where there may be fewer local insurance brokerages with which to do business, their experience finding insurance may be less than satisfactory.

(8) Volunteers wishing to serve seniors who live in rural areas may face driving long distances, possibly resulting in higher premiums or difficulties finding insurance.

What does seem clear is that there is variation in response by insurance brokers and carriers to volunteers and volunteer driving programs that seek adequate insurance coverage at affordable rates.

\footnotetext{
${ }^{36}$ Firestone, Lauren and Paulette Geller. Insurance Company Survey, May 22, 2006. Survey results reported in "Florida's Volunteers: The Driving Force for Senior Mobility; Identifying Barriers and Enabling Change", Winter Park Health Foundation, Issue Brief, December 2006. p. 4. See also Carlin-Rogers Consulting. "Keys to the City: Volunteer Drivers Open Doors for Senior Riders: An Analysis of Barriers to Volunteering in Florida Driving Programs". September 2006.
} 
Although this study did not find evidence of difficulty by volunteers finding insurance coverage, it is reasonable to assume, under the circumstances, that volunteers may encounter difficulty. The fact remains that volunteer drivers do increase their exposure to risk simply by driving more miles than they otherwise would. This criterion would seem more reasonable to apply to calculate risk than many other standard but discriminatory criteria commonly applied by the auto insurance industry to calculate premiums, such as gender, age, residential location, credit rating and type and age of motor vehicle driven. Actual mileage would matter more to premium rate calculations if auto insurance companies asked for yearly odometer readings. However, many insurance companies usually use as a measure, the number of miles driven to and from work or school. Surprisingly, miles driven as a volunteer may not even figure into the calculation of the auto insurance premium. As another example, the cost of personal auto insurance generally decreases for retirees under the age of 75 , presumably because they no longer work or attend school. However, many retirees drive long distances on vacation trips, but insurance companies might not consider this.

\section{NEW FLORIDA LAW OFFERS LITTLE PROTECTION TO VOLUNTEERS}

At the time that this study had begun, Florida Governor Crist had signed HB 359 into state law in June 2007. This amended Section 627.7261, F.S. with regard to circumstances under which an insurance carrier may refuse to issue private motor vehicle insurance policies. This law was passed largely through the work of the Florida Chapter of AARP and its partners. This effort raised the profile of volunteer driver concerns before policy makers. Tailored after a similar law in Maine, it states that an insurer may not deny an application for automobile liability insurance, impose a surcharge, or otherwise increase the premium rate for an automobile liability policy solely on the basis that the applicant is a volunteer driver. However, the insurance industry avoids any new assumption of risk because the new law allows an insurance carrier to refuse to renew, impose a surcharge or otherwise raise premiums based on other factors besides volunteer status. An analysis of the implications of this law, contained in Appendix E, identifies the problem of enforceability in that it would be difficult to prove that an insurance carrier was not discriminating solely on volunteer status.

The fact remains

that volunteer

drivers do increase

their exposure to

risk simply by

driving more miles

than they

otherwise would.

Interestingly, insurance professionals interviewed for this study claimed

that volunteer driving is not a factor in issuing insurance. Additionally, brokers interviewed for this study shortly after HB 359 became law, had no knowledge of the newly passed law. A review of the history of the bill prior to passage found no evidence of debate on record. This would seem to indicate that the insurance industry did not pay attention to HB 359. Brokers said the new law made no difference with regard to the issuance of policies or the manner in which premiums for insurance are calculated.

\section{PERSONAL NO-FAULT INSURANCE PROVIDES LIMITED PROTECTION ONLY}

Florida state law requires licensed drivers to carry personal no-fault insurance to pay expenses arising from minor traffic accidents. However, if a volunteer driver were in an accident in which lives were lost or devastating injuries occurred, his or her personal no-fault insurance would not cover it. The volunteer driving program or the organization under whose auspices the volunteer driving program operated would share the liability. 
Commercial hired and non-owned auto insurance is an advisable coverage for volunteer driving programs to carry. It would cover beyond the limits of a volunteer's personal auto insurance. Examples of situations that this type of insurance covers include those in which a paid staff person or volunteer is running an errand on behalf of the company or is on his or her way to a business meeting and is in an accident while driving his or her own car. However, in recent years, hired and non-owned auto insurance has been more difficult to obtain. According to World Wide Specialty Programs, a provider of staffing insurance, commercial insurance carriers are now more reluctant to provide hired and non-owned auto coverage because "...in recent years, this coverage has been called upon to respond in some unusual and unanticipated circumstances, bringing a whole new twist to the interpretation of coverage and when and where it responds. It is safe to assume that as the parameters of this coverage are being reconfigured, hired and non-owned auto coverage will be more costly and less available than ever before." ${ }^{37}$ There is some question whether hired and non-owned auto insurance would be considered applicable to cover volunteer drivers while they are conducting the business of transporting senior riders in their cars. The driving activity is not incidental but rather the major activity of the volunteer, whose time is primarily spent on driving. Hired and non-owned auto coverage does not cover taxi or livery service, in which individuals run a business using their own vehicles to transport others.

\section{AMOUNT OF ASSETS AFFECTS AMOUNT OF INSURANCE NEEDED}

An organization's insurance coverage amounts should align with the asset base and the level of risk. Unfortunately, experience suggests that plaintiffs generally seek financial compensation equal to an insured limit of coverage. The likelihood that a nonprofit organization is held liable for negligence of a volunteer driver may be associated with the size of its asset base. ${ }^{38}$ Likewise, the Beverly Foundation found in their development of the Volunteer Friends service model, that the risk of liability and the consequences to the sponsor of a transportation program could be greater when the organization has more assets. $^{39}$

\section{ADEQUATE INSURANCE COVERAGE REQUIRES THE SERVICES OF A DILIGENT BROKER}

After establishing a solid risk management program, staff should search for an insurance broker willing to work with them. It is the job of the broker to find a carrier that will underwrite a policy. This may take some effort and perseverance. Staff should be ready to provide a convincing case that the volunteer driving program is successfully minimizing risk.

In summary, volunteer driving program histories indicate that the programs are safe but perception of future risk outweighs history of safety. Aside from volunteer driving programs, even informal volunteers assume risk and liability and they will be held accountable, as illustrated by the case of Thomas Muster v. General Motors Corp. et al. Unfortunately, federal and state protection for volunteer drivers is minimal despite the existence of Federal and State Volunteer Protection Acts. The case provides insight as to critical elements that risk management programs should contain.

\footnotetext{
${ }^{37}$ World Wide Specialty Programs, Inc., World Wide New York Insurance Services, Inc., Melville, NY. Go to http://www.worldwidespecialtyprograms.com/pdf/02summer_p3.pdf (Last accessed 09/10/09).

${ }^{38}$ Chris Neal, State Farm, Florida Division, Telephone interview, February 14, 2008.

${ }^{39}$ Beverly Foundation. "PasRide: A Pilot Low Cost/Low Maintenance STPs", White Paper 3.1, prepared for the Supplemental Transportation Program for senior (STPs) Mobilizer Project, p. 7.
} 
Furthermore, identifying and eliminating driver distractions are key. Generally, the more risk averse a program, the less flexible it becomes with regard to providing the more personalized type of service that distinguishes volunteer driving programs from public transportation.

Unlike informal neighborly volunteering, the creation of a formal volunteer driving program alters the placement and magnitude of liability. Programs can manage liability to some degree by operations characteristics. For example, charging fares and hiring paid drivers increases liability. Insurance is necessary for volunteer driving programs regardless of fault in the event of an accident. It was found that volunteer driving programs rely primarily on the volunteer's personal auto insurance as the first line of defense. In Florida and elsewhere, volunteer driving programs have indicated that some volunteer drivers have been denied personal auto insurance because of their status as a volunteer driver. As a result, HB 539 was passed into Florida state law. However, this study found no indication that insurers have taken notice of the new law. Prior to its passage, no history of debate or involvement by the insurance industry was found. After the law was passed, there has been no indication that personal auto insurance premiums are calculated differently. Premiums are based on other indicators of risk, such as the number of miles driven. A particular type of commercial auto insurance, hired and non-auto, is difficult for volunteer driving programs to obtain. Hired and nonauto insurance may not be considered appropriate protection for volunteer drivers, as the parameters for its application are being revised by the insurance industry. Unfortunately, the amount of assets of a program may affect the amount of a claim. This points to a strength of using the Volunteer Friends service model as a means to keep assets low. In this environment, it is incumbent upon the volunteer driving program to search for a broker willing to consider the unique nature of the program, advise on strengthening risk management and find a carrier willing to assemble the most appropriate and affordable package of insurance to protect the program.

\section{A LEGAL ANALYSIS OF RISK ASSOCIATED WITH VOLUNTEER DRIVING PROGRAMS UNCOVERS GAPS}

This study closely examined legal issues that are associated with volunteer driving programs for seniors, especially those relating to the liability risks posed by those programs. This report provides a number of options for remedies, but understanding the reasoning behind these options requires knowing a bit of the background, which is presented in Appendix E. Court cases that are analogous in various respects to volunteer driving programs were studied. These court cases refer to federal and state law, which has a long history. The law has shifted in its ideological emphasis over time. The old doctrine of "charitable immunity" from tort (a wrongful act for which relief may be obtained in the form of damages or an injunction) was eventually followed by a spate of modern laws that sometimes capped charities' liability, and by a large set of state "volunteer protection acts" that, at least in principle, protected volunteers from civil liability. In the system of Federal and Florida statutes that aim to protect volunteer drivers from heavy civil liability, some gaps in protection were found. In general, the relationships involved in a volunteer driving program for seniors are beneficial for all parties. The non-profit organization or agency, the volunteer, the client, and outsiders as well as society in general will derive benefit from this helping relationship. Adverse events are unlikely in most individual cases. However, prudent management and planning requires program officials to foresee those situations that could pose future problems, in order to develop methods to avert, limit, or remedy them.

The legal analysis, conducted by an expert in public health law, focused upon the most common scenario of concern, in which a volunteer driver accidently causes injury to a client or to a third party. The analysis presents an historical summary of the evolution of the law protecting volunteers over time, including charitable immunity, sovereign immunity and the volunteer protection movement. 
The analysis explores the Florida Volunteer Protection Act (FL-VPA) and the Federal Volunteer Protection Act (FED-VPA) relative to volunteer driving programs.

MINIMUM REQUIREMENTS FOR RISK MANAGEMENT WOULD SET STAGE FOR LIABILITY REFORMS

On the premise that priority should be given to the vulnerable clients of volunteer driving programs over other parties as a basis for policy, several options for action are presented. The analysis explores administrative and operational reforms, including a recommendation that state lawmakers articulate some minimum risk management requirements with regard to screening, training, and supervision of volunteers and inspection of vehicles. In general, volunteer driving programs already conduct these risk management activities; therefore, minimum requirements would not create an excessive burden on these programs. Many states already have minimum risk management requirements relating to the care of vulnerable persons. $A$ list of these related examples are included in Appendix $\mathrm{F}$.
... having senior riders sign waivers, releasing the volunteer driving program of liability, is not recommended.

CONTRACTS BETWEEN THE VOLUNTEER DRIVING PROGRAM AND THE RIDER ARE RECOMMENDED BUT WAIVERS ARE NOT

Throughout the legal analysis there is acknowledgement of the multiple policy trade-offs that must be considered. With respect to volunteer driving programs, this includes increasing safety of vulnerable clients versus the desirability not to place excessive burden upon volunteers and volunteer driving programs. The legal analysis discusses and recommends the use of contracts between riders and volunteer driving programs as a means of making clear from the start the roles, duties, obligations and entitlements of each party. The use of waivers from liability in contracts is also considered, as one volunteer driving program service model uses. These clauses release the program of liability. However, having senior riders sign waivers, releasing the volunteer driving program of liability, is not recommended. Waivers are inappropriate in a volunteer driving context, as seniors are arguably a vulnerable population. Furthermore, waivers historically have not held up in court.

AMENDING THE FLORIDA VOLUNTEER PROTECTION ACT IS AN OPTION

Most notably, the legal analysis uncovers gaps in liability protection for volunteer drivers in both the Federal and Florida Volunteer Protection Acts (FED-VPA and FL-VPA). When volunteers commit an act or omission that results in personal injury or property damage to another, they can be protected from civil liability by the FL-VPA only if they are "acting as an ordinary reasonably prudent person would have acted under the same or similar circumstances." On its face, the existing requirement of the FLVPA to "act as an ordinary reasonably prudent person," sounds altogether fair and desirable. By also requiring that a volunteer driver behave "as an ordinary reasonably prudent person," the Act has basically raised his or her duty to the standard one required of all drivers on Florida's roads. In the language of tort law, the FL-VPA is saying that the volunteer may not even commit any act of simple (or ordinary) negligence on the roadway, or the full burden of civil liability will descend on him or her. This gives the volunteer virtually no special protection by virtue of his/her charitable act; all he or she gets is the illusion of protection. This vulnerability of volunteer drivers was illustrated previously in the case of Thomas Muster v. General Motors Corp. et al., in which volunteer driver Linda Boyd was found to an incompetent driver. It is recommended to remedy this gap in volunteer protection by revising the FL-VPA to remove the requirement that a volunteer driver must "act as an ordinary reasonable 
prudent person." ${ }^{40}$ The conditions that volunteer drivers must act in good faith within the scope of their official duties, and not perform those duties in a wanton manner or with willful misconduct, would continue to be in force to protect riders against negligence and wrongful acts.

\section{AMENDING THE FEDERAL VOLUNTEER PROTECTION ACT IS ANOTHER OPTION}

An alternative legislative remedy is to change the FED-VPA by removing the exception from protection for volunteers operating a motor vehicle, as shown in Appendix $\mathrm{E}^{41}{ }^{1}$ This would better address the explicit Congressional concern, found in the law's own preamble, over the high cost of insurance policies that may be burdening volunteer drivers and the volunteer driving programs that have hired them. ${ }^{42}$ Of course, Congressional amendment of the FED-VPA would no doubt be slower and harder than state action but this federal statutory remedy might be preferable, since it could offer protection for volunteer drivers across states.

\section{THERE ARE SEVERAL OPTIONS FOR LIMITING DAMAGES}

In the case that volunteer driving programs are found to be liable, there are recommendations for limiting the amount of damages that organizations must pay. Options include the placement of a cap or ceiling on the amounts of damage. Another option is the use of a "charitable redress system." This report describes one such system, originally developed by Charles Robert Tremper. Other options include risk pools for volunteers. One example is the Nonprofits' Insurance Alliance of California (NIAC), which was consulted for the PasRide pilot project by the Beverly Foundation. Another example is the CIMA Volunteer Insurance Program, described in Appendix D. Lastly, a final option for limiting the burden of payment of damages is recommended. This would involve the federal government covering the liability costs of nonprofits in much the same way Congress has agreed to cover lawsuit costs of pharmaceutical companies for vaccine-related injuries.

${ }^{40}$ Sec. 768.1355(1)(a), F.S.

${ }^{41} 42$ U.S.C. $\$ 14503(\mathrm{a})(4)$

${ }^{42} 42$ U.S.C. s $14501(\mathrm{a})(6)$ 
There are several excellent comprehensive sources and detailed guidebooks for those interested in developing a volunteer driving program. These are listed in Appendix A. This study looked beyond the comprehensive guidebooks to examine specific issues relating to the start-up and implementation of volunteer driving programs for seniors. This study identified alternative service configurations for volunteer driving programs, documented operations issues

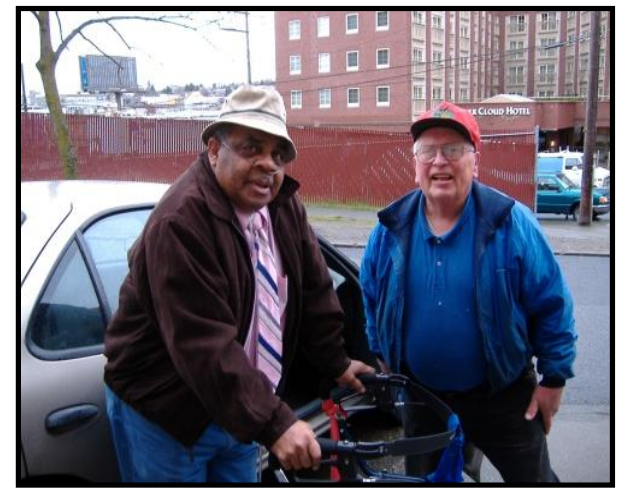
of greatest concern to volunteer driving program administrators, and described issues both practical and legal, regarding risk, liability, and insurance. From the perspective of research sponsored and funded by FDOT and NCTR, and throughout the course of this research, staff explored the potential role public transit and commuter assistance programs can play in providing transportation to seniors who no longer drive and how public transit can complement volunteer driving programs for seniors.

To support volunteers, a two-pronged approach is suggested. First, there are recommendations to remove barriers from program operation and from volunteering. Second, recommendations are provided to give incentives and rewards to volunteers. Recommendations for action by volunteer driving programs, transit agencies, Area Agencies on Aging, the Governor's Commission on Volunteerism and Community Service and for policy makers to support volunteer driving programs are summarized below.

WHAT VOLUNTEER DRIVING PROGRAMS CAN DO

Many of these volunteer driving programs already work wonders by managing to provide a great deal of service on shoestring budgets. What more can volunteer driving programs do?

PROVIDE SUPPORT FOR VOLUNTEERS

Volunteers are the heart of a volunteer driving program. The rising cost of fuel is causing many programs to lose their volunteers. The issues of volunteers include finding enough volunteers who have suitable qualifications to be drivers, then removing as many obstacles as possible from volunteering, providing incentives to volunteer, then helping to make the experience of volunteering rewarding so that they choose to continue in their capacity as drivers. It is just as important to retain existing volunteers as finding new ones otherwise the investment of effort and time in the application, orientation and training processes with each volunteer is lost. The following recommendations as outlined in Figure 2 are based on ideas gleaned from the interviews with staff of volunteer driving programs conducted for this study.

\section{EXPLORE OTHER VOLUNTEER RECRUITING APPROACHES}

For recruiting, volunteer driving programs interviewed for this study have demonstrated that they are always looking for ways to find and recruit volunteers. They use multiple strategies in combination, such as distributing brochures, giving presentations to civic groups, and posting ads in local newspapers. One strategy that may have good potential is to identify "affinity groups," and focus some portion of recruitment efforts upon them. For example, the fact that a significant proportion of volunteer drivers are retirees demonstrates an age affinity. The American Cancer Society's Road to Recovery program finds that many cancer survivors are willing to serve as volunteer drivers. For other programs, it is suggested that the individual senior riders could be interviewed and characterized in 
enough detail to identify what affinity groups in the community could be attracted to serve as volunteers for the existing client base. These "interviews" could actually be informal conversations between volunteer drivers and riders. The affinity can be based upon numerous things, such as a shared experience of some type. Sharing the same type of difficulty often brings people together, illustrated by Modest Needs, an online nonprofit that enables donors to help others with short-term money problems. Seven out of every ten recipients from Modest Needs later log back into the site as donors. ${ }^{43}$ An affinity can be based upon a shared hometown or country of origin, a shared hobby, alma mater, sorority or fraternity, etc. Current volunteers may know others of the same affinity group who might volunteer.

Another recommended approach is to develop a partnering relationship with other local organizations that have a service mission. This may include churches or in the case of the West Austin Caregivers, their longstanding relationship with the Junior League has provided them with a source of many committed volunteers. The recruitment thrust is to develop networks of service organizations within the community. Where there is a collaborative relationship between the volunteer driving program and another entity, there is a better chance of finding a volunteer. Volunteer driving programs should focus on establishing and maintaining these relationships with other organizations that may provide a source of volunteers.

ENLIST THE SUPPORT OF THE GOVERNOR'S COMMISSION ON VOLUNTEERISM AND COMMUNITY SERVICE

Several organizing mechanisms exist that provide updated listings of volunteer opportunities and perform the function of "suggesting" volunteer opportunities, based upon a person's interests. These include the national VolunteerMatch, based in San Francisco, which provides a robust online volunteer recruiting service for other nonprofit organizations. Potential volunteers can search by a selected radius from a zip code, interest area, skill, keyword, and target group by age. There also is the national Hands On Network, with regional affiliates that organize volunteer opportunities to fit the evening and weekend schedules of volunteers. In Florida, there is "Volunteer Florida," the Governor's Commission on Volunteerism and Community Service. Volunteer Florida helps develop, promote and implement volunteerism and service throughout the state. Volunteer Florida also provides service matching.

Volunteer programs of all kinds, including several volunteer driving programs, have used these online recruiting opportunities by submitting descriptions of the type of volunteer assistance needed and profiles of what a volunteer would be asked to do. Descriptions include whether the assistance needed is ongoing or has an end date, how much time the assistance would require, and what types of skills and knowledge are sought. Programs seeking volunteers typically provide only cursory information. Individual programs do not appear as though they are making the effort to stand out. This

Online volunteer matching services should provide an opportunity for programs to personalize their submittal in some way, even if it is just a box for inserting comments. may be a limitation of the online volunteer matching service rather than the volunteer program if the profiles developed are based upon answers to rigid survey questions. Online volunteer matching services should provide an opportunity for programs to personalize their submittal in some way, even if it is just a box for inserting comments.

${ }^{43}$ Peterson, Mark. “Saving Lives, One Rent Check at a Time”, Forbes. August 11, 2008, pp. 66-70. 


\section{What Volunteer Driving \\ Programs Can Do}

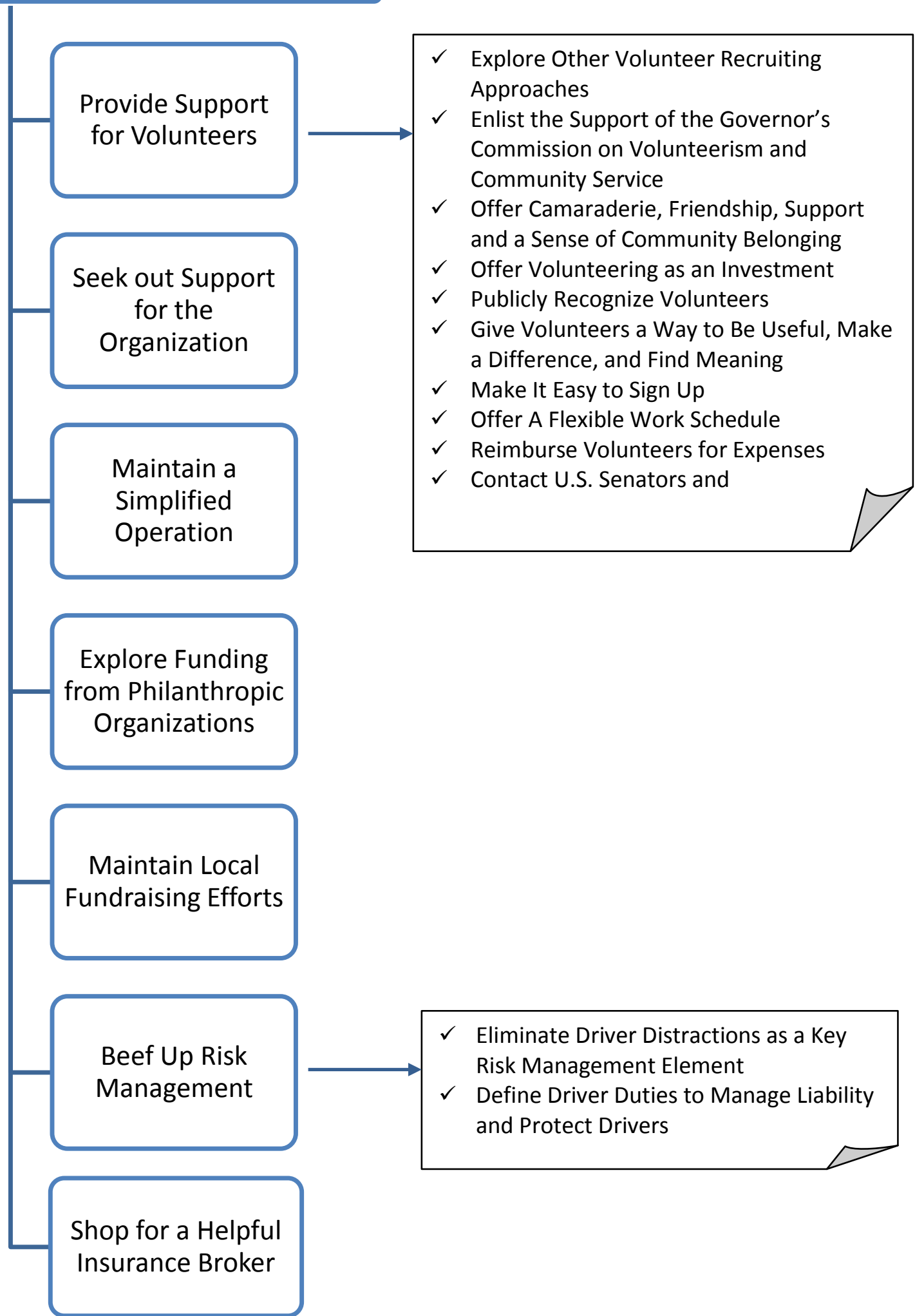

Figure 2-Outline of Recommendations to Volunteer Driving Programs 
Nonetheless, these online resources have the capability to reach out to potential volunteers who might not know that volunteer driving programs even exist or who might have never considered volunteering as a driver. In this way, those who would search on these resources represent all those who already know they want to volunteer-they just haven't decided yet what to do. This presents two opportunities.

First, volunteer driving programs should ask these online volunteer recruiting services, such as Volunteer Florida, to further refine the matching function by incorporating the tools of various profiling instruments commonly used for career counseling and dating. For example, eHarmony ${ }^{\circledR}$ is a matchmaking web site that provides matches based upon a detailed questionnaire. The Jung Typology Test ${ }^{\mathrm{TM}}$, the DiSC Personality Profiling Assessment, and several others measure and describe an individual's work and communication styles, interests, values and personal goals, and temperament for various types of work. While this report does not endorse any specific profiling instruments, such testing is widely used by the general public. People are fascinated by their personal results from these tests. In a society where a multitude of career opportunities abound and there is a cultural emphasis on personal fulfillment, people commonly set their expectations high on finding the best possible fit. Similarly, the sheer number and diversity of volunteer opportunities can make it a challenge for those individuals who view volunteering as a commitment and want to make a wise choice. By offering a personalized list of volunteer opportunities generated based upon the unique attributes of the inquirer, more people might seriously consider volunteering.

The second opportunity is for volunteer driving programs to devote more attention to the content and appearance of web sites and submittals requesting volunteers from online matching services. Like a cover letter and resume, first impressions can make the difference in attracting volunteers to driving programs. Such descriptions of volunteer opportunities might include what the program has to offer to the volunteer, such as skills development, experiential learning, and meeting community leaders.

While some individuals have a desire to volunteer on behalf of certain populations, such as children or single parents, others may seek to volunteer because they want to improve conditions in their own neighborhoods and communities. In this case, the volunteer should be matched, according to his or her motivations, with a senior in his or her neighborhood or community. Volunteer driving programs that can match the provision of rides for seniors as a means to respond directly to each individual volunteer's motivation to serve will be more successful in attracting volunteers.

OFFER CAMARADERIE, FRIENDSHIP, SUPPORT AND A SENSE OF COMMUNITY BELONGING

What would motivate someone to make a long-term commitment as a volunteer driver? It is well understood by volunteer driving programs that the more a volunteer opportunity meets the needs of the volunteer the more likely he or she will stay involved. Each volunteer may have more than one need or motivation. Volunteers are really a different set of customers of the volunteer driving program. As evidenced by the programs interviewed, one of the strengths of volunteer driving programs is the personalized nature of the programs. Volunteer drivers and riders share a pleasant car trip and get to know one another. Driver and rider testimonials indicate the value of the social experience to both participants. Volunteer driving can be socially rewarding, building camaraderie, support and friendships among volunteers, riders and program staff. It is recommended that staff look for ways to foster, celebrate, and market this attribute of the volunteer driving experience. 
OFFER VOLUNTEERING AS AN INVESTMENT

By definition, volunteering is not a money making venture. However, potential volunteer drivers might value the opportunity for developing new skills, acquiring a community service credential and community networking. Volunteers are not only retirees, but also high school and college students and professionals. For example, the RidingTogether program volunteers include a real estate agent and a restaurant manager. For individuals who are exploring a career change, a job change, or interested in making business contacts on behalf of their own businesses or employers, the contact with program staff, board members, clients and their families can be valuable. The content and tone of conversations in response to potential volunteer inquiries as well as the intake procedure for volunteers can make a critical impression. These early "conversations" include the content of newspaper ads, brochures and civic presentations. Early conversations can subtly communicate a sense that the service exchange goes in one direction only and the volunteer will be doing all the giving. The program serves a bottomless pit of needs and volunteers will work until they are burned out. Alternatively, initial impressions can communicate that the program/volunteer relationship will be a beneficial twoway exchange. A volunteer's service will be an important contribution that is greatly appreciated and they will get something valuable back in return. Program marketing could feature a story about someone who made a career decision because of volunteering, or a job contact with promising results. Upon an initial visit, warm first impressions could be made by introducing a potential volunteer to staff, riders, volunteers and others who may be in the office at the time. The manner in which volunteer inquiries and application processes are handled should be tailored for each volunteer driving program and each potential volunteer, but clearly the introductory impressions can mean the difference between never seeing an inquirer again and signing a new volunteer on.

... the Florida Governor's Commission on Volunteerism and Community Service could seek collaboration with the Florida Department of Highway Safety and Motor Vehicles to create a separate endorsement class for volunteer drivers on driver licenses for "a private passenger vehicle designed to transport no more than six people including the driver".

Some volunteer programs also provide tangible economic benefits. For example, Independent Transportation Network ${ }^{\circledR}$ affiliates offer volunteer drivers the ability to earn credits toward rides that can be donated to a friend or family member or for oneself in the future. This can be a powerful incentive to "invest" volunteer time because practically every family has or will have senior members at some time in the future.

PUBLICLY RECOGNIZE VOLUNTEERS

While annual volunteer appreciation dinners and the like are welcomed and enjoyed by volunteers, frequent personal expressions of thanks, both written and verbal can go a long way to remind volunteers that their individual contributions are being noticed. Recognition from community partners can reinforce the worthiness of volunteer driving for seniors and confer "VIP" status upon volunteers. Volunteer driving programs may win in-kind donations more successfully from community sponsors if the donors know contributions directly assist the volunteers themselves. These sponsor donations could be in the form of deep discounts or free services for volunteers from area automotive businesses, including vehicle maintenance, oil changes, safety inspections and car washes. It could include other useful products and services as well, such as grocery gift cards from the same supermarkets that enjoy business from seniors who shop there because of rides from the volunteer driving program. 
The State of Florida also could recognize the importance of volunteer drivers. Related to volunteer driver training, the Florida Governor's Commission on Volunteerism and Community Service could seek collaboration with the Florida Department of Highway Safety and Motor Vehicles to create a separate endorsement class for volunteer drivers on driver licenses for "a private passenger vehicle designed to transport no more than six people including the driver." This driver license endorsement would be received by volunteers after successful completion of volunteer driver training. It could qualify a volunteer driver to park in a handicapped parking space when transporting a senior or qualify for other allowances that make the job of volunteer driving easier. A volunteer driving endorsement could qualify a volunteer for a discount on annual vehicle registration and other appropriate privileges.

GIVE VOLUNTEERS A WAY TO BE USEFUL, MAKE A DIFFERENCE, AND FIND MEANING

Those people in society who are inclined to volunteer are those already predisposed to the desire to be useful, make a difference and do something meaningful. Volunteer driving programs should point out how providing a ride is a pleasant experience and it makes an immediate difference. On a personal level, volunteers and riders share conversation and become acquainted with one another. Through this contact, the volunteer might hear the personal stories of riders and learn just how much the rides helped the riders. The volunteer driving program should use the opportunity to share with the community what are the specific benefits that have sprung from a single volunteer ride. Providing a single ride can mean the difference between sickness and health for someone. ${ }^{44} \mathrm{~A}$ single ride can generate opportunity, such as friendship between a child and a foster grandparent. The point that can be vividly drawn in as many ways as there are riders is the great positive impact, both direct and indirect, of a ride volunteered relative to the effort spent. This will attract donors and volunteers alike because the case will be made that effort and resources are well invested.

\section{MAKE IT EASY TO SIGN UP}

The process of preparing a volunteer to be ready to serve as a driver is not quick and easy. Unlike other volunteer opportunities, such as the national Hands On Network, in which a person lends an hour or two of time without an ongoing commitment, volunteer driving programs may require significant volunteer preparation even before the volunteer provides the first hour of service. Proper risk management requires a volunteer application and interview process, a background check, reference checks, training, vehicle inspection, and other elements. Typically, the final number of volunteer drivers is far fewer than those who expressed initial interest. The goal is to reduce the "attrition" that occurs during the volunteer application and preparation process. This can be aided by designing the application process to be as simple as possible, providing online information, forms and tools, such as an online volunteer driver safety course, and providing easy-to-use forms for record keeping. The volunteers themselves may have good suggestions to make the process simpler.

There are few people who have an abundance of free time, but there are more people with a little bit of free time. The objective is to enable a person to use that little bit in a way that provides more satisfaction than doing other things. Where possible, turn a negative into a positive. For example, because volunteer driver programs rely on the volunteer's personal auto insurance coverage, volunteer driving programs can assist volunteer drivers to keep their personal auto insurance premiums low. Program staff can review with them the many criteria that insurance companies use to calculate an individual's personal auto insurance premium. While these include some elements that are generally not possible or desirable to change, such as age and marital status, there are other criteria more within the sphere of control of a volunteer driver. These include history of driving

${ }^{44}$ See Stories from the Road. Beverly Foundation. Found at

http://www.beverlyfoundation.org/stories_from_the_road/index.html 
violations, accident claims, credit rating, the presence of theft protection devices on the car, current insurance limits, and multiple cars and drivers covered by the same insurer. One's credit is affected by whether bills are paid on time, presence of bad debt, and frequent opening and closing of savings and credit accounts. Volunteers should be reminded to seek a free yearly report of their credit rating to make sure that the information used to determine their rating is accurate. The volunteer driving program might offer ideas on risk pools for personal auto insurance that he or she may qualify for, such as professional organizations, AARP, etc. Being a member of an auto club can also provide insurance discounts. While the application process for becoming a volunteer driver may require extra time, the program should emphasize that regardless whether the individual ultimately volunteers, the reviews and training he or she receives is time well spent as a personal safety and money saving benefit.

OFFER A FLEXIBLE WORK SCHEDULE...

Providing schedule flexibility will enable volunteers to fit driving into the course of their weekly or monthly activities. For example, Senior Services in Seattle provides flexibility regarding how many hours per month a volunteer donates as well as when they drive.

\section{...BETTER YET, REQUEST NO SCHEDULE COMMITMENT AT ALL}

For maximum flexibility to volunteers, another approach is to ask for no scheduling commitment whatsoever. Many volunteer driving programs will initially ask when a volunteer is available to provide rides. Then the volunteer is expected to provide rides during that time. Especially if the program employs paid drivers who work on a consistent time schedule, the volunteers then must fill in the gaps. This scheduling makes it easier for the dispatcher but also has the effect of making a volunteer feel locked into donating hours on a regular basis at a particular time. Responsible people will shy away from committing themselves if they feel they may not be able to follow through.

The RidingTogether program takes flexibility a step further, in that the program manager asks for no commitment at all. Volunteers are asked how many times a month they might be willing to drive. From time to time, a volunteer may be called upon to provide a ride, but the volunteer is under no obligation to do it. The dispatcher makes it clear that it is entirely okay for the volunteer to turn down a driving request. When the dispatcher receives a request for a ride, he starts calling people on his list of approved volunteer drivers, with those willing to drive more times per month located higher up on the list. The dispatcher usually finds someone on his list willing and available to provide a ride. If not, the dispatcher himself steps in to provide the ride.

\section{CONTACT U.S. SENATORS AND REPRESENTATIVES}

Managers of volunteer driving programs should consider getting active in the public policy arena to advocate and raise awareness about volunteer driving programs. One immediate opportunity to consider is contacting U.S. Senators, Representatives, and their legislative staff regarding the impact that rising gas prices has on their volunteer driver recruitment. Such contact would coincide with the U.S. Congressional Committee on Finance consideration of S. 3429, the Giving Incentives for Volunteers Everywhere (GIVE) Act of 2008, which, if passed, would amend the Internal Revenue Code to allow volunteers to claim an income tax deduction of 70 percent of the standard business mileage deduction rate. This would raise the volunteer rate from 14 cents to 41 cents per mile and allow the rate to be adjusted annually. Furthermore, the Act would exempt from taxable income, reimbursements from charities for mileage travelled by a volunteer up to the business rate and the Act would exempt the reporting requirement by volunteers. If such an amendment to federal income tax 
law passes, then volunteer driving programs could reimburse volunteers for mileage without the volunteer having to pay taxes on those reimbursements.

REIMBURSE VOLUNTEERS FOR EXPENSES

To recruit and retain volunteer drivers, it is recommended whenever possible to reimburse volunteers for the full cost of fuel, personal vehicle wear-and-tear, and any increases in personal auto insurance premium because of their volunteerism. Taking care of the volunteers by providing excess auto liability coverage and purchasing for them auto club memberships will communicate to the volunteers their importance. While these expenses will be costly to the program, reimbursements will accomplish two things. First, it will guard the volunteer driving program against losing its volunteers due to rising fuel costs, thus keeping the program active. Second, reimbursing volunteers for their expenses will help avoid the more expensive necessity of employing paid drivers.

SEEK OUT SUPPORT FOR THE ORGANIZATION

Staff of existing volunteer driving programs, as well as those in the development stages, should avail themselves of the numerous resources devoted to senior transportation. A list is included in Appendix A. Most of these resources are available online. Staff should also reach out to other potential community collaborators to marshal resources and leaders. Volunteer driving programs need a social and institutional "infrastructure" in place, composed of the decision makers from related organizations and agencies, such as Rotary Club members, who have the combined local knowledge and resources to get a job done. Developing that social infrastructure includes an identification of representatives of helpful entities such as local hospitals, charities, the media, elected officials, attorneys, insurance companies, the local chapter of AARP, etc.

MAINTAIN A SIMPLIFIED OPERATION

In the development and operation of a volunteer driving program, especially those that provide trips for any seniors and for any trip purpose, it is recommended to start the operation small and not attempt to grow the program faster than available resources. Keep the organization of the program as simple and informal as possible. Program simplicity also keeps the operation on a more personal scale, which is the strength and spirit of a volunteer service. Drawing from the examples of using a rider's own network of associates, such as NuRide ${ }^{\circledR}$, GoLoco $^{\mathrm{TM}}$ and the Volunteer Friends service model, the element of personalization has the potential to provide better service to riders. Simpler programs are easier to implement for smaller communities where many seniors reside, keeping the operation within the constraints of limited budgets. A smaller operation with limited assets may also be a less inviting target for insurance claims. Alternatively, under the auspices of a larger organization, it may be easier for a simply designed volunteer driving program to be covered under an umbrella policy. If it makes sense to do so, a driving program might seek to form under the wing of a larger established organization. Freed from the expense of insurance, resources may be available to hire a full-time volunteer recruiter. 
EXPLORE FUNDING FROM PHILANTHROPIC ORGANIZATIONS

An examination of volunteer driving programs found that they exhibit resourcefulness and creativity in finding funds from a wide variety of sources, including grants, memberships, donations, fares and fees, sponsorships and in-kind contributions. Program administrators are sensitive to the conditions attached to various funding sources and must weigh the value of the funding against its impact on program operations. Program administrators see the value of funding source diversity and try to limit dependence upon grant funds that can suddenly disappear at the end of the year. In fundraising, there may be numerous opportunities to approach targeted philanthropic organizations to provide a compelling case on behalf of the need for transportation for seniors. This may be relevant to the mission of many organizations and as a result, financial support for volunteer driving programs for seniors may work its way into their strategic plans. Fundraising campaigns should highlight the personal value of a ride and the ripple effect: all the concrete and positive ways that a single ride improves the life of a senior and his or her family. A ride provides compounded dividends that can be illustrated.

MAINTAIN LOCAL FUNDRAISING EFFORTS

Some managers of nonprofit organizations are under the mistaken notion that donors will not contribute to an organization that receives government funds. In fact, donations do not fall because of receipt of government funding. They fall because of a management decision to reduce local fundraising efforts. Donors usually have no idea how much a local charity gets from the government. ${ }^{45}$ Receipt of government grants in no way diminishes the worthiness of a program to receive private donations. Instead, donors who do ask about funding sources respond well to the presentation of organized information about donors, the wise use of those funds, why more funds are needed and what further donations would provide in their very own community. For example, in the case of volunteer driving programs, proceeds from fundraising should go toward volunteer reimbursement of fuel expenses to retain volunteer drivers.

Volunteer driving programs have the task not only to raise funds but to rally and assemble other necessary resources, in the form of leaders, professional know-how and donated services, organizational partners, vehicles, computer hardware and software, and of course, volunteers. The example of Polk County Public Transit illustrates an ongoing process of assembling and developing the physical and personal "infrastructure" needed to conduct a volunteer driving program.

BEEF UP RISK MANAGEMENT

ELIMINATE DRIVER DISTRACTIONS AS A KEY RISK

MANAGEMENT ELEMENT

Many traffic accidents, in general, happen due to a brief moment of driver distraction, such as spilling coffee or simply conversing with car passengers. One of the goals in designing driver training of a risk management program is to identify and eliminate as many driver

Donors who do ask about funding sources respond well to the presentation of organized information about donors, the wise use of those funds, why more funds are needed and what further donations would provide in their very own community.

\footnotetext{
${ }^{45}$ Dalton, Aaron. "Is It Getting Crowded in Here, Or Is It Just the Academics?" Stanford Social Innovation Review, Stanford University, Palo Alto, CA. Fall 2005.
} 
distractions as possible. For example, maps should be studied prior to the beginning of the ride, with notes on key turns written in large letters on a notepad. If a bee flies into the car, the driver should know to pull over to the side of the road before attempting to remove the bee.

Another key example, offered by the West Austin Caregivers, is the necessity to plan extra time into the ride, approximately 30 minutes or more. Seniors may move very slowly and may require extra time getting into and out of a car. It also takes time to fold a wheelchair and place it into the car trunk, then unfold it at the destination. A senior may need help with the seat belt. Having not provided sufficient time for the ride, the temptation is to make up for the lost time by driving too fast. Worse yet, there even may be the temptation to rush the senior, risking accident and injury, not to mention an unpleasant travel experience.

Another example is that no cell phone conversations should take place while driving. Some research even suggests that talking while driving causes drivers to experience a tunnel vision effect. Recognizing that providing sorely needed social contact for seniors who may otherwise be isolated; it is possible to develop a driving protocol that discourages involved discussion en route, saving it for before and after travel. Riders should also be made aware of this driving protocol, first, to understand that the driver is not ignoring them, and second, to help minimize the distractions.

\section{DEFINE DRIVER DUTIES TO MANAGE LIABILITY AND PROTECT DRIVERS}

The Federal Volunteer Protection Act protects the volunteer from personal liability if certain criteria are met, including that the volunteer must have been acting within the scope of his or her responsibilities for the organization at the time the harm took place. ${ }^{46}$ Most state volunteer protection acts echo this condition. This means that it is essential for volunteer driving programs to specifically and completely spell out a written scope of a volunteer driver's duties, make sure the volunteer driver understands the scope, and impress upon the volunteer that he or she must be scrupulous about abiding by it.

Associated with a written scope, it is recommended that volunteer driving programs formalize their relationships with their volunteers and clients by using contracts. All parties in a volunteer driving program should have a clear idea of their roles, duties, obligations and entitlements from the start. Naturally, the contracts should be in clear and simple language, and they should be thoroughly explained before signing. The organization would have a duty to ask its volunteers and clients if they understood the terms and had any questions about them. In a more general way, it would also behoove the volunteer driving program to discuss the hazards and safety precautions of the driving service with a prospective client in advance. This action would not be done to excuse the program from liability but for simple safety purposes, and to avoid misunderstandings and ill will later.

\section{SHOP FOR A HELPFUL INSURANCE BROKER}

While a solid risk management program is developed, the staff must convince an insurance broker that the risk management practices of an individual volunteer driving program will ensure a minimal claims rate. Based upon the results of previous studies and this research, it appears that there is presently a wide variety of response among insurance carriers with regard to providing coverage for volunteer driving programs. This suggests the importance of making the effort to "shop around" to select a broker who is willing to work with the volunteer driving program staff to find a carrier that will underwrite an adequate policy. Each insurance carrier has its own criteria for judging risk. There is no

${ }^{46} 42$ U.S.C. Sec. $14503(a)(1)$ 
standard that every carrier adopts. Part of the conversation between the broker and the carrier should include identifying the carrier's specific concerns about exposure to risk, that are presented by the volunteer driving program. Knowing the specific concerns can enable the development of a focused risk management approach. Under the proper set of conditions, hazards are insured every day. After all, this is the purpose of insurance. Sufficient coverage should be available to enable worthwhile programs to operate, such as volunteer driving programs. Insurance brokers who provide quality customer service understand that this is why they are in business.

\section{WHAT TRANSIT AGENCIES AND COMMUTER ASSISTANCE PROGRAMS CAN DO}

While most commuter assistance programs allow anyone to sign up for ride matching, the service emphasis is primarily upon trips to and from work. Commuter assistance programs might consider how they can make their services more marketable to seniors. Transit agencies have a vital complementary role to play in the provision of transportation services for seniors. Many transit agencies recognize this role and are targeting "young" seniors as an untapped market for transit service through advertising, travel training and special discounts. The continued development and expansion of regular fixed route transit services will enable more seniors to ride regular transit service and will postpone the need for younger seniors to access the still limited services of volunteer driving programs. Regional commuter assistance programs might consider the examples of GoLoco ${ }^{\mathrm{TM}}$ and NuRide ${ }^{\circledR}$. As outlined in Figure 3, transit agencies and commuter assistance programs should consider the following recommendations. 


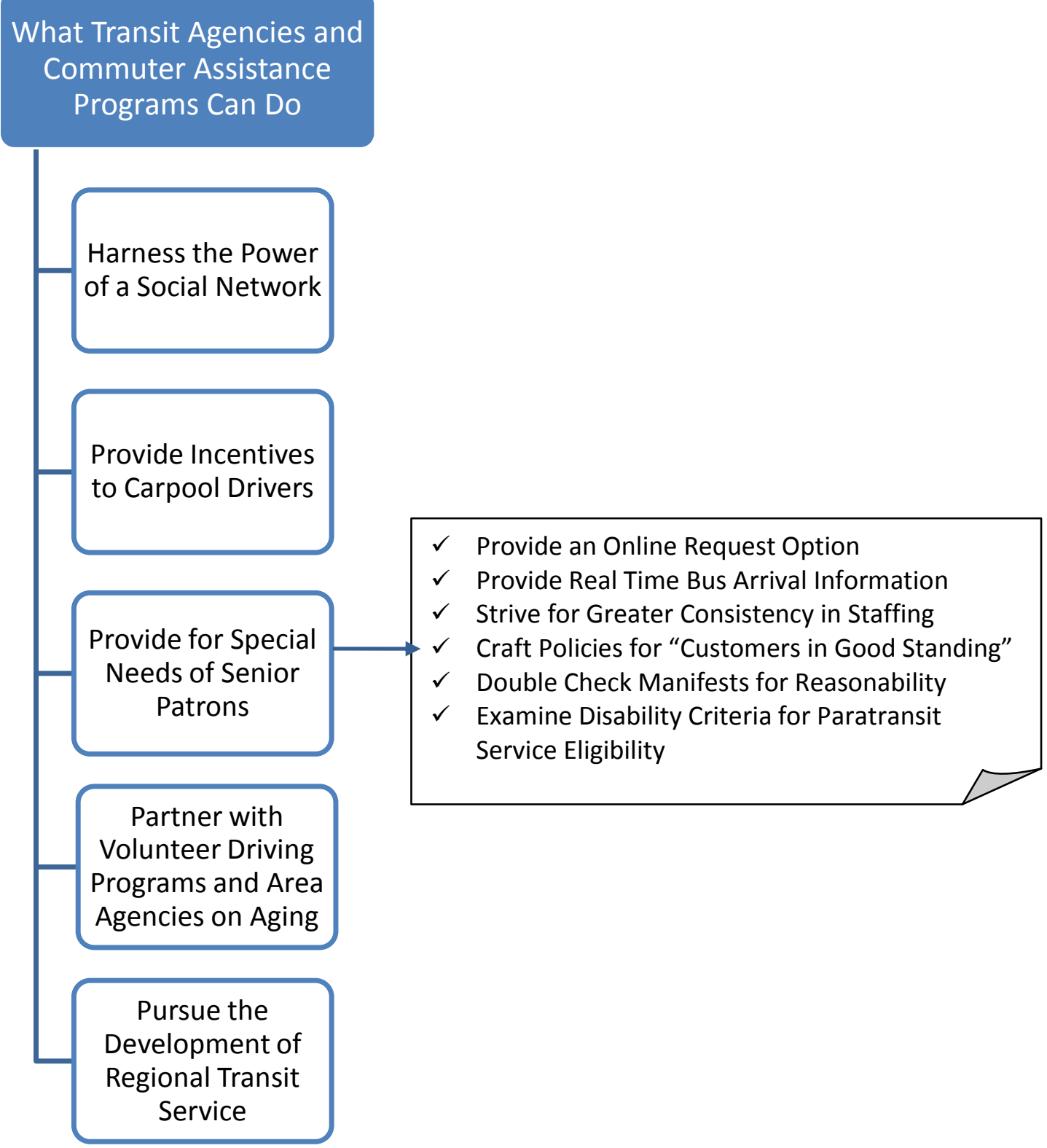

Figure 3 - Outline of Recommendations to Transit Agencies and Commuter Assistance Programs

HARNESS THE POWER OF A SOCIAL NETWORK

Programs like NuRide ${ }^{\circledR}$ and GoLoco ${ }^{\mathrm{TM}}$ offer ways to overcome ridesharing barriers such as people's natural hesitance to ride with a stranger. As with the example provided by the manager of RidingTogether in Deltona, Florida, the senior riders are predominantly female and they tend to prefer being driven by a female driver. By allowing travelers, including senior travelers, to develop and use their own personal social network of friends and associates as a source of rides, this barrier is overcome. 
PROVIDE INCENTIVES TO CARPOOL DRIVERS

Most commuter assistance programs have an abundance of applicants looking for a ride but very few drivers looking for passengers. Our senior market of interest will also be riders; therefore, program development emphasis should focus on ways to provide incentives to carpool drivers, such as those offered by NuRide ${ }^{\circledR}$, described in Appendix C.

\section{PROVIDE FOR SPECIAL NEEDS OF SENIOR PATRONS}

Frail seniors tire easily. Reducing the rider wait time both prior to boarding a bus and during the trip would especially help seniors. Information technologies can assist seniors as well as the general population. Recent research on using Global Positioning Systems (GPS), GPS-enabled mobile phones as "Travel Assistant Devices (TAD)" to alert riders as they approach their stop could reduce the learning curve for new riders of the transit system and assist seniors during their everyday travel. This research is also examining how real-time bus location information by automatic vehicle location (AVL) systems can be delivered to riders through the mobile phone in order to make their travel via transit more convenient. This technology could potentially reduce the waiting time for seniors at the bus stops by allowing them to rest in nearby air-conditioned facilities until they are notified that their bus is approaching their bus stop location. Real-time information could therefore allow the senior to avoid waiting for extended periods at the actual bus stop where they may be exposed to harsh weather conditions such as extremely high temperatures and rain. ${ }^{47}$ Other improvements important to seniors are bus stops that are easy to access and that provide weather protection, a clean dry place to sit down and security. Transit agencies might consider providing seating priority to seniors on the bus and equipping priority seats with seat belts. Public transit regular fixed route service expansion ideally provides not only for the needs of seniors but also for the general population. Future service expansion of benefit to seniors would include extending hours of operation, extending service routes, and increasing service frequency.

PARTNER WITH VOLUNTEER DRIVER PROGRAMS AND AREA AGENCIES ON AGING

There may also be opportunities to exchange expertise and services between transit agencies and volunteer driving programs for seniors. For example, some transit agencies might be able to provide driver training and background checks for volunteers. In return, the staff of senior driving programs can provide training in proper techniques for assisting someone to get into and out of vehicles as well as aging and dementia sensitivity training to transit agency drivers. Transit agencies also might be able to provide the following.

- Resources for the purchase of vehicles or the borrowing of vehicles from other programs

- Funding to reimburse volunteer drivers their cost of fuel

- Program administrative services, such as handling all recordkeeping and serving as accountable officer for monitoring and auditing purposes

- Customer service staff to help schedule rides

- Data collection on all trips provided and other reporting required of agency funders

\footnotetext{
${ }^{47}$ Sean J. Barbeau, Philip Winters, and Nevine Georggi. "Travel Assistant Device (TAD) to Aid Transit Riders with Special Needs," Final Report, National Center for Transit Research. USF, July 2008.

http://www.nctr.usf.edu/pdf/77711.pdf See also Sean J. Barbeau, Miguel A. Labrador, Philip L. Winters, Rafael Perez, Nevine Labib Georggi. "The Travel Assistant Device: Utilizing GPS-Enabled Mobile Phones to Aid Transit Riders with Special Needs," Presented at the $15^{\text {th }}$ World Congress on Intelligent Transportation Systems, New York, New York, November 16-20, 2008.
} 
- Computer hardware and scheduling software to organize rides and enable information technologies compatibility across agencies.

PURSUE DEVELOPMENT OF REGIONAL TRANSPORTATION SERVICE

Presently, many sources of transportation dollars do not follow the individual traveler but are contained and spent within political boundaries. While senior driving programs currently attempt to fill the need for cross-jurisdictional travel, it is recommended that public transit agencies continue to pursue the development of regional transportation service.

RECOMMENDATIONS TO PARATRANSIT SERVICES

There are five recommendations for paratransit services to consider for strengthening their role as transportation providers for seniors.

PROVIDE AN ONLINE REQUEST OPTION

For seniors with disabilities, it is recommended to improve paratransit services by providing an online ride request option. This option would accommodate a shorter advance notice, accept a later cancellation, and accept requests for multiple trips that are routine, such as a 9 a.m. ride to the senior center every weekday.

\section{STRIVE FOR GREATER CONSISTENCY IN STAFFING}

It is recommended to strive toward greater consistency in staffing paratransit service to allow riders and drivers to get to know one another. This would enable drivers to become more acquainted with the needs of specific riders and to provide better service.

\section{CRAFT POLICIES FOR “CUSTOMERS IN GOOD STANDING"}

Crafting policies for "customers in good standing" who normally demonstrate abidance to service rules, would demonstrate that the paratransit agency values customer relations and has a customer service mentality. It is recommended to construct friendlier customer service-based policies that deal more leniently with paratransit riders who break the " 5 -minute rule" (arriving at the pick-up location later than 5 minutes from the scheduled pick-up time) only due to extenuating circumstances beyond their control, such as illness. Under such circumstances, these policies would waive a "no show" penalty.

\section{DOUBLE CHECK MANIFESTS FOR REASONABILITY}

It is recommended that transit dispatchers double-check computer-generated manifests to ensure both routing and scheduling are reasonable.

\section{EXAMINE DISABILITY CRITERIA FOR PARATRANSIT ELIGIBILITY}

It is recommended that paratransit agencies examine the criteria used for determining eligibility for service based upon disability. General physical frailty should be considered as a factor in determining the presence of a disability that would make a senior eligible for paratransit service. 
Recommendations for Area Agencies on Aging are outlined in Figure 4.

\section{What Area Agencies on}

\section{Aging Can Do to}

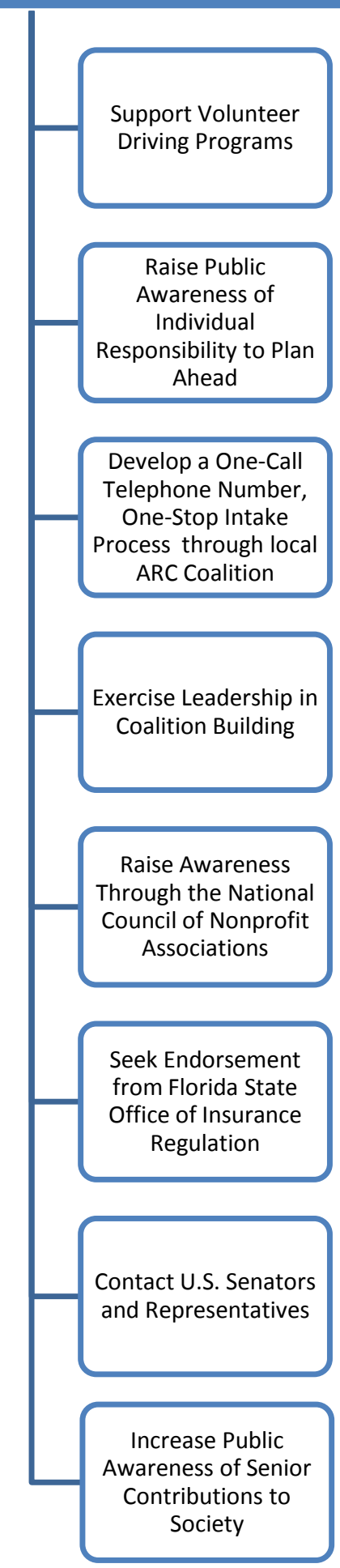

Figure 4-Outline of Recommendations to Area Agencies on Aging 
COLLABORATE WITH PUBLIC TRANSIT AGENCIES ON INFORMATION CAMPAIGNS

It is recommended that Area Agencies on Aging (AAAs) could collaborate with transit agencies on an awareness campaign to educate people approaching retirement that they should plan and prepare for their transportation needs for that time when they no longer drive.

DEVELOP A ONE-CALL TELEPHONE NUMBER, ONE-STOP INTAKE PROCESS

Through their local ARC Coalitions, is recommended that AAAs could spearhead the development of a one-call number for seniors to provide all intake information necessary to determine eligibility for all available transportation services in the region and make referrals to local volunteer driving programs as appropriate. This way, the senior goes through an application process just once. There should be enough knowledgeable staff to field calls in a timely manner, without putting a caller on hold for long periods. While there already are online resources that can tell a senior what they may be eligible for, many seniors today are not computer literate and need to talk to a considerate human being who listens and provides one-on-one service. AAAs could coordinate with transit agencies to devise a system to track calls and provide follow-up to make sure requests are being met. The existence of such a one-call number needs to be common public knowledge. An ongoing marketing campaign would be required to achieve this.

EXERCISE LEADERSHIP IN COALITION BUILDING

AAAs already provide important referral services to seniors and their families on a host of topics and concerns. It is recommended that AAAs can serve in a leadership role to develop networks and collaborative partnerships among service providers to identify the best volunteer driving program model for their service areas. AAAs can help assemble the community leaders and the "right people sitting around the table talking" to get a new program off the ground or find the resources needed to help existing volunteer driving programs survive and thrive. AAAs may have enough knowledge of the available resources in the community to be able to suggest matches on exchange of expertise. AAAs can stimulate interest on the part of the private for-profit business sector to sponsor volunteer driving programs in exchange for the connection to potential customers. Interested businesses could be shopping malls and individual retailers, supermarkets, pharmacies, funeral homes, nursing and assisted living centers, dentists, and others.

RAISE AWARENESS THROUGH THE NATIONAL COUNCIL OF NONPROFIT ASSOCIATIONS

Under current federal and state laws, there are gaps in justifiable protection for volunteers. Changing legislation would require much attention, effort and resources. At this time, the issues of volunteer driving programs would not be high on the priority list of the Florida state legislature. Florida is awash in problems regarding homeowner insurance for hurricane protection, with many insurance companies refusing to write policies in the state. The topic of volunteer driver programs has received little attention and there was no indication that it would in the near future. However, if legislative changes were to be pursued, one strategy to raise awareness for public policy action is to present the case in a white paper to the National Council of Nonprofit Associations (NCNA). The NCNA has access to all the state associations of nonprofits, who in turn have access to the state legislatures that make decisions regarding nonprofits in those states. 
SEEK ENDORSEMENT FROM FLORIDA STATE OFFICE OF INSURANCE REGULATION

Due to the difficulties presently experienced by the Florida insurance market, particularly regarding homeowner policies in areas vulnerable to flooding, the Florida Office of Insurance Regulation (OIR) has cast little attention upon the issues faced by volunteer driving programs. While liability considerations weigh heavily on the minds of volunteer driving program managers and insurance carriers alike, what is not figured into the overall picture are the automobile accidents ultimately avoided by the operation of volunteer driving programs for seniors. Policy makers should be reminded of this risk avoidance as a service to society that should deserve some consideration in the assignment of the liability burden. By providing safe transportation for seniors, these programs prevent accidents. In seeking legislative remedies that provide greater protection from liability for volunteers and volunteer driving programs, AAAs should seek an endorsement from OIR. To reduce the arbitrary treatment experienced by volunteers and volunteer driving programs seeking insurance, AAAs should also request that the OIR offer clarification to insurance providers doing business in Florida. To ensure consistency, the OIR should provide guidance for the appropriate foundation on which insurance policies are written and premiums are calculated for volunteer driving programs and their volunteers.

CONTACT U.S. SENATORS AND REPRESENTATIVES

Area Agencies on Aging should consider getting active in the public policy arena to educate policy makers about issues facing the growing senior population and the role of volunteer driving programs. One opportunity to lessen the impact of the rising price of fuel on volunteer drivers is for AAAs to contact their U.S. Senators and Representatives to pass legislation that would raise the federal income tax deductions allowed by volunteer drivers for mileage. The U.S. Congressional Committee on Finance is presently considering S. 3429, the Giving Incentives for Volunteers Everywhere (GIVE) Act of 2008, which, if passed, would amend the Internal Revenue Code to allow volunteers to claim an income tax deduction of 70 percent of the standard business mileage deduction rate. This would raise the volunteer rate from 14 cents to 41 cents per mile and allow the rate to be adjusted annually. Furthermore, the Act would exempt from taxable income, reimbursements from charities for mileage travelled by a volunteer up to the business rate and the Act would exempt the reporting requirement by volunteers.

INCREASE PUBLIC AWARENESS OF SENIOR CONTRIBUTIONS

Lastly, it is recommended that AAAs launch a public awareness campaign about senior citizens to provide a counterpoint to the messages of popular media that tend to place more value upon youthfulness. Why invest volunteer time and funding in seniors? Volunteers and financial donors initially may not know how they want to provide community service but many have definite feelings about whom they want to assist, whether it is children, refugees, the homeless, etc. A public awareness campaign can help articulate the value of the senior generation to our communities, as a worthy recipient of assistance. A campaign can remind us that seniors are the keepers of our heritage, wisdom, insight and historical memory. Their lives provide a connection to a rich past that can inform the present. A campaign should highlight what seniors in our communities have done and are currently doing in later life. It would be easy to find many inspiring examples. To those in the public audience who respond better to business arguments and practicality, the public awareness campaign should highlight how seniors are plainly good for the economy. Beyond the driving years, more seniors are continuing to lead otherwise longer, healthy and active lives. More seniors continue to work past age 65 out of necessity. Other seniors continue to work by choice and because their communities depend on their specialized skills. Society relies upon the quantity and quality of community volunteer work and public service accomplished by seniors, despite that many seniors 
become challenged by mobility constraints. A public awareness campaign would illustrate why volunteering for a driving program for seniors would be a good investment in the community.

\section{WHAT POLICY MAKERS CAN DO}

This study has uncovered several ways that policy makers can improve conditions for the operation of volunteer driving programs for seniors. The recommendations as outlined in Figure 5 are discussed below.

\section{INCREASE FUNDING FOR PUBLIC TRANSIT AND PARATRANSIT}

It is recommended that policy makers increase funding to enable public transit authorities to improve regular transit service and paratransit, as these are services that can be used by younger seniors. Such an investment would not just be serving a minority of the population. Public transit that serves seniors better will also serve everyone better. Additionally, as public transit service becomes more attractive to younger seniors, this will free capacity of the volunteer driving programs to serve those who cannot use regular public transit or paratransit.

PROMOTE AND SUPPORT REGIONAL TRANSPORTATION SERVICE DEVELOPMENT

It is recommended that public policy makers promote collaboration of counties within regions to address the issue of the need for better cross-jurisdictional transportation service. The pursuit of regional cooperation and service has begun in some but not all Florida regions.

CONSIDER ESTABLISHING MINIMUM STANDARDS FOR VOLUNTEER SCREENING, TRAINING

In addition, there are certain recommended changes to state law and federal law that would promote volunteer driving programs by providing a more equitable balance of liability. As a means to justify stronger liability protection for volunteer driving programs, it is proposed that the state consider requiring volunteer driving programs to implement certain minimum standards of screening, training, supervision, and inspection practices for volunteer drivers. Most volunteer driving programs already have substantive risk management programs and procedures, so a requirement should not be an undue burden. More intensive programs of screening, training, supervision, and inspection practices might be encouraged, with incentives for the nonprofits and their volunteers to participate. It might be possible for state agencies to subsidize, or even take on, some of the routine vetting and training functions. In principle, these measures would help protect everybody involved, including the volunteer driving programs, the vulnerable clients, and the volunteers themselves, so that these programs could be presented in the favorable light of common safety and public trust.

ENACT LIABILITY REFORMS AT THE STATE AND FEDERAL LEVELS

In June 2007, Governor Crist signed HB 359 into law, prohibiting insurers from denying insurance coverage to volunteer drivers solely based on their status as a volunteer. This law in itself does not obviate the arguable need to accord volunteer drivers a degree of statutory protection under the Florida Volunteer Protection Act from liability for simple negligence. Accordingly, liability reforms are recommended at the state and federal levels. In exchange for mandating certain administrative and operational protection to riders, the policy "scales" could be further balanced somewhat by amending state and/or federal volunteer protection act statutes to reduce the liability burden on volunteer drivers in senior volunteer driving programs. 


\section{What Policy \\ Makers Can Do}

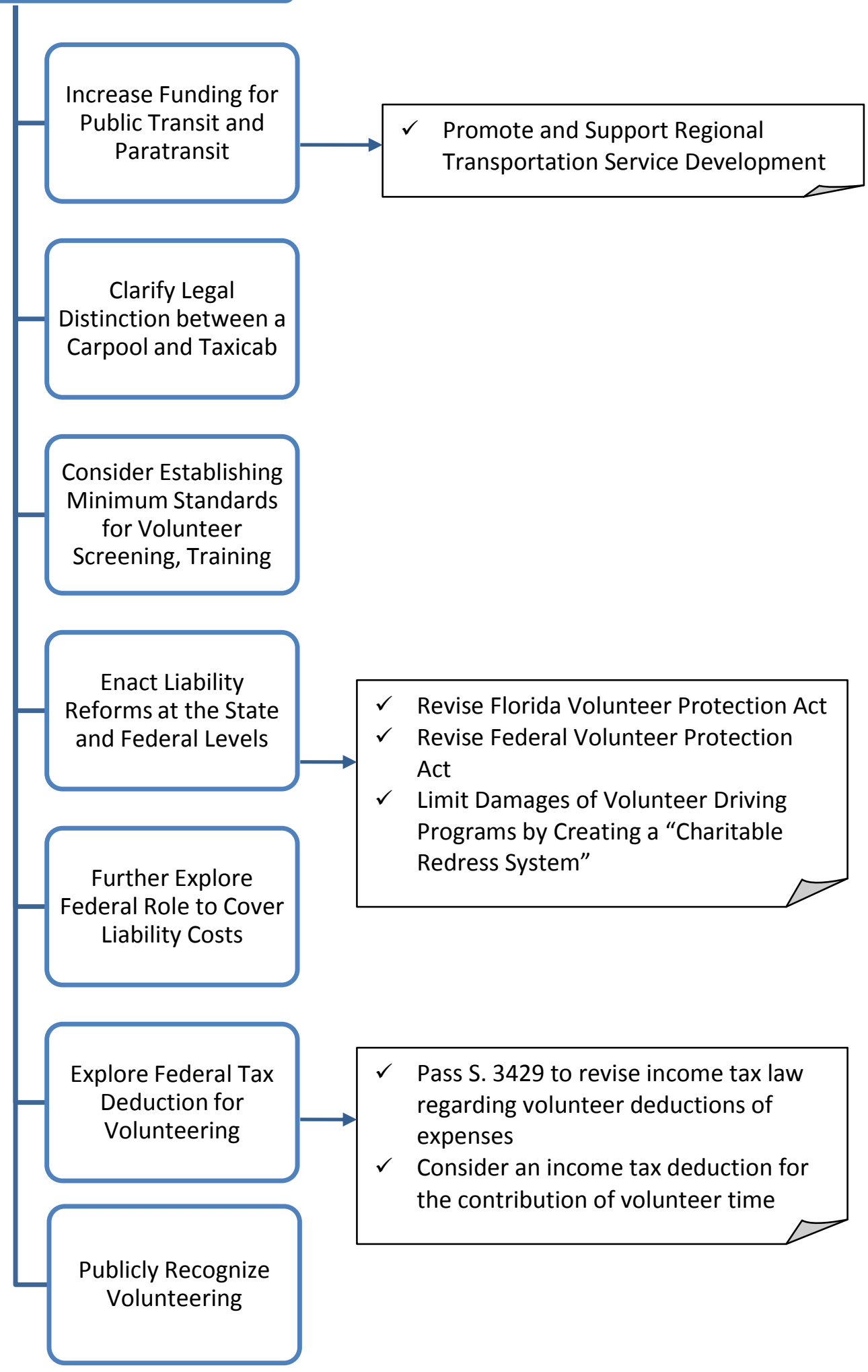

Figure 5-Outline of Recommendations for Policy Makers 
IN FLORIDA LAW, DISTINGUISH A TAXI CAB FROM A CAR POOL

As described in the Ride Finding Alternatives section of this report, a related arrangement known as ridesharing or carpooling may serve as an informal variation of volunteer driving programs for seniors. In the event that someone, such as a senior, receives a ride from another and contributes some money for fuel, it is important to note what Florida law includes in its definition of a 'for-hire vehicle'. It includes "...any motor vehicle, ....offered or used to provide transportation for persons solicited through personal contact ... on a 'share-expense' basis." ${ }^{48}$ No references in the Florida Statutes could be found that distinguished any difference between a 'for-hire vehicle' and a taxicab. Furthermore, the Florida Statutes define a carpool narrowly as transportation serving commuter trips within the context of farm labor contractor registration law. ${ }^{49}$ As the definition for a 'for-hire vehicle' is indistinguishable from a taxicab, a number of disturbing conditions apply to a motor vehicle used to provide transportation for persons solicited through personal contact on a 'share-expense' basisessentially a carpool. These conditions include Sec. 627.733(1)(b), F.S., which requires a higher level of auto insurance, as specified in Sec. 324.032(1)(a). The law requires insurance with minimum limits of $\$ 125,000 / 250,000 / 50,000$. This is higher than the minimum requirements for personal auto insurance policies. The law also removes the protection of a tort exemption of the Florida Motor Vehicle No-Fault Law from persons who provide transportation on a 'share-expense' basis. As a result, any driver of a carpool who accepts money to help pay for gas will be responsible for a greater degree of liability for damages from any bodily injury to a passenger arising from operating a motor vehicle. Clarification in Florida state law is needed to distinguish a taxicab from a carpool and should provide protection to carpool drivers of non-commute trip making. This clarification can easily be made by excluding a clause to Sec. 320.01(15)(a), F.S., as follows:

"For-hire vehicle" means any motor vehicle, when used for transporting persons or goods for compensation; let or rented to another for consideration; offered for rent or hire as a means of transportation for compensation; advertised in a newspaper or generally held out as being for rent or hire; used in connection with a travel bureau; of offered or used to provide transportation for persons solicited through personal contact or advertised on-a "share-expense" basis. When goods or passengers are transported for compensation in a motor vehicle outside a municipal corporation of this state, or when goods are transported in a motor vehicle not owned by the person owning the goods, such transportation is "for hire." The carriage of goods and other personal property in a motor vehicle by a corporation or association for its stockholders, shareholders, and members, cooperative or otherwise, is transportation "for hire."

This could be further clarified by including a clause to Sec. 320.01(15)(b), F.S., as follows:

The following are not included in the term "for-hire vehicle": a motor vehicle used for transporting school children to and from school under contract with school officials; a hearse or ambulance when operated by a licensed embalmer or mortician or his or her agent or employee in this state; a motor vehicle used in the transportation of agricultural or horticultural products or in transporting agricultural or horticultural supplies direct to growers or the consumers of such supplies or to associations of such growers or consumers; a motor vehicle temporarily used by a farmer for the transportation of agricultural or

${ }^{48}$ Sec. 320.01(15)(a), F.S.

${ }^{49}$ Sec. $450.28(3)$, F.S. 
horticultural products from any farm or grove to a packinghouse or to a point of shipment by a transportation company; or a motor vehicle not exceeding $11 / 2$ tons under contract with the Government of the United States to carry United States mail, provided such vehicle is not used for commercial purposes.; or a motor vehicle used for personal ridesharing purposes in which passengers pay no more than their fair share of the expenses of operating the motor vehicle for the trip.

REVISE FLORIDA VOLUNTEER PROTECTION ACT

It is recommended to revise Florida's existing FL-VPA (Sec. 768.1355, F.S.) so that it finally has real protective meaning. The wording in Sec. 768.1355(1), F.S. should simply state that volunteers (including senior rideshare drivers) will be protected from civil liability if they were acting in good faith within the scope of their official duties, and not performing those duties in a manner of wanton or willful misconduct. In other words, legislators should expunge the "ordinary reasonable person" requirement from Section (1)(a).

REVISE FEDERAL VOLUNTEER PROTECTION ACT

Alternatively, it is recommended to seek an amendment to the Federal Volunteer Protection Act. The curious protection "hole" that Congress left around volunteer drivers in the FED-VPA should reasonably be removed. Specifically, this would require taking out the word "not" in the FED-VPA language, as shown below.

Liability protection for volunteers, 42 USC. Sec. 14503(a)(4)

...no volunteer of a nonprofit organization or governmental entity shall be liable for harm caused by an act or omission of the volunteer on behalf of the organization or entity if - ...the harm was not caused by the volunteer operating a motor vehicle...for which the state requires the operator...to

(A) possess an operator's license; or

(B) maintain insurance.

This would better address the explicit Congressional concern, found in the law's own preamble, over the high cost of insurance policies that may be burdening volunteer drivers and/or the non-profit organizations that have hired them. Of course, Congressional amendment of the FED-VPA would no doubt be slower and harder than state action. Still, this federal statutory remedy might be preferable, since it could offer protection for volunteer drivers across states. It is recommended that this effort be undertaken through a collaboration of the Department of Elder Affairs, Area Agencies on Aging, and the Governor's Commission on Volunteerism and Community Service. An additional partner should be the National Council of Nonprofit Associations.

LIMIT EXTENT OF DAMAGES BORNE BY VOLUNTEER DRIVING PROGRAMS

In return for taking administrative and operational measures to avert accidents, the volunteer driving programs themselves should be entitled to a limited measure of protection. A "Charitable Redress System" (CRS) as proposed by Charles Robert Tremper would operate like a combination of Workers' Compensation programs and the National Childhood Vaccine Injury Act compensation program. Tremper's CRS proposal would involve the following components:

- A first-party insurance that would cover charities for most injuries to third parties. The insurer would make relatively quick payment offers to the latter that would apply only to 
economic losses, including medical expenses, expenses for adjustment to disability, and property damages.

- Replacements of lost earnings and loss-of-life compensation would be treated differently from the standard tort-law system.

- Non-economic losses, such as injuries to dignity, would not be compensated, and plaintiffs could only get punitive damages under a high standard of proof establishing that the harm was caused deliberately.

- If the accident victim were compensated by other sources, these would reduce his or her recoveries under the CRS (as in Workers' Compensation cases).

- As a separate matter, joint-and-several liability would not be permitted.

- Finally, if the charity did not make the accident victim a CRS offer, the accident victim would have a last-resort opportunity to file a lawsuit, with potential recovery being a multiple (perhaps $1 \frac{1}{2}$ ) of his or her CRS entitlement, plus attorney fees.

Rather than the current tort system, the CRS might better serve the goals of social policy and serve the interests of all parties in the case of an accident caused by a volunteer. For the injured claimant/client, the proposed system would provide relatively certain and rapid payment of medical bills and collateral bills. The volunteer driving program would benefit by having more predictable and limited costs, which could enable it to better obtain insurance in the market. The CRS would efficiently spread the losses incurred in an accident, not leaving them to the accident victim. As Tremper recommended, volunteers would also be protected from overwhelming loss when the charitable organization cannot cover them for simple negligence. In such cases, the volunteers' losses should be statutorily limited to the extent of their own liability insurance coverage, if any.

CONSIDER FEDERAL ROLE TO COVER LIABILITY COSTS

Lastly, it is recommended to explore a role for federal government. As a concrete expression of the federal appreciation for charities' services (also expressed in federal income tax exemptions for certain non-profits), the government might cover their liability costs. The Swine Flu Immunization Act of 1976 would be a model for such federal action. If this payment method is adopted, it should be associated with a mandate for adequate risk management efforts by the volunteer driving programs.

EXPLORE FEDERAL TAX DEDUCTIONS FOR VOLUNTEERING

Through various federal initiatives, such as the "One Thousand Points of Light" and promotion of faithbased programs, volunteerism has been touted in recent years as a means to strengthen our communities. Policy makers could back up their call to volunteerism by considering various options for providing relief and support to volunteer drivers. Like federal income tax deductions for charitable donations, one option is a tax deduction for donating time as a volunteer. In this way, the federal government would be backing up its call to volunteer with a financial incentive.

\section{RAISE FEDERAL INCOME TAX DEDUCTIONS FOR MILEAGE}

Rising fuel costs are negatively affecting the capacity of volunteer driving programs to recruit volunteer drivers. One opportunity to lessen this impact is for federal policy makers to raise the federal income tax deductions allowed by volunteer drivers for mileage. State and local policy makers should address this issue by contacting their U.S. Senators and Representatives. Such contact would coincide with the U.S. Congressional Committee on Finance consideration of S. 3429, the Giving Incentives for Volunteers Everywhere (GIVE) Act of 2008, which, if passed, would amend the Internal Revenue Code to allow volunteers to claim an income tax deduction of 70 percent of the standard business mileage deduction rate. This would raise the volunteer rate from 14 cents to 41 cents per mile and allow the 
rate to be adjusted annually. Furthermore, the Act would exempt from taxable income, reimbursements from charities for mileage travelled by a volunteer up to the business rate and the Act would exempt the reporting requirement by volunteers. If such an amendment to federal income tax law passes, then volunteer driving programs could reimburse volunteers for mileage without the volunteer having to pay taxes on those reimbursements.

\section{PUBLICLY RECOGNIZE VOLUNTEERING}

It is recommended that public policy makers officially recognize, in as many ways as possible, volunteer driving programs and the volunteers who serve. This will raise the profile, spread general public awareness of the existence of these services, and communicate to nonprofit organizations and volunteers that their efforts are appreciated.

\section{RECOMMENDATIONS FOR FURTHER RESEARCH}

Topics for further research in the future are suggested here. These include a quantification and characterization of the unmet need for transportation by seniors. Previous survey research has shown that after driving cessation, overall travel decreases, including a decline in trips taken for medical appointments. However, we know less about the differences among seniors. It would be useful to know what factors enable some seniors to maintain higher levels of activity and travel after they stop driving. The use of activity-based travel demand modeling recognizes that demographics, including age, play a large role in determining travel patterns. A better understanding of travel behavior of seniors before and after they stop driving, including the range in differences among seniors and the factors that determine those differences would inform the planning of transportation services and facilities, especially to support Florida's Communities for a Lifetime. To develop activity-based models, a richer base of Florida-specific travel survey data should be collected from senior study participants through the use of GPS-enabled cell phone technology. Another area that would benefit from policy research is the potential conflict between volunteer driving programs and taxicab companies. There is a need to explore and draw an equitable line between the two so that volunteer driving programs, especially those that receive government grant funds, do not infringe upon private enterprise, and that government policies and regulations do not prohibit the operation of volunteer driving programs. 


\section{CONCLUDING RECOMMENDATION}

The above discussion provides some ideas on how to attract individuals to volunteer driving programs within the pool of all those who have already decided they wish to volunteer. However, the more basic problem is finding enough people willing to volunteer. An ethic of supporting and leveraging civic engagement needs to be fostered. Volunteerism is a key element to civic engagement. While it was recommended that Area Agencies on Aging provide public awareness of the

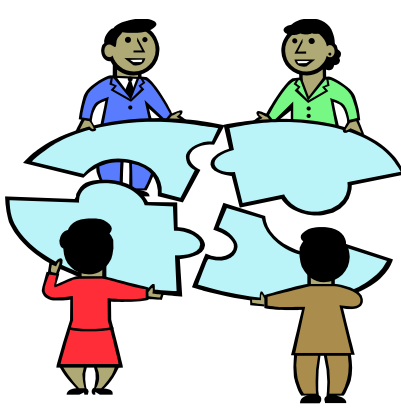
contributions of seniors to society, it is recommended that the Governor's Commission on Volunteerism and Community Service launch a complementary public awareness campaign and a public discourse to promote volunteering, in general. The services of social marketing professionals should be sought. Different messages should be targeted to different audiences. For example, the message that volunteerism is good for the economy might be targeted to public policy makers and Chambers of Commerce. As a result, member businesses might be more inclined to sponsor volunteer driving programs or other charities and elected leaders might be more inclined to remove legal barriers to volunteering, such as those described above. That the individual experience of volunteering reaps numerous personal benefits is a message that should be targeted to the general public. Like other successful social marketing campaigns, such as anti-smoking campaigns and "Don't Be a Litterbug" from the 1960 's, a social marketing campaign promoting volunteerism ideally would result in an ethic of community service that is culturally ingrained, so that the question for each citizen is not whether to volunteer, but how?

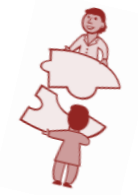


APPENDICES 


\section{VOLUNTEER DRIVING PROGRAM RESOURCES AND REFERENCES}

This list of resources and references is by no means an exhaustive collection of the available resources; however, the resources below are recommended as a good starting point for community groups or individuals interested in exploring the feasibility of starting a volunteer driving program.

GUIDEBOOKS, TOOLKITS AND PROGRAMS

- Beverly Foundation A primary resource for senior transportation, the Beverly Foundation in Pasadena, California conducts research and community demonstrations, maintains a senior transportation library, and provides transportation technical assistance. A new report will soon be issued, "Planning a Volunteer Driving Program." The Beverly Foundation developed and piloted the Volunteer Friends service model. Several of their resources are listed below. http://www.beverlyfoundation.org/index.html (Last accessed 08/01/08)

○ The Volunteer Driver Turnkey Kit is a resource for planning, implementation and evaluation of volunteer driving programs, developed by the Beverly Foundation. http://www. beverlyfoundation.org/turnkeykit/index.html (Last accessed 08/01/08)

- STAR Search Volunteer Driver Awards. This is an annual program of research of the Beverly Foundation, which gathers information about volunteer driving programs around the country and presents that information back to the community in the form of research reports and assistive products. Data is collected through yearly surveys. Volunteer driving programs apply to win recognition and cash awards. Each year, a new STAR Report profiles the programs and the winners. http://www. beverlyfoundation.org/awards/index.html (Last accessed 08/01/08)

$O$ STP Exchange: The STP Exchange is a resource for peer-to-peer communication, information exchange, and networking among members. Members have the opportunity to tap into web-based information, to exchange information with other members, to receive awards for excellence, to identify STPs (Supplemental Transportation Programs for seniors) and facilitate new ones, and to encourage efficiency, and coordination of transportation programs that serve seniors. Membership is free. http://www.stpexchange.org/home/ (Last accessed 08/01/08)

○ "Volunteer Driver Recruitment: An Idea Book for Action," Beverly Foundation, Pasadena, CA, Summer 2006.

http://www.beverlyfoundation.org/senior_transportation_resource_store/pdf/technical_as sistance_materials/idea-book.pdf (Last accessed 08/01/08)

- Communities for a Lifetime is a statewide initiative that assists Florida cities, towns and counties in planning and implementing improvements that benefit both youth and the elderly. Florida Department of Elder Affairs. http://elderaffairs.state.fl.us

- Community Transportation Association of America The Community Transportation Association of America (CTAA) provides listing of resources on volunteer driving programs. http://web1.ctaa.org/webmodules/webarticles/anmviewer.asp?a=776\&z=39 (last accessed 08/04/08) One such program, the Community Transportation Insurance Program (CTIP) provides viable insurance option to address auto liability; general liability and physical damage insurance needs for public and community transportation providers that are members of CTAA. This is a new program. This may be of particular interest to established programs with a vehicle fleet. 
http://web1.ctaa.org/webmodules/webarticles/anmviewer.asp?a=805\&z=37 (last accessed 08/04/08)

- DriveWell Toolkit. The National Highway Traffic Safety Administration (NHTSA) provides numerous resources to help older drivers recognize their changing abilities and adapt their transportation practices accordingly. NHTSA provides publications, research, and useful links and guides, including the DriveWell Toolkit, which promotes older driver safety and is a useful programmatic link to volunteering driving programs. http://www.nhtsa.dot.gov/portal/site/nhtsa/menuitem.31176b9b03647a189ca8e410dba046a0/

- Senior Transportation Toolkit and Best Practices. This is a publication of the Community Transportation Association of America. Written by Jane Hardin, the Toolkit provides examples of excellent transportation programs that utilize volunteer drivers, information on local collaboration and decision-making, and principles of volunteer management.

http://web1.ctaa.org/webmodules/webarticles/articlefiles/senior_toolkit_color1.pdf (last accessed 08/04/08)

- People on the Move. Easter Seals Project ACTION (ESPA) provides a free "train-thetrainer" class and toolkit, called "People On The Move", to expand community transportation options and increase accessible public transportation for persons with disabilities.

http://projectaction.easterseals.com/site/PageServer?pagename=ESPA_people_move\&s_esLocation $=$ tc_ (last accessed 08/04/08)

- Staying Out of Trouble: An Overview of Regulatory Requirements for Non-Profits. Many volunteer driving programs, particularly those using the membership model, seek to incorporate as 501(c)(3) organizations; therefore, it is critical to know the business of running one. This publication was developed as a resource manual for participants in a series of workshops sponsored by the Washington State Department of Community Development. Editors: Lois Irwin, Community Development Specialist for the Partnership for Rural Improvement, and Karl M. Johanson, Executive Director of the Council on Aging \& Human Services. Published: January, 1994, Revised: May, 2002. Found at http://www.wsdot.wa.gov/Transit/Training/vdg/Sponsor.htm (Last accessed 08/01/08)

- Transportation Solutions for Caregivers: A Solutions Package for Volunteer Transportation Programs. Easter Seals, Chicago, IL. Supported by a grant from the Administration on Aging National Family Caregiver Support Program, U.S. Department of Health and Human Services. Found at http://www.easterseals.com/site/PageServer?pagename=ntl_tsc_volunteer (last accessed 09/09/08)

- "Volunteer Drivers Guide -- A Guide to Best Practices" is a comprehensive resource for planning and running a volunteer driving program. It was developed by the Washington State Department of Transportation in coordination with the Agency Council on Coordinated Transportation and other partners. It contains model forms, templates and attachments. http://www.wsdot.wa.gov/Transit/Training/vdg/ (Last accessed 08/01/08)

RESOURCES ON VOLUNTEERING

- AmeriCorps VISTA. This is a program of the Corporation for National and Community Service, an independent federal agency that also administers RSVP (a program of Senior Corps). AmeriCorps Vista provides full-time volunteers who commit a full year to community organizations and public agencies to create and expand programs that help bring low-income individuals and communities out of poverty. AmeriCorps may be a good source for volunteers, which places individual volunteers in assignments across the nation. AmericCorps VISTA and RSVP can establish a memorandum of understanding 
with any nonprofit or government to recruit volunteers and can provide no-cost supplemental and excess auto liability insurance to volunteers.

http://www.americorps.gov/about/programs/vista.asp (last accessed 08/04/08)

- Civic Engagement with Older Adults. The American Society on Aging (ASA) has established a Civic Engagment Program, sponsored by The Atlantic Philanthropies, that harnesses the knowledge, skills and life experience of older adults to enrich communities. ASA's working definition for this program is "Late life civic engagement encompasses individual and collective actions wherein older adults participate in activities of public and personal concern that are both individually life enriching and socially beneficial to the community". http://www.asaging.org/asav2/civiceng/aboutciviceng.cfm (last accessed 08/04/08)

- Volunteer Match. VolunteerMatch is a nonprofit organization in San Francisco, CA, which provides an online volunteer recruiting service for other nonprofit organizations. Potential volunteers can search by zip code, interest area and keyword. VolunteerMatch strategic initiatives include "Preparing for the coming wave of 77 million Baby Boomer retirees in partnership with Senior Corps and other independent sector leaders," and "Partnering with Corporate America to fulfill their civic responsibilities by investing in employee volunteer activities that strengthen our communities."

http://www.volunteermatch.org/ (last accessed 08/04/08)

- Volunteer Center National Network and Florida Association of Volunteer Centers. The Volunteer Center National Network (VCNN), in partnership with the Points of Light Foundation, helps mobilize people and resources to find creative solutions to community problems. Volunteer Centers are conveners for the community, catalysts for social action and key local resources for volunteer involvement. They bring people and community needs together through a range of programs and services based upon community needs, demographic area, population size, and other factors. The Volunteer Center's role in the community is centered on the ability to:

- Connect people with the opportunity to serve

- Build the capacity for effective local volunteering

- Promote volunteering

- Participate in strategic initiatives that mobilize volunteers

The Volunteer Center National Network is a membership of 360 Volunteer Centers. Despite variations in size, structure, and programs, Volunteer Centers recognize that acting collectively as a unified network is the single most powerful strategy for boosting their efficiency. The Florida Association of Volunteer Centers (FAVC) provides a network of support and professional development to the leaders of Florida's Volunteer Centers. Through quarterly meetings, FAVC members discuss new opportunities for volunteers, professional development and grant opportunities for volunteer leaders, as well as share best practices to ensure that Florida's volunteers have the best possible volunteer experience. Florida currently has 24 member Volunteer Centers, many of which provide online volunteer matching and volunteer management training.

http://www. pointsoflight.org/centers/centerlist.cfm?State=FL (last accessed 08/04/08)

- Volunteer Florida. Volunteer Florida is the short name for the Governor's Commission on Volunteerism and Community Service. Volunteer Florida helps develop, promote and implement volunteerism and service throughout the state. The Governor's Commission on Volunteerism and Community Service was established in 1994 by the Florida Legislature to administer grants under the National and Community Service Trust Act of 1993. The Commission grants funds to Florida AmeriCorps and National Service programs; encourages volunteerism for everyone from youth to seniors to people with disabilities; promotes volunteerism for disaster preparedness and response; and helps to 
strengthen and expand Volunteer Centers in Florida. http://www.volunteerflorida.org/ (last accessed 08/04/08)

\section{ADDITIONAL USEFUL RESOURCES}

Alan M. Voorhees Transportation Center. "Safe Mobility at Any Age Policy Forum Series, Final Report", Edward J. Bloustein School of Planning and Public Policy, Rutgers, The State University of New Jersey and the New Jersey Foundation for Aging, April 2005 http://www.state.nj.us/transportation/works/njfit/links/pdf/safemobil.pdf (last accessed 08/04/08)

Beverly Foundation \& American Public Transportation Association: A Partnership Project, "Project Report: Transitions to Transportation Options: How They Affect Older Adults", January, 2007. http://www.beverlyfoundation.org/senior_transportation_resource_store/pdf/research_papers_and_reports/tr ansitions_final_report_1.pdf (last access 08/04/08).

Foreman, Chandra C., Lisa E. Tucker, Jennifer Flynn, and Michael West. "Senior Transportation Alternatives: Why Are They Important and What Makes Them Work?", Funded by the Florida Department of Transportation, sponsored by the National Center for Transit Research, prepared for the Florida Commission for the Transportation Disadvantaged, prepared at the Center for Urban Transportation Research, University of South Florida, Tampa, December 2003. http://www.nctr.usf.edu/pdf/473-09.pdf (last accessed 08/04/08)

Kerschner, Helen. "Transportation Innovations for Seniors: A Report from Rural America". The Beverly Foundation and the Community Transportation Association of America. Funded in part by the U.S. Department of Health and Human Services, June 2006.

http://www.ctaa.org/webmodules/webarticles/articlefiles/Senior_Rural_Innovations.pdf (last accessed 08/04/08)

Leibson, Russell, and William Penner. "Successful Risk Management for Rideshare and CarpoolMatching Programs", Carroll, Burdick \& McDonough, San Francisco, CA. Prepared for LEGAL RESESARCH DIGEST, September 1994-Number 2, Transit Cooperative Research Program, Federal Transit Administration, Transportation Research Board of the National Research Council, Washington, DC.

Molnar, Lisa J.; David W. Eby; Renée M. St. Louis; Amy L. Neumeyer. “Promising Approaches for Promoting Lifelong Community Mobility", University of Michigan Transportation Research Institute. Ann Arbor, Michigan, MI, Sponsored by the American Association of Retired Persons, December 2007.

Polzin, Steven and Oliver Page. "Transit Use Viability Among Older Drivers Losing Driving Privileges", Funded by the Florida Department of Transportation. Sponsored by the National Center for Transit Research. Prepared at the Center for Urban Transportation Research, University of South Florida, Tampa, May, 2006. http://www.nctr.usf.edu/pdf/77601TechMemoOne.pdf (last accessed 08/04/08)

Seekins, Tom, Steve Bridges, Annesa Santa, Daniel J. Denis, and Andrea Hartsell, "Faith-Based Organizations: A Potential Partner in Rural Transportation", University of Montana, Published in the Journal of Public Transportation, National Center for Transit Research, Center for Urban Transportation Research, University of South Florida, Vol. 11, No. 1, pp. 109-125. http://www.nctr.usf.edu/jpt/pdf/JPT11-1seekins.pdf (last accessed 08/04/08) 
Ward, Beverly; Wendy Hathaway, Oliver Page and Victoria Perk. "Investigation of Potential Local Area Transportation Alternatives for An Aging Population, Final Report", Volusia County

Metropolitan Planning Organization, November 2006. This is a study of the anticipated effects of the aging Baby Boomer population on the demand for public services through 2035.

http://web1.ctaa.org/webmodules/webarticles/articlefiles/Final_Report_v.3.1.pdf (last accessed 08/04/08) 


\section{APPENDIX B}

\section{VOLUNTEER DRIVER TURNKEY KITC AND SENIOR FRIENDLINESS CALCULATOR C}

Beverly Foundation, Pasadena, CA and Transportation Reimbursement and Information Project (TRIP), Riverside, CA. Reprinted with permission

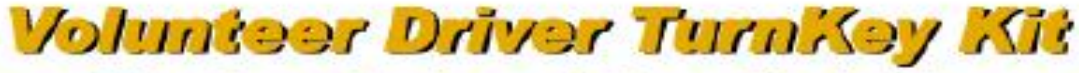 Planning Implementation Evaluation}

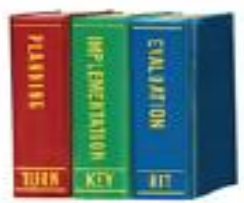

\section{A 5 A's "Senior Friendliness" Evaluation Strategy For Volunteer Driver Programs}

Trends in the past century reveal a growing reliance on community-based services as people age, in part because of the fading networks of extended families and friends that traditionally provided support for the elderly. Community transportation, in particular, can be critical to older adults who have limited their driving or have stopped driving altogether. However, it is the degree of "senior friendliness" of the transportation option that will determine whether transportation enables seniors to experience a sense of independence, to get where they need to go, or to enjoy an acceptable quality of life.

In 2000, following extensive focus group and survey research with senior drivers, seniors who were no longer driving, and caregivers concerned about senior mobility and transportation, the Beverly Foundation identified the " 5 A's of Senior Friendly Transportation". Subsequent research conducted by the Foundation and policy and program initiatives of government and non-profit agencies at the national, state, and local level have further defined the 5 A's and have adopted them as criteria for standards in senior transportation. The criteria focus on the five key factors below:

Availability (transportation services that are available to seniors)

Acceptability (transportation services that are acceptable to seniors)

Accessibility (transportation services that seniors can access)

Adaptability (transportation services that can be adapted to senior needs)

Affordability (transportation services that are affordable for seniors and the community)

Adopting this set of criteria can provide a framework for ensuring the "senior friendliness" of a transportation service, regardless of who sponsors it, who supports it, or who acts as the service provider. Such criteria also can serve to establish a baseline for measuring the effectiveness of coordination efforts and can provide benchmarks that help move coordination initiatives forward. Specific factors important to each of the five A's are included in the "Senior Friendliness Evaluation Guide" found on the following page.

\section{B -1}




\section{A "Senior Friendliness" Calculator For Volunteer Driver Programs}

The 5 A's of Senior Friendly Transportation have been refined as criteria for use by volunteer driver programs in making a preliminary judgment as to their senior friendliness. To initiate your review, check each of the factors below that are represented within your volunteer driver program. Each check equals one point. When you have completed your review, add up your score and look at the scoring key at the bottom of the page to know where you are on "the road to senior friendliness."

\section{Availability: The Volunteer Driver Program....}

provides transportation to seniors

is able to recruit and retain sufficient number of drivers

can provide transportation anytime (days, evenings, and weekends) does not limit number of rides maintains organizational relationships with human $\&$ transit services

Acceptability: The Volunteer Driver Program....

uses automobiles to provide majority of transportation

does not require advance scheduling

involves riders to determine appropriate wait time

conveys guidelines to ensure vehicles are clean and well maintained

provides driver "sensitivity to seniors" training

Accessibility: The Volunteer Driver Program....

can accommodate needs of majority of elders in the community

can take riders to destinations beyond city \& county boundaries

provides "door-to-door" transportation

provides training to riders on how to access services

can provide services to essential and non-essential activities

Adaptability: The Volunteer Driver Program....

can accommodate riders who need or want to make multiple stops

makes an effort to link riders with other services when appropriate

can access vehicles to accommodate wheelchairs and walkers

provides "door-thru-door" transportation when needed

will provide transportation escorts when needed

Affordability: The Volunteer Driver Program....

provides insurance coverage for volunteer drivers

does not charge seniors for transportation services

accepts passenger donations for transportation services

covers the driver's deductible in the event of a crash

is willing to reimburse drivers for mileage or costs

Total ( Possible Score $=25$ )

\section{The Road to Senior Friendliness}

0

5

10

15

20

\begin{tabular}{|c|c|c|c|c|c|}
\hline $\begin{array}{l}\text { Just } \\
\text { Starting }\end{array}$ & $\begin{array}{c}\text { Out of } \\
\text { the Garage }\end{array}$ & $\begin{array}{l}\text { On the } \\
\text { Road }\end{array}$ & $\begin{array}{l}\text { Chugging } \\
\text { Along }\end{array}$ & $\begin{array}{l}\text { Good } \\
\text { Show }\end{array}$ & $\begin{array}{l}\text { Senior } \\
\text { Friendly }\end{array}$ \\
\hline
\end{tabular}

\section{B -2}

Developed by Beverly Foundation (Pasadena, CA) and TRIP (Riverside, CA) 
RIDESHARING

GOLOCO ${ }^{\text {TM }}$ HTTP://WWW.GOLOCO.ORG/GREETINGS;GUEST

While it was originally developed to reduce the number of single-occupant vehicles and associated air pollutants, GoLoco ${ }^{\mathrm{TM}}$ is an online ride matching service that can be used to meet the needs of seniors. A senior will need to have access to a computer and the Internet. GoLoco ${ }^{\mathrm{TM}}$ allows registrants to use the service free of charge. GoLoco ${ }^{\mathrm{TM}}$ helps people and communities create their own personal public transportation network. It is a way to turn one's social network into a travel network. It can be used for routinely scheduled trips or occasional trips. It is advertised as a service that can be used among friends, co-workers, religious groups, school pools, clubs and other groups of people who know each other. A person can also join an existing group or create a group with which to travel. It is an easy way to coordinate trips with one's associates, using the available cars and sharing expenses. Either drivers can choose to let riders ride free of charge, or they can arrange with riders to share expenses. If it is decided to share expenses, then GoLoco ${ }^{\mathrm{TM}}$ also offers an accounting service to keep track of expense sharing.

A person joins by registering online and creating a personal account. GoLoco ${ }^{\mathrm{TM}}$ keeps each member's account and transfers trip expenses from one account to another based upon who is driving and who is riding. A registrant posts his or her desired trip to selected persons or to the whole network, which is where he or she plans to go and whether he or she intends to drive or ride. The registrant may choose to post this trip notice to only selected persons or to the whole network. Registrants automatically receive email alerts about trips to places they may want to go. GoLoco ${ }^{\mathrm{TM}}$ matches trip requests with others in the same area who may want to go to the same place at the same time The trip details are posted online to all participants. GoLoco ${ }^{\mathrm{TM}}$ automatically transfers money from the other passengers to the driver's account. If money is transferred online, GoLoco ${ }^{\mathrm{TM}}$ charges a $10 \%$ transaction fee. There are no other membership costs or monthly fees.

A trip cost is computed using the average $\$ 0.50$ per mile. The drivers can also add parking, tolls, etc. GoLoco $^{\mathrm{TM}}$ participants can also arrange to share a taxi or rental car. According to the GoLoco ${ }^{\mathrm{TM}}$ web site, in the event of an accident, passengers should be covered by the driver's personal auto insurance policy if the passenger is paying no more than his or her fair share of the costs of the trip, sometimes known as a "share-the-expense car pool arrangement". Nonetheless, riders should ask the driver for details of what the driver's insurance policy covers in the event of an accident. GoLoco ${ }^{\mathrm{TM}}$ does not check driver's insurance and does not represent that drivers are insured.

NURIDE ${ }^{\circledR}$ HTTP://WWW.NURIDE.COM/NURIDE/MAIN/MAIN.JSP

NuRide ${ }^{\circledR}$ is another example of a ride-matching program that is free to join and use by members. NuRide ${ }^{\circledast}$ also offers a reward system that encourages members to rideshare. Rewards are given by local and national sponsors. Like GoLoco ${ }^{\mathrm{TM}}$, its primary purpose is to reduce greenhouse gas emissions from cars, but it potentially can be used by seniors to meet their trip needs. A senior would need to have a computer, access to the Internet, and an email address issued by an organization of which he or she is a member. NuRide ${ }^{\circledR}$ is a membership service in which a member seeks or advertises rides online to family, friends and associates. Each NuRider ${ }^{\circledast}$ is in control regarding with whom a ride is sought. A NuRider ${ }^{\circledR}$ can choose to seek rides only with selected individuals or can choose to seek a ride with any NuRider ${ }^{\circledR}$. Interested persons sign up to join NuRide ${ }^{\circledR}$, then they plan a trip. NuRide ${ }^{\circledR}$ 
drivers and riders come to an individual agreement among themselves, for each trip, whether and how to share travel expenses.

After the ride, driver and passengers confirm online that they have used a carpool arrangement for a trip. Reward points are placed in the riders' and driver's accounts. Points are redeemed for rewards provided by program sponsors, such as restaurant gift cards, retail discounts and tickets to shows and attractions. Sponsors include governments who sponsor commuters, businesses who sponsor their employees, and businesses also sponsor consumers. Members of NuRide ${ }^{\circledR}$ are required to be affiliated with an organization. This increases traveler comfort by ensuring that each NuRide ${ }^{\circledR}$ member is not anonymous. By knowing where other NuRiders ${ }^{\circledR}$ work, attend school, etc. a member can make a more well informed decision about choosing a NuRide ${ }^{\circledR}$ travel partner. A member's organization affiliation is verified by his or her organizational email address. An organization, such as a senior center, might enable seniors to use NuRide ${ }^{\circledR}$ by providing computer access and issuing email accounts to its seniors.

Presently, NuRide ${ }^{\circledR}$ is available in Minneapolis, MN, and the New York City/Connecticut metropolitan area, Hampton Roads, VA, Washington, D.C. and Houston TX. In West Chester County, NY, a local chapter of AARP serves as the organization affiliation for interested seniors. NuRide ${ }^{\circledR}$ members can set up a "volunteer" profile indicating when they would volunteer rides for seniors. In this way, if a senior seeks a ride at an off-peak time, such as Sunday at 9 a.m., the system will automatically pull up volunteer contacts.

LOCAL GOVERNMENT PROGRAMS

HUMAN SERVICES DEPARTMENT, CHARLOTTE COUNTY, FLORIDA

HTTP://WWW.CHARLOTTECOUNTYFL.COM/HUMANSERVICES/TRANSPORTATION/

Some county governments will employ volunteers to provide services under their Transportation Disadvantaged Program. Charlotte County Human Services Department is one example. Sunshine Ride, the Transportation Disadvantaged (TD) service in Charlotte County, Florida uses both County buses and vans to provide TD services. County employees drive the buses while volunteers from several organizations, including the Council on Aging, drive County vans to provide rides.

GULFPORT EXTENDED MINI-BUS SERVICE (GEMS), FLORIDA

HTTP://WWW.CI.GULFPORT.FL.US/CITY_DEPARTMENTS/LEISURE_SERVICES/MPSC/GEMS_SCHEDULE.HTM

This is a door-to-door service of the City of Gulfport in Pinellas County, FL. All Gulfport residents age 55 years or older may use the service. There is a $\$ 120$ annual registration fee and a $\$ 3.00$ one-way charge for each trip. The rider must have exact fare. The rider must schedule prior to $1 \mathrm{p} . \mathrm{m}$. at least one day in advance of the desired trip. Riders must cancel a scheduled ride at least $1 / 2$ hour before the trip. Riders are asked to carry on board only what they are able to carry. The bus operates on a schedule Monday through Friday, between 8:30 a.m. and 3:30 p.m. and provides for medical appointments to the downtown, Pasadena and Tyrone area. The service also provides for grocery shopping with scheduled runs to the Tyrone Mall \& Gardens, Wal-Mart and K-Mart. 
SOCIAL SERVICE PROGRAMS

MEALS ON WHEELS PLUS PROGRAM, MANATEE COUNTY, FLORIDA

HTTP://WWW.MEALSONWHEELSPLUS.ORG/

The Transportation Program operated by Meals on Wheels PLUS within Manatee County enables homebound clients to participate in daytime social functions not normally available to them. These functionally impaired clients are unable to drive a car and have no access to normal public bus service. Therefore, they come to rely upon the mobility provided by the program. Meals on Wheels PLUS supports national, state and local organizations including Florida Council on Aging, Florida Association of Service Providers, Second Harvest, Florida Association of Senior Nutrition Programs, Florida Association of Food Banks, Florida Adult Day Care Association, National Association of Nutrition for Aging Service Providers, and Meals on Wheels Association of America. The program receives operating funds from a variety of sources including individuals, federal and local governments, and civic, religious, and fraternal organizations.

AMERICAN CANCER SOCIETY, ROAD TO RECOVERY PROGRAM, TAMPA, FLORIDA

http://www.cancer.org/docroot/COM/content/div_Southeast/COM_4_2x_Road_to_Recovery_Service_Progra m.asp?sitearea $=\mathrm{COM}$

The Road to Recovery is a service program of the American Cancer Society (ACS), Inc. ACS is a charitable 501(c)(3) corporations and nationwide community-based volunteer health organization dedicated to eliminating cancer. ACS is a large organization with 3,400 local offices nationwide. ACS held over $\$ 2$ billion in total assets in 2007. (from web site)

The Road to Recovery program began in 1993 and is a volunteer-based cancer patient transportation service. It operates nationally within its various service divisions of the American Cancer Society. A sister program in the Tampa Bay area, Lifeline, began in 2003 and utilizes a variety of communitybased transportation service providers to meet patient and family transportation needs that cannot be satisfied by volunteers. Both programs were implemented to address patient and family access to treatment and care, which is one of the most significant issues facing cancer patients and their families. Neither program charges passengers for service. One hundred percent of the calls received for service have been accommodated by the two programs.

The Road to Recovery program has faced significant challenges in recruiting and retaining volunteer drivers. In rural areas, long driving distances dissuade people from volunteering. The rising cost of fuel and concerns among potential volunteers about insurance issues pose recruiting challenges. In many areas, traffic congestion and long travel times are barriers to volunteers. The Society has 16 area patient service representatives throughout Florida, each of which is responsible for promoting the program and recruiting volunteers. The representatives work with local print and broadcast media to promote the program, speak to local service organizations, and conduct one-on-one conversations to help recruit more volunteers.

Volunteers receive training on the history of the American Cancer Society and the Road to Recovery program, client/passenger sensitivity, vehicle safety and maintenance, and supplemental transportation services that are available to assist patients. Lifeline passengers often must wait for their ride to arrive or they may have to walk to a bus stop. Patients much prefer the Road to Recovery service over the Lifeline service because of the more personalized service and the quality of service. Many volunteer drivers are cancer survivors, who offer hope and inspiration to passengers. 
Liability insurance for Road to Recovery has been a minimal concern since the American Cancer Society is a large organization and provides $\$ 1$ million in umbrella coverage. Volunteers are required to have the state minimum required personal automobile liability insurance coverage.

\section{SENIOR SERVICES OF KING COUNTY, WASHINGTON}

HTTP://WWW.SENIORSERVICES.ORG/VTS/VTS.HTM

The Senior Services Transportation Program began approximately 30 years ago, as part of a larger menu of services provided to the elderly in King County, Washington. Senior Services is a private nonprofit organization. Originally, the program used taxicabs to provide service to seniors. The service began because there was insufficient transportation for seniors, particularly those with greater mobility challenges. The service was also a response to the "hodge podge" of senior transportation organizations and approaches that existed in the mid-1970s.

The program now relies mostly on volunteers who pick up passengers, transport them to their destination, wait for the passenger, then drive the passenger back to their origin. Ten years ago, Senior Services started a "senior shuttle" with one van and a small contingent of volunteer drivers. Currently they operate 18 shuttles using both paid and volunteer drivers. The agency has a current budget of $\$ 1$ million and a staff of 20 .

The agency works closely with the local area Agency on Aging, Washington DOT and local transportation providers, including King County Metro Transit and HopeLink, the Medicaid provider for the county. Numerous transportation service providers in the metro area serve specific populations and/or geographic areas. The region also offers an on-line "ride finding" service (www.findaride.org). However, Senior Services focuses on those senior citizens whose physical and/or mental condition requires a higher level of transportation service or who may reside in an area where there are no other transportation options. Priority is also given to lower income people, people older than 75 , and those with limited English speaking abilities. Client enrollment is simple and conducted over the phone.

The 2008 budget for the volunteer program is $\$ 411,000$. Client donations are projected at $\$ 48,000$ or approximately $12 \%$ of the operating cost. In 2007, the program served 1,909 unduplicated clients and provided 25,952 trips. The program's 400 volunteers logged over 380,000 miles. Volunteers are reimbursed for mileage at $\$ 0.35$ per mile. While there are never enough volunteers, the program satisfies approximately $90 \%$ of trip requests. The program tries to offer flexibility for volunteers, such as how many hours donated and when they drive. Forty percent of the volunteer drivers have been with the program for more than 5 years. The personalized nature of the program and the on-going contact between staff members and volunteers minimizes attrition. Recruitment techniques include media announcements to 70+ newspapers and 900+ churches, postings on web sites of other organizations, presentations to local businesses, distribution of promotional flyers at resource fairs, and a streaming audio (http://www.seniorservices.org/vts/vts.htm) where current volunteers tell their stories.

The program formerly used CIMA for their liability insurance coverage but no longer has the need. Senior Services is large enough that their insurance broker can find whatever coverage is necessary. However, the volunteer's liability coverage is primary. The program provides $\$ 1$ million in supplemental coverage and the agency carries $\$ 5$ million in umbrella coverage. All volunteers undergo a criminal background check and a driving record check. No one can be a volunteer if a moving violation has occurred within the past three years. Volunteers must remain "incident free" to remain in the program. All volunteers sign a statement of confidentiality and a no conflict of interest form. 
The program director conducts a 1-hour orientation with each volunteer and each volunteer's vehicle is inspected. The program has a formal client complaint process.

INFORMAL VOLUNTEER DRIVING PROGRAM

PASRIDE, PASADENA, CALIFORNIA

For more information, contact the Beverly Foundation

In February of 2002, an 18-month Volunteer Friends pilot project called PasRide was initiated by the Beverly Foundation, Pasadena, California. The project had two objectives: (1) to test the viability of the service model that would provide rides to seniors and complement existing transportation services; and (2) to create a process model that could be adapted by communities throughout the country at low cost. Low cost means no need to purchase vehicles, hire paid drivers and to schedule rides. A key to the PasRide pilot was providing seniors with the means to reimburse drivers for the ride, as provided by contributions from local businesses. The ability to reimburse drivers is considered essential so that riders feel empowered to ask for a ride, knowing that they have something to give in return. Reimbursement is in the form of a check made out to the rider, after the rider submits documentation of trips taken. Riders cash the check and distribute the reimbursement to the driver.

Initially, riders register into the program. Riders recruit their own drivers, who are registered as part of a rider's profile. These drivers then participate in a driver screening process that requires a driver to provide signature verification indicating compliance with minimum qualifications as determined by the Nonprofits' Insurance Alliance of California (NIAC). Driver history is based upon self-reports, which reduces staff time in conducting motor vehicle background checks. Riders schedule rides directly with the drivers. Program administrative activities are kept to a minimum and include the following.

- Acquiring insurance

- Registering riders and drivers

- Filing

- Inputting and managing databases

- Reviewing reimbursement forms

- Preparing and sending reimbursement checks

- Meeting with groups

- Distributing promotional materials

- Soliciting and distributing in-kind support

The Beverly Foundation created a set of materials for communities to use to adapt the Volunteer Friends model to their own area. These materials include the following.

- Participant registration kit

- Service partner information kit

- Administrative materials, forms and templates

- Community outreach scripts

- Databases in Excel spreadsheets, including ones for riders/driver, in-kind contributions, and communications database for tracking and follow-up.

The Beverly Foundation reported that the pilot project cost less than $\$ 15,000$. One of the pilot conclusions was that insurance does not need to be a barrier to operating a volunteer driving program, but it needs to be addressed right from the beginning. 
MEMBERSHIP-BASED PROGRAMS

ITNORLANDO ${ }^{\circledR}$, ORLANDO, FL, HTTP://WWW.ITNORLANDO.ORG/DEFAULT.ASPX

ITNOrlando ${ }^{\circledR}$, Orlando, FL is a 501(c)(3) organization. Through the combined efforts of numerous organizations and government agencies, program planning for ITNOrlando ${ }^{\circledR}$ began in 2005 after being selected by ITNAmerica ${ }^{\circledR}$ through an application process that determines feasibility and likelihood of program success. ITNAmerica's ${ }^{\circledR}$ mission is to provide a community-based, community-supported (accepts no taxpayer dollars), economically viable and consumer-oriented, quality transportation service for seniors, 24 hours a day, seven days a week. This is a member-based organization. Riders pay a fee per ride and for a little extra, they can link trips. (from web site)

The ITNOrlando ${ }^{\circledR}$ service began in October 2006. The program is a community collaboration that involved the Senior Resource Alliance, the Winter Park Health Foundation, and the Florida Chapter of AARP. The Winter Park Health Foundation financed the initial planning and start-up, with the MPO providing $\$ 10,000$ over two consecutive years for planning. The program used both paid drivers who operate two fleet cars, and volunteers who use their own cars. Volunteers deliver up to 35 percent of the rides.

There is an annual membership fee paid by riders, which is $\$ 50$ per individual and $\$ 65$ per family. Membership fees and service payments cover approximately 50-60 percent of the service cost. The remaining 40-50 percent comes from local, voluntary community support. There are two pricing options for riders. The first is pre-scheduled service, which costs $\$ 3$ for the pickup and $\$ 1$ per mile, with a minimum charge of $\$ 5$. The second option is same-day service, which costs $\$ 3$ for the pickup, $\$ 2$ per mile, with a minimum charge of $\$ 8$. When a member quits driving, he or she can choose to donate his or her car to ITNOrlando ${ }^{\circledR}$. The value of the car is placed in the member's account to help pay for future rides.

There is a positive working relationship between ITNOrlando ${ }^{\circledR}$ and the local transit provider, LYNX. The two organizations recently submitted a joint application to the National Center for Senior Transportation. ITNOrlando ${ }^{\circledR}$ also has a close relationship with local businesses and professionals, including grocery stores and other retailers, physicians and dentists. They work to establish business relationships ("ride and shop"; "healthy miles" and "smile miles") that provide a public relations tool for the business, a reduced cost to the passenger, and a revenue stream for ITNOrlando ${ }^{\circledR}$.

Recruiting volunteers is a challenge. Numerous people express interest in becoming volunteers but far fewer actually donate their time. However, the liability issue limits the ability of the program to recruit volunteers. Volunteers are recruited through presentations to civic clubs, newsletter articles, bulletin boards, and churches. The program cannot aggressively recruit new members because the supply of volunteers will not satisfy the increased demand. The goal of ITNOrlando ${ }^{\circledR}$ is 25 rides per day by the end of 2008.

ITNOrlando ${ }^{\circledR}$ has a formalized risk management program. Volunteers rely on their personal insurance for coverage while they are in the vehicle. ITNOrlando ${ }^{\circledR}$ provides no additional coverage for in-vehicle incidents. ITNOrlando ${ }^{\circledR}$ does provide coverage for the volunteers while they are outside their vehicle-i.e. escorting a member to their home. The program reports that it cannot obtain "hired and non-owned auto" coverage. Examples of situations that this type of insurance covers include those in which a paid staff person or volunteer is running an errand on behalf of the company or is on his way 
to a business meeting and is in an accident while driving his own car. All volunteers undergo fingerprinting and a criminal background check. Each volunteer completes a driver skills assessment.

EZRIDE, PINELLAS COUNTY, FL

HTTP://WWW.NEIGHBORLY.ORG/EZRIDE/TABID/207/LANGUAGE/EN-US/DEFAULT.ASPX

EZride opened its doors in October 2007 as a service with the goal to renew independence for seniors age 55 and older and persons with disabilities by providing rides to those who can no longer drive themselves. EZride is a membership transportation service of the Neighborly Care Network, Inc. Neighborly Care Network is a private non-profit organization that began serving seniors in 1966. Neighborly provides a variety of services in coordination with other agencies, including long-term home care assistance as an alternative to institutionalized care, a reduced price pharmacy, and nutrition services. Neighborly also provides transportation services in agency vehicles, to medical appointments with a 7-day advance notice, to nutrition sites and adult day care centers.

Alternatively, the EZride service allows members to call 48 hours in advance to reserve a ride for any trip purpose. Days of operation are Tuesday through Saturday from 8 a.m. to 6 p.m. EZride requires an advance rider eligibility application and is available to persons with no other means of transportation. The rider must be ambulatory. EZride drivers will not go inside a rider's house. There is a $\$ 50$ annual membership fee. The cost of each ride includes a $\$ 3.00$ pick-up fee and a charge of $\$ 1.50$ per mile. A round trip is double this amount. No tipping is permitted. A companion, such as a spouse, may ride at half price and caregivers/escorts can ride free of charge. Riders pay in advance of the trip by keeping a balance of funds in their accounts.

Initially, the service was confined to rides within the city limits of Clearwater and Dunedin but now serves all of Pinellas County because of grant funding conditions. EZride is funded through MPO funds as well as sponsor donations. The grant covers the costs of administration, Workers Compensation, insurance and route matching. Separate from Neighborly, the EZride program itself carries a \$1 million umbrella coverage for personal auto liability of volunteer drivers.

EZride uses a combination of paid and volunteer drivers. Volunteers receive credits for each trip taken to be applied to their own future EZride member trips or to be donated to another. Family or friends can donate funds toward rides for a member. EZride has a toll-free phone number. Funding may be available for persons age 65 or older. EZride staff members print marketing materials to recruit volunteer drivers who want to help people, give back to the community and "keep their minds sharp". Presently, EZride has a membership of 79 and 50 of these members are low to moderate income. Drivers go through a formal training program as well as a criminal background check and a motor vehicle record check.

The challenges experienced by EZride are serving the entire Pinellas County, finding volunteers, and financial sustainability beyond grants. Volunteers are reimbursed $\$ 0.48$ per mile presently and this will increase to $\$ 0.55$ next year. Volunteers are asked to serve as ambassadors of the program. There are sufficient volunteers now but the demand is growing. EZride started with some ready vehicles from its parent agency, Neighborly Care Network, Inc. that has vans to transport seniors to meal sites. EZride obtained a grant through the Pinellas MPO to use federal New Freedom grant dollars, which now obligates the program to provide service countywide. The challenge is sustainability over time. EZride staff does not want to get into the habit of applying for grants because the application process is time consuming with no guarantee of being selected. 
RIDINGTOGETHER, DELTONA, FL (NO WEB SITE)

RidingTogether is a private non-profit 501(c)(3) volunteer driving program serving six zip codes in West Volusia County, Florida, including the towns of DeLand, Orange City, Deltona, and DeBary. This volunteer driving program was planned by starting with concepts from the ITN ${ }^{\circledR}$ model of operation but changing some of the elements. Changes include no paid drivers, which makes the operation much simpler and less expensive. The RidingTogether manager was involved with the initial meetings for planning ITNOrlando ${ }^{\circledR}$, which serves the Maitland, Eatonville, and Winter Park areas. However, the towns of interest, 24 miles to the north, were considered too far away and could not be included in the ITN ${ }^{\circledR}$ service area. The service radius of an ITN ${ }^{\circledR}$ affiliate is generally 15 miles. The distance between the towns of DeBary and DeLand is approximately 10 miles long. These small towns are west of Interstate 4, in a largely rural area, and for all practical purposes, on the edges and in between the service areas of Space Coast Area Transit (Brevard County) and VOTRAN in Volusia County. VOTRAN is operated from Daytona Beach and DeLand is the closest city, located 25 miles away.

RidingTogether matches the needs of seniors who no longer drive with the schedules of volunteer drivers who have available time. The manager established this service and operates it from his home, using a large planner notebook with calendar and a telephone. He describes it as a grassroots approach to serving the transportation needs of seniors with a goal to make the service self sustaining. He borrowed several elements from ITN ${ }^{\circledR}$ but tailored the service to suit the needs of West Volusia County. He calls it the "RT Model". No salaries are paid to staff or drivers. Drivers are reimbursed 90 percent of the fare paid by the rider. The other 10 percent is used for administrative expenses.

This service is for seniors and for those who are visually impaired. Trips can be for any purpose, including taking a pet to the veterinarian. Trips are Monday through Friday between sunrise and sundown. This service uses a membership model, in which the initial one-time membership fee of $\$ 5.00$ is applied to the cost of the first trip. Some members have signed up just for peace of mind in the event they need it. Both riders and volunteers initially fill out a two-page application, with the drivers filling out an additional page detailing insurance, driving record, type of vehicle and other details. Membership is granted upon completing the application.

Members call by telephone to reserve a ride. The dispatcher places a courtesy call to both driver and rider one hour before the scheduled pick-up time to make sure everyone agrees. There is an acceptable window of five minutes on each side of the driver's arrival time to pick up the rider. Riders may sit in the front seat of private automobiles. Volunteer drivers are expected to provide doorthrough-door service if needed. The manager tries to be sensitive to the needs and preferences of his riders. For example, a majority of seniors are women. Women volunteers are particularly needed because women riders tend to prefer to ride with women drivers.

The RT Model appears to differ from other more formal programs that may be set up in more urbanized areas or which have a larger service area and are housed under the auspices of a larger organization. These more formal programs tend to take a more conservative approach to risk exposure. For example, programs that are more conservative may require riders to sit in the back seat for their safety. No pets are allowed. Drivers do not go inside a rider's home. With less formal programs operating in rural areas, there appears to be a greater flexibility shown as well as a more personalized approach to meeting the needs of the rider and ensuring a rider's comfort and sense of dignity. It is true that car passengers are less likely to be injured in an accident if they are riding in the back seat and seniors are at even greater risk of injury; however, riders generally prefer the front seat.

The service area is generally within a radius of 15 miles and is composed of six contiguous zip codes. The use of zip codes to define service boundaries was borrowed from ITN ${ }^{\circledR}$. Zip codes are used 
because everyone knows their own zip code but not the often-convoluted boundaries of city limits. This makes it easy to determine someone's eligibility to become a member. The interesting thing about RidingTogether is that there are few rigid absolutes. For example, the operating time of the service is generally sunrise to sunset, which varies with the seasons, relies on common sense and exceptions are made from time to time. Exceptions are considered for rides longer than a 15-mile radius as well as a special request for weekend service.

No money is required at the time of a trip and no cash is ever exchanged. Gratuities and tips are not allowed. Statements are issued at the end of each month, similarly to ITN ${ }^{\circledR}$. Balances under $\$ 10.00$ carry forward to the next month. Members are charged a $\$ 5.00$ trip minimum with $\$ 0.55$ per mile and mileage is based upon the shortest route shown by MapQuest ${ }^{\circledR}$. When two or more members carpool, they receive a 50 percent cost savings. This means, for example, that both spouses can ride for the price of one.

A round trip reservation must be made at least one day in advance. After the trip is arranged, the manager creates a riding ticket with the names of the rider, driver, date and times, origin and destination, emails it and prints it out for himself. For a reservation made the same day, the charges are double; however, RidingTogether recommends to its members to use a taxi for these short notice trips. RidingTogether does not want to compete with taxi service.

When the first leg of a trip has a planned gap of over an hour from the return trip, it will be computed as two separate trips, called a split trip. A pick-up time can be pre-arranged or the rider can call when their desired pick-up time becomes definite. Frequently, doctor or dentist appointments involve a long wait time or the visit takes longer than expected. In this situation, when there is an unplanned delay of over an hour for the return trip, there is no additional charge. The second time this happens, the trips are computed as a split trip, with the return trip charged at 50 percent of the first.

Volunteers are asked how many times they would like to drive during each month. In matching a ride request with a volunteer, the dispatcher has a list of volunteers and starts calling down the list. The volunteers are listed in an order with those wanting to drive the most number of trips at the top of the list. Those wanting to drive the least number of times are at the bottom of the list. Volunteers can decline a request to drive. Volunteers assist riders door-through-door, both at the home and destination. This includes assistance with packages and walkers, etc. Riders must be able to get into and out of a car with assistance but not needing to be lifted.

Friends and relatives can purchase gift cards for members. Friends, relatives and other members can also buy Booster Miles on behalf of other members who cannot pay. These ideas are from ITN ${ }^{\circledR}$.

A main point emphasized by the manager is that volunteer driving programs need a social and institutional "infrastructure" in place, composed of the decision makers from related organizations and agencies, such as Rotary Club members, who have the combined local knowledge and resources to get a job done. Developing a social infrastructure includes an identification of representatives of helpful entities such as local hospitals, charities, the media, elected officials, attorneys, insurance companies, the local chapter of AARP, etc.

The manager is approaching the development of RidingTogether by seeking out individuals who have expertise and power in each of the four towns, then encouraging them to talk together, organize and develop a social infrastructure that can rally and organize resources. The manager's main concern is finding enough volunteers in each of the four towns to match riders with volunteers who live in the same town. RidingTogether is active in DeBary with an average of two trips served each day (73 trips total) during April and May of 2008. However, in DeLand, there are presently ten people signed up who seek rides but only one volunteer from DeLand. The manager says this is because the 
infrastructure is not there yet. As of this interview, he has a presentation scheduled at three Rotary Clubs and has contacted the City Council and Senior Council in DeLand. The manager said he would be glad if these towns set up and ran their own satellite programs.

When the service started in 2007, riders were charged $\$ 0.50$ per mile, then the fee dropped to $\$ 0.40$ per mile and volunteers were reimbursed $\$ 0.15$ per mile. Soon after, fuel prices began escalating rapidly. Now the cost to riders is $\$ 0.55$ per mile with a $\$ 5.00$ minimum and 90 percent of the fare paid by the rider goes to the volunteer to reimburse for expenses. The mileage count starts at the driver's home. Volunteers also have established member accounts and they receive a credit of one mile for every mile driven. At the end of each quarter, the driver can give these credits to another member, donate it to Booster Miles, hold the miles in the driver's own account in the event of a need of a lift (eyes exams, dead battery, etc.), cash at $\$ 0.15$ per mile, or some combination of these. The $\$ 0.55$ per miles fee to riders works out to be $\$ 0.495$ per mile reimbursed to the driver. Most trips have been local trips averaging $\$ 5.00-7.00$.

Presently, RidingTogether has 25 members and 8 drivers. Eight of the members use the service on a frequent basis, the other members use the service occasionally. During the first quarter of 2008, 110 rides were given. The manager says that a program is able to support that level of demand with 4-5 volunteer drivers. He believes there are plenty of people out there willing to volunteer. He just has to find them. When the manager takes a driver application, he asks the applicant approximately how many times per month the volunteer might like to drive, to get a ballpark sense of the level of availability of a driver. He does not pin them down. When a member calls, asking for a ride, he may call a particular driver who lives in the same zip code as the member. The driver can choose to accept the assignment or not, with no questions asked. This gives the volunteer drivers a certain level of comfort afforded by flexibility. The manager reaches out to volunteer drivers in a way that they do not have to commit. A key is to take the commitment out of it. His current volunteers are a diverse group, including a restaurant manager, a stay-at-home mom, and a real estate agent.

The manager does not want to develop a fleet of vehicles. For example, donated cars can cost $\$ 5,000$ per year in insurance alone. The rider ends up paying the bill unless the volunteer driving program can depend on winning grants to cover this cost.

The manager says it took a long time to start up the program. He said that perhaps he could have started the program sooner if he had made different decisions but then there would have been financial risk. In the last two months, RidingTogether provided 73 trips and the organization owes no money. Starting a program very small initially means the organizer does not have to worry where the money will come from to sustain the program.

To check volunteer drivers' motor vehicle records (MVR), he uses the service provided by the American Safety Council. On the Internet, businesses can request the MVR for persons according to Driver License number. He pays $\$ 5.00$ per record to go back three years or $\$ 8-10$ per record to go back 7 years. The manager checks volunteer driver insurance coverage to make sure the minimum coverage requirements are in place.

The manager said that the "RT Model" keeps the size of the program small to operate it on a "no money basis". He said the RT Model would work in a church, senior center, mobile home park or neighborhood association. 
FAITH-BASED PROGRAM

WEST AUSTIN CAREGIVERS, TX HTTP://WWW.MAIN.ORG/WACAREGIVERS/INDEX.HTML

The West Austin Caregivers is a coalition of member congregations that make up eight operating units. The West Austin program is one operating unit that focuses on older adults. The program provides service Monday through Friday, from 9-5 pm. West Austin Caregivers was formed in 1985. The Robert Wood Johnson Foundation had a pilot "Interfaith Volunteer Caregivers" (IVC) program in 25 sites nationwide including in Texas. West Austin Caregivers adopted the IVC model. The program began with five member congregations and has provided transportation, telephone reassurance, friendly visiting and home repair services. The program now has grown to 17 sponsoring congregations. Sponsoring congregations make an annual monetary pledge, provide a congregant to serve on the board, and these board members help recruit volunteers. The program recently secured federal Section 5310 operating funds to help underwrite the cost of taxi service to supplement volunteer rides provided.

Program representatives conduct home assessments to determine level of need. Functional ability is tracked as rider needs change. There is no charge for riders. A three-day advance reservation is required and the focus is on ambulatory riders, although efforts are made to accommodate riders with adaptive equipment. Occasionally, family members or other caregivers will ride along to assist. Given the current number of volunteers, participants are allowed only two rides per week. The program encourages one ride a week for essential services (i.e. a medical trip) and one ride a week for fun (i.e. library). The program provides $40-50$ rides per week.

Volunteer drivers use their own vehicle and serve any person over the age of 60 who resides within the program's service area. Volunteers provide three levels of service---curb-to-curb, door-to-door, and door-through-door. Volunteer recruitment can be difficult but at the same time, there is minimal volunteer turnover. Over 50 percent of volunteers come from member congregations. Additional recruitment tools include a long-standing business relationship with the Junior League, advertising on the ESPN radio station, internet-based volunteer matching services, postings on web sites of professional associations, and collaboration with courses at the University of Texas that require service learning hours. Volunteers must complete a written application and participate in a personal interview with program personnel. Potential volunteers also receive a criminal background check, participate in training, and must submit personal references.

Staff for West Austin caregivers has said that insurance for the program is not a problem. The program provides a $\$ 1$ million liability umbrella policy. Texas recently passed legislation that requires persons over the age of 85 to pass a vision test before renewing a driver license. This legislation will place increased demand on the program. 
CIMA VOLUNTEER INSURANCE PROGRAM

The following profile was developed from information gathered in interviews with Vicki Brooks and Laurie Coleman, CIMA, March 12, 2008.

A risk pool is composed of an affinity group, such as members of a professional association, or members of AARP. The case of interest to this study is nonprofit organizations that engage volunteers. Volunteers, as a group, are considered low risk by the CIMA Volunteer Insurance Program, which is an example of an insurance risk pool of 5000+ nonprofit organizations across the country that engage volunteers of all kinds. CIMA writes policies only for nonprofit organizations. CIMA does not impose risk management procedures on nonprofit organizations. For those nonprofits that offer volunteer transportation and use volunteer drivers, CIMA does not require a Motor Vehicle Record search, a driver license record search, or a criminal background check.

Each participating nonprofit organization pays an annual fee of $\$ 135$ for membership in Volunteers in Service. CIMA has flat rates provided to cover all the volunteers for each member nonprofit organization. CIMA writes three types of coverage---accident, personal liability, and automobile (liability only). To protect volunteers, CIMA's Volunteers Insurance Service program offers the following three coverage options, separately or combined.

- Up to $\$ 25,000$ in medical expense reimbursement as a result of a covered accident, at a cost of $\$ 3.75$ per volunteer per year

- Up to $\$ 1,000,000$ in personal liability insurance, at a cost of $\$ 1.72$ per volunteer per year, with a minimum premium of $\$ 100$

- For those volunteers who drive, up to $\$ 500,000$ in excess automobile liability insurance above the volunteer's own insurance, at a cost of $\$ 6.04$ per volunteer per year, with a minimum premium of $\$ 100$

Consider an example to provide all three types of coverage for eight volunteers, which is about the size of a start-up volunteer driving program in Florida. This would include the $\$ 135$ annual member fee, $\$ 30$ total for accident coverage, $\$ 100$ total for personal liability coverage, and $\$ 100$ for automobile liability coverage, totaling $\$ 365$ per year.

To control liability and increase the chances of finding insurance coverage, one strategy used by volunteer driving programs is to accept donations only and not charge fees to riders. However, an organization must clearly demonstrate in the way it does business that no rider is under obligation to make a donation. According to CIMA, by accepting donations instead of charging fees, the organization can receive insurance coverage from CIMA, as long as the organization does not solicit donations for a posted amount. 


\section{APPENDIX E}

A LEGAL ANALYSIS OF RISK ASSOCIATED WITH VOLUNTEER DRIVING PROGRAMS

Presented by Peter O. Okin

The following legal analysis was conducted and authored by Peter Okin, JD, who received his

doctorate in health law from Rutgers Law School. Mr. Okin is a member of the Bar of the United

States Supreme Court. He also is a member of the Bar of the 5th, 6th, 9th, 10th and 11th Federal

Appeals Courts. Mr. Okin is a member of the American Public Health Association.

This study closely examined legal issues that are associated with volunteer driving programs for seniors, especially those relating to the liability risks posed by those programs. This report provides a number of options for remedies, but understanding the reasoning behind these options requires knowing a bit of the background, presented below.

Court cases that are analogous in various respects to volunteer driving programs were studied. These court cases refer to federal and state law, which has a long history. Briefly summarized below, the law has shifted in its ideological emphasis over time. The old doctrine of "charitable immunity" from tort (a wrongful act for which relief may be obtained in the form of damages or an injunction) was eventually followed by a spate of modern laws that sometimes capped charities' liability, and by a large set of state "volunteer protection acts" that, at least in principle, protected volunteers from civil liability. In the system of Federal and Florida statutes that aim to protect volunteer drivers from heavy civil liability, some gaps were found.

In general, the relationships involved in a volunteer driving program for seniors are positive for all parties. The non-profit organization or agency, the volunteer, the client, and outsiders as well as society in general will derive benefit from this helping relationship. Adverse events are unlikely in most individual cases. However, prudent management and planning requires program officials to foresee those situations that could pose future problems, in order to develop methods to avert, limit, or remedy them.

\section{THE PARTIES INVOLVED}

From a legal perspective, one can see a variety of scenarios that could have adverse impacts on the ridesharing relationship. To approach these analytically, one first considers the four basic types of parties involved in a standard ridesharing program, among which legal conflicts could arise. All of these parties have some basic duties of care to one another. Although individual programs could have numerous participants interacting in complex ways, the fundamental parties listed below would provide a basic model from which to develop needed concepts.

THE VOLUNTEER DRIVING PROGRAM

This is usually a private nonprofit or charitable organization. In some cases, for-profit private or public sector providers might be involved, which would raise different considerations.

THE VOLUNTEER

Usually, this individual donates his or her services free of charge, although often with reimbursement of such expenses as gas and car maintenance. Paid employees of senior driving programs may present a host of separate issues. 
THE CLIENT

Usually, an elderly person who is legally "competent" and able to make arrangements for himself or herself, and generally the client is not legally "disabled" or requiring special equipment, such as a wheelchair. When the arrangement involves transportation of persons who are mentally or physically impaired, the situation becomes more complicated legally, with the possibility of guardians having to contract on behalf of the client, concerns over special vehicle equipment and driver training, and requirements by the Americans with Disabilities Act (42 U.S.C. ss 12101, et seq.).

THIRD PARTIES

A significant third party could be a pedestrian or other motorist who is injured by the volunteer's car. Numerous other third parties can be visualized, including regulatory agencies, donors to the charities, insurers, property owners and even society in general, which has broad interests in the transaction.

It is crucial to distinguish these participants analytically because their legal interests are not identical. Sometimes these interests do converge, as when a charity and its volunteers seek to reduce their collective liability to injured parties in an accident. Under the ancient legal doctrine of respondent superior (or "vicarious liability") the employer (or "master") is responsible for the actions of its "servant" done in the scope of employment, so the charity could become liable for the negligence of its volunteer driver. Cf. BLACK'S LAW DICTIONARY 1311-12 (6 ${ }^{\text {th }}$ ed. 1990). See also Baxter v. Morningside, Inc., 10 Wash.App. 893, 521 P.2d 946 (Ct. App., Div. 2 1974), but see Alms v. Baum et al., 343 So.2d 618, 2005 Fla. App. LEXIS 6936 (Ct. App. 3d Dist. 2003).

Thus, the charity and the volunteer might sit on the same side of a courtroom, defending themselves against a common lawsuit. However, the interests of the various driving program participants might also be adversarial. For example, volunteers could sue their non-profit or charity "employer" for injuries sustained during the scope of their employment or, theoretically, the charity could sue the volunteers for damage to an organization's vehicle, or to recover costs from a third-party victim's suit.

It is important from the start to recognize these divergent party perspectives involved in a volunteer driving program, and the inherent tension among them. While service to elderly persons is basically a harmonious enterprise, with the participants having many common goals, there still remains some degree of "tug-of-war" among them, especially in "worst-case scenarios." In such situations, to favor one of these parties often means to disfavor another.

The goal of policy makers is to accomplish some sort of balance among the interests, weighing each by its social importance. For example, it might be decided as social policy that the special vulnerability of elderly clients means that a volunteer driving organization should "bend over backwards" to protect them by thoroughly screening, monitoring, and supervising its volunteers, even if such actions can be burdensome to the volunteers and can chill the recruitment and retention of altruistic drivers.

HISTORICAL PERSPECTIVE

The classic scenario in which a volunteer driver causes injury to a client or to a third-party victim is the primary analysis focus. The history of this situation was examined from the perspective of the charity/non-profit and from the perspective of the volunteer.

Societal and legal thinking about this scenario has shifted in its emphasis over time. A theoretical pendulum has swung from protecting charities against liability, to giving injured litigants their day in court, to protecting the interests of volunteers, and, most recently, to a closer monitoring of volunteers and holding their employers liable. Each swing of the pendulum has left in its wake some 
statutes, regulations, administrative practices, and case law that continue to affect the rideshare relationship today. To a certain extent, these trends have been true both nationally and in Florida.

A large number of law review articles were examined. These discussed the broad history of the doctrine of charitable immunity that originally prevailed in state statutes and court decisions in the late nineteenth and early twentieth centuries.

THE DOCTRINE OF "CHARITABLE IMMUNITY"

In the latter half of the nineteenth century, many American courts enunciated and developed the doctrine of charitable immunity, which aimed to protect charities from liability for negligence (see, e.g., MacDonald v. Massachusetts Gen. Hosp., 120 Mass. 432 [1876]). Among other things, supporters of this doctrine argued that charities had little practical control over their supposedly autonomous staff members. It also argued that beneficiaries of charities "assumed the risk" of negligence when they used such services, and that, in any case, entrusted charity funds should not be used to pay tort claims. The basic premise was that charitable organizations and their "servants" were doing valuable work for society and its needy, which should not be discouraged by the threat of lawsuits. By 1938, forty American legislatures had statutorily adopted the charitable immunity principle.

The policy pendulum at that time was greatly against injured persons, who could find little redress in the courts if they were injured by the staff of charitable organizations. However, the doctrine of providing immunity to charities did not necessarily protect the employees and volunteers themselves from suits.

THE MOVEMENT TO INCREASE TORT VICTIMS' ACCESS TO THE COURTS

Meanwhile, a countervailing view was developing, which held that charitable immunity was unjustified. A Minnesota court expressed this position as early as 1928. Geiger v. Simpson MethodistEpiscopal Church of Minneapolis, 174 Minn. 389, 395-96, 219 N.W. 463, 465-66. In a landmark 1942 decision, the U.S. Court of Appeals for the D.C. Circuit sharply and thoroughly rejected charitable immunity under at least one particular set of circumstances (patient injury at a large university-run hospital). President and Directors of Georgetown College v. Hughes, 130 F. $2 d 810$ (D.C. Cir. 1942). Soon, many courts and states were also chipping away at the old doctrine, articulating a number of rationales for doing so. Mainly, they claimed that:

- charities could readily control their employees and volunteers,

- stripping immunity from the charities would motivate them to use greater care, and

- in any event, liability insurance was becoming easier to obtain.

More fundamentally, though, the "pendulum" was shifting from concern for the social good of charitable works to concern for tort victims and their losses. The prevailing view was that victims of torts deserved their day in court, and restrictions on the right to sue should be narrowed. Proponents of this doctrinal shift would stress that numerous charities had become very large and operated as businesses in many respects, so a general business model could be reasonably applied to them, and they should carry some of the same burdens as businesses. From both economic and equity perspectives, these charities would be better able to bear the cost of damages than many victims of wrongful acts or omissions would. Thus, by 1985, the old doctrine of charitable immunity, as it had once existed, was widely diminished. However, the doctrine has never really died. A number of state laws still cap the ultimate liability of charities within their jurisdictions. 
THE “VOLUNTEER PROTECTION” MOVEMENT

As with all social policies, an ideological swing too far in favor of one side could underemphasize competing interests and cause undue harm in individual situations. This appeared in the form of several developments.

First, there was a general increase in tort litigation against all sorts of individuals and institutions, which reached levels not seen in past eras. This provoked a reaction in some quarters against what was seen as an excess of "frivolous lawsuits." While relatively uncommon, suits against charities and their volunteers also appeared in the courts (e.g., Baxter v. Morningside, 10 Wash. App. 893, 521 P.2d 946 [1974] [volunteer driver for charity caused injury]; Manor v. Hanson, 123 Wis. 2d 524, 368 N.E. 2d 41 [1985] [same]; Niehaus v. Rural Peoria Co. Council on Aging, 314 III. App. 3d 665, 732 N.E. 2d 132, 247 III. Dec. 416 [2000] [same]).

Moreover, one of the mainstays of the arguments against charitable immunity-the alleged "wide availability of insurance protection for charities" - was also under challenge. In the 1980s, a "hard" insurance market developed, which made it increasingly difficult for many institutions to get insurance protection, especially at affordable rates. This trend was especially harsh for small charities, which could not afford the premiums. Furthermore, many insurance carriers were fundamentally suspicious of all organizations that relied on volunteers. They thought that those charities were operating outside the standard business model, with its usual objectives and constraints, and they feared that the organizations would poorly manage and control their volunteers, leading to actuarial uncertainty and widened liability. Even if litigated cases involving volunteers were actually few, the perception of great hazard disturbed the insurers. Thus, many of them threatened to deny, reduce, or repeal coverage to charities and their volunteers (See, e.g., Insurance Services Office, SIMPLIFIED COMMERCIAL LINES MANUAL).

Other public and political ideas were emerging and economic conditions also had an impact on general thinking. Increasingly, some political figures, including Presidents Ronald Reagan and George $\mathrm{H}$. W. Bush, began trumpeting the virtues of volunteerism over public sector social programs. Their administrations reduced federal spending on social programs. They sought to encourage actions by private charities and volunteers in place of it. Moreover, public officials and charities were becoming more and more concerned that a fear of lawsuits was constraining charities' activities and discouraging people from volunteering. These trends and policy concerns spawned a variety of legislative remedies.

In several places, charitable immunity re-emerged, at least in a different form. Several states enacted laws that either flatly precluded damages for certain charitable conduct, or capped recoverable damages for charities' torts at amounts ranging from $\$ 10,000$ to $\$ 1,000,000$ (e.g., G.L.M. c. 231 , s $85 \mathrm{k}$ [1971]). However, this was a minority approach, and some commentators strenuously denounced it (e.g., 82 MASS. L. REV., at 231).

Another notable example of remedial legislation was the "Volunteer Protection Acts (VPA)," which were enacted by the federal government (42 U.S.C. ss 14501, et seq.) and by a large number of states (e.g., Wash. Rev. Code s 4.24.264 [1988]; Tenn. Code Ann. S 48-58-601 [Supp. 1989]; Minn. Stat. Ann. S 317.201 [West Supp. 1991]; Fl. Stat. Ann. 768.1533 [1993]). (See, e.g., 105 HARV. L. REV., at 1682). The latter statutes are worth examining in further depth (see discussion below).

THE MOVEMENT TO PROTECT VULNERABLE PERSONS FROM ABUSIVE CAREGIVERS

In more recent years, the pendulum of socio-legal opinion and policy may have swung back some distance from protecting volunteers and their non-profit employers from liability to protecting their 
clients from harm. During the last two decades, the public and lawmakers have become preoccupied with the danger of abuse by caregivers of the vulnerable. A number of high-profile cases stoked these fears. In response, legislators and administrators promulgated a number of statutes and regulations that required charities/non-profits to conduct more stringent pre-hiring screenings of employees and volunteers. After hiring, stiffer ongoing monitoring and supervision requirements have also been imposed.

THE CURRENT VOLUNTEER LIABILITY SITUATION IN FLORIDA

Particular attention in the research and analysis was paid to the Florida and federal Volunteer Protection Acts, looking closely at how they interact in a volunteer driving context. From review of the statutes, Florida case law, and commentaries, it is concluded that these acts in their collectivity do not give Florida's volunteer drivers much protection against lawsuits for accidents.

FLORIDA'S VOLUNTEER PROTECTION ACT

Volunteer protection laws are different, state-by-state. The laws of many states specifically exclude any motor vehicle accident from state VPA protection, whether a volunteer for a senior driving program was driving or anyone else. According to the Nonprofit Risk Management Institute, this is because these states have no-fault insurance laws for automobile accidents in general, to avoid the flood of costly court fights regarding whose fault it was. However, in general, the no-fault insurance minimums required by states would likely not cover the medical costs of a serious accident. Florida requires licensed drivers to carry a minimum of $\$ 10,000$ no-fault insurance protection but in the context of volunteer driver liability in Florida, this is a moot point. Florida is one of 15 states, in which drivers (volunteer drivers included) are not mentioned in the state's volunteer protection act. By its terms, this law does not exclude them from its scope. In the absence of a court case outcome that interprets otherwise, this means volunteer drivers are protected by Florida's Volunteer Protection Act.

However, Florida's Volunteer Protection Act (“FL-VPA") (Fla. Stats. s 768.1355), which preceded the federal law historically, may provide "liability protection" for volunteer drivers that is in a large sense illusory. The FL-VPA imposes three crucial requirements on all volunteers. When volunteers commit an act or omission that results in personal injury or property damage to another, they can be protected from civil liability only if:

(1) they are "acting in good faith within the scope of any official duties performed under such volunteer service." Fla. Stats. Ann. 768.1355(1)(a);

(2) they do not cause the injury or damage "by any wanton or willful misconduct." Id., Sec. (1)(b); and

(3) they are "acting as an ordinary reasonably prudent person would have acted under the same or similar circumstances." Id., Sec. (1)(a); E.

The first two of these legal requirements are not highly problematic. The first one merely requires that the volunteers were acting as volunteers when they committed the alleged torts. For example, they could not be driving on some private errand when they caused the accidents. This makes the nonprofit organization appropriately responsible for the conduct of the volunteers. The second requirement is a little more troublesome, since it does not specifically define "willful or wanton misconduct," but these are general tort law "terms of art" that refer to a relatively high degree of culpability. 
It is the third criterion that raises the basic problem. By also requiring that a volunteer driver behave "as an ordinary reasonably prudent person," the Act has basically raised his or her duty to the standard one required of all drivers on Florida's roads. In the language of tort law, the FL-VPA is saying that the volunteer may not even commit any act of simple (or ordinary) negligence on the roadway, or the full burden of civil liability will descend on him or her. This gives the volunteer virtually no special protection by virtue of his/her charitable act; all he or she gets is the illusion of protection.

The liability exposure of volunteers is more than hypothetical. One recent Florida case, Campbell $v$. Kessler, 848 So. $2 d 369$ (Fla. $4^{\text {th }}$ Dist. Ct. App. 2003) starkly showed how it can happen in real life. While the volunteer in that case was a neighborhood watch driver rather than a driver of seniors, the situation was still closely analogous to that of volunteer drivers for the elderly. Seeking to provide additional "eyes and ears" to the local police, Reuben D. Berger would drive a citizen patrol car through his neighborhood during an allotted time period. In the incident in question, he was reportedly talking on a cellular phone when he struck Deanna Campbell's car at a stoplight. Ms. Campbell sued for damages. Although the trial court ruled for the defendant, stating that the FL-VPA would protect him from liability, the appellate court overturned that decision, saying that "[t]he statute clearly and articulately provides that volunteers are protected [only] if they are carrying out volunteer duties in good faith and as reasonably prudent persons." Id., at 3 . As a result, the appeals court ordered the trial court to consider Berger's negligence while acting as a volunteer driver. One commentator on the FL-VPA remarked dourly that the statutory language, as interpreted by the Fourth District Court of Appeals, "makes the immunity protection of minimal value to volunteers." 28 Nova L. Rev. 317 (2004).

It is unclear why Florida legislators adopted this statutory wording. A search of the references cited in the history section of the Florida Statutes Annotated and several contemporary journals of the Legislature showed no specific reference to legislative thinking that would justify this major weakening of protection.

THE FEDERAL VOLUNTEER PROTECTION ACT

On June 19, 1997, President Clinton signed the Federal Volunteer Protection Act ("FED-VPA") (42 U.S.C. ss 14501 , et seq.). Generally, it seemed to give volunteers more substantial protection, immunizing volunteers from the legal impact of ordinary or simple negligence, requiring only that they not cause harm "by willful or criminal misconduct, gross negligence, reckless misconduct, or a flagrant indifference to the rights or safety of the individual harmed." 42 U.S.C. s 14503(a)(3) (plus meeting certain other criteria, including "scope of duty" requirements). While the FED-VPA's terms are not fully defined, this statutory protection does seem to have real "teeth." However, it should be emphasized that the federal statute specifically excludes from its protection volunteers who caused harm by acts or omissions when:

...the harm was ... caused by the volunteer operating a motor vehicle, ... for which the State requires the operator or owner of the vehicle ...to-

(A) possess an operator's license; or

(B) maintain insurance. (42 U.S.C. s 14503(4); emphasis added).

This provision essentially denies the FED-VPA's liability protection to virtually all volunteer drivers, perhaps because the drafters assumed that they could easily obtain coverage through their personal auto insurance policies. But this possible Congressional assumption does not address the modern problem noted in the statute's own preamble, that "Congress finds ... that ... due to high liability costs and unwarranted litigation costs, volunteer and nonprofit organizations face higher costs in purchasing 
insurance, through interstate insurance markets, to cover their activities..." 42 U.S.C. s 14501(6). In reality, these insurance-created problems facing charities also confront their volunteers.

The only protection that volunteer drivers per se get under the FED-VPA is a general bar against punitive damages when they act within the scope of their duties and they do not engage in "willful or criminal misconduct" or with "a conscious, flagrant indifference to the rights or safety" of the victims. 42 U.S.C. s 14503(e)(1). In addition, an injured plaintiff who seeks to levy such punitive damages against a volunteer, including a volunteer driver, has a heavier burden of making his case by "clear and convincing evidence," instead of the usual, easier "preponderance of the evidence" standard of proof. In addition, the FED-VPA does restrict volunteer drivers' liability for non-economic losses (such as pain and suffering) to their own percentage of responsibility for such losses, as that percentage determined by a court. 42 U.S.C. $s$ 14504. This provision protects the drivers from the traditional tort principle of "joint and several liability," which can force every defendant in a lawsuit involving multiple defendants to pay 100 percent of the damages.

The reasons for the federal exclusion of volunteer drivers are also not readily apparent. The legislative history specified in the United States Code Annotated was reviewed, including the Congressional Record from spring 1997 and House Report, No. 105-101(I), dated May 19, 1997. There was extensive legislative "give-and-take," with intense disagreement on some rather odd issues (including a claim that the act would somehow immunize the Ku Klux Klan); however, Congress did not specifically state why they would not cover volunteer drivers. This particular exception was added relatively late in the process, perhaps during committee or cloakroom exchanges, but it was not discussed in open debate on the Senate or House floors.

Possibly, the FED-VPA was modeled after several existing state Volunteer Protection Acts, which also specifically excluded volunteer drivers from their protections against civil damage suits. For example, Colorado's 1992 volunteer protection statute, Colo. Rev. Stat. Ann. s 13-21-115.5(5), excluded this set of volunteers, although it limited any claimants' recoveries to the extent of liability insurance coverage held by the drivers. Meanwhile, New Jersey's 1995 VPA was more categorical, flatly denying any protection at all to an "employee, agent, servant or volunteer" of a charity who caused "damage as the result of negligent operation of a motor vehicle." N.J. Stats. Ann. s 2A:53A-7.c.)

In sum, with regard to liability for simple or ordinary negligence, volunteer drivers in Florida may fall "between the cracks" of the two statutes, state FL-VPA and federal FED-VPA.

RECOMMENDATION: PLACE PRIORITY PROTECTION ON VULNERABLE CLIENTS

In policy making for volunteer driving programs, it is useful to prioritize the divergent interests of senior clients, volunteers, volunteer driving programs, and third parties.

(1) As a matter of social policy with regard to liability, it is arguably reasonable to favor the generally vulnerable clients of volunteer driving programs, and to give their needs primacy. This assumes that elderly riders tend to be vulnerable due to frailty as well as a lack of personal resources to pay for other transportation service. Due to acts or omissions of volunteer drivers, third-party victims would also be favored over volunteer driving programs. Besides the ethical grounds for this primacy, there are pragmatic ones. Volunteer driving programs would suffer disproportionately from even a single incident of client abuse or accidental injury, and so it is in the best interests of the volunteer driving program to do everything possible to avoid an incident. Moreover, elderly clients of volunteer driving programs may 
have few resources to bear the risks of accidents. This may not be true across the board, for example, some programs, such as ITN, are targeted to elderly who are able and willing to pay for superior transportation service. In this case, the elderly clients and their families may have substantial resources. However, it remains that many charities and nonprofits do have some capacity to avert or mitigate damages. Those that do have the capacity tend to be the larger programs that may come under the protective umbrella of a parent organization. Operationally, averting damages means effective screening, instruction, and supervision of drivers, both paid and voluntary, and inspections of vehicles to prevent adverse events. It might also mean some sort of insurance underwriting arrangements to mitigate disasters that do occur. However, none of these solutions are simple and none ensure an avoidance of problems. Furthermore, they all require tradeoffs with possible adverse consequences, such as impaired recruiting of volunteers.

(2) While granting the primacy of protecting the vulnerable passengers, some deference is also due to the interests of volunteers. To a degree, policy makers have long recognized the social importance of encouraging altruism by not overburdening volunteerism. For example, the old English common law used to penalize first-aiders and medical providers who intervened to help in an emergency but unintentionally caused harm when doing so. By contrast, bystanders who did nothing to help would suffer no legal consequences. This doctrine emphasized the legal freedom of persons to do no affirmative acts in a "hands-off" society ("Nonfeasance over "malfeasance."). In doing so, however, this legal policy had the unfortunate effect of constraining beneficial impulses and leaving many accident victims to their fate. Hence, legislators began passing "Good Samaritan laws" that exonerated well-meaning interveners who caused harm in a crisis (e.g., Neb. Rev. Stat. s 25-21, 186; Va. Code Ann. s 8.01-223). Arguably, some of this "Good Samaritan" philosophy would apply to the present context. Volunteer drivers should also be accorded some measure of this kind of legal protection, although it might be proportionally less, given the routine nature of their altruism. In other words, society might elect to place less of a premium on conduct that is less urgent, so the exculpation of volunteer drivers might be less complete than that given emergency workers.

(3) On similar grounds of purpose and beneficence, it also seems arguable that non-profits and charities are entitled to some limited degree of legal protection. Their exposure to legal risk should probably not be as great as that of for-profit entities, who can insure against accidents as a simple economic calculus of doing business. Moreover, the same concerns that motivate the doctrine of sovereign immunity apply here: anticipating legal action and defending against it can be a distraction from a charity's legitimate mission. 
ADMINISTRATIVE AND OPERATIONAL REFORMS

RISK MANAGEMENT REQUIREMENTS

First, it may be possible to take some measures to reduce the probability of liability situations in the first place. These would be preventative actions that volunteer driving programs could undertake at the administrative or operational level, which might be termed "screening, training, and supervision" and, with regard to equipment, "inspection."

There is a continuum of such administrative/operational measures, ranging from the lightest and least onerous to the strictest and most formal. At one end of this spectrum, these actions might include drivers' license checks, contractual agreements of services to be rendered and records to be kept, simple orientations and training on spotting signs of illness, monitoring of volunteers by supervisors, and annual vehicle inspections. At a far stricter level, they might include thorough background checks (even with fingerprinting), driving tests, defensive-driver training, physical examinations, mandatory $\mathrm{CPR} /$ defibrillator/first-aid/special equipment training, close supervision, and frequent car/equipment checks.

Obviously, an equilibrium point needs to be found here between the extremes of regulatory laxity and severity. Once again, there are multiple policy trade-offs, with increasing safety and security being counterpoised against excessive burdens on volunteers and organizations. Among other factors, implementing authorities need to remember the voluntary nature of the services provided and the capitalization of the providers. These factors might call for reduced levels of stringency for charities relative to the measures imposed on for-profit liveried organizations and drivers.

To better protect the clients of volunteer driving programs, it is proposed that federal and/or state laws require them to implement certain screening, training, supervision, and inspection practices for volunteer drivers. There is little doubt that highly stringent procedures for vetting and reviewing volunteers would stretch the resources of small volunteer driving programs and potentially antagonize their drivers. Volunteers also have some reasonable expectations of privacy that need consideration and their service records as volunteers may need protection.

One statutory/regulatory approach might be to require better-capitalized charities to implement more stringent screening, training, supervision, and inspection procedures than poorer ones, but this seems a doubtful idea from an operational and policy perspective: It would be cumbersome administratively to set up a hierarchy of standards based on the organizations' varying (and changing) wealth, and it could send a wrong message that the clients of poorer charities somehow deserved less protection.

Thus, it would probably be more realistic for statutes or regulations to mandate minimum procedures for all volunteer driving programs, such as driver license checks, criminal record checks, record keeping and supervision, simple first aid and resources training, and annual car inspections. More intensive programs of screening, training, supervision, and inspection practices might be encouraged, with incentives for the programs and their volunteers to participate. It might be possible for state agencies to subsidize, or even take on, some of the routine vetting and training functions. In principle, these measures would help protect everybody involved, including the vulnerable clients, the volunteer driving programs, and the volunteers, so these programs could be presented in the favorable light of common safety and public trust.

From a legal perspective, the FED-VPA would probably permit Florida to impose such increased standards, since this law says that it will allow states to condition any reduced volunteer liability on added state statutory requirements that "a nonprofit organization or governmental entity ... adhere to 
risk management procedures, including [the] mandatory training of volunteers." 42 U.S.C. $\mathrm{s}$ 14503(d)(1)

CONTRACTS

In association with the above protective measures, it would probably be prudent for volunteer driving programs to formalize their relationships with their volunteers and clients by using contracts. Understandably, the participants of some small, informal and amicable programs might regard this step as somewhat chilling. Still, it is arguably crucial for all parties in a volunteer driving program to have a clear idea of their roles, duties, obligations and entitlements from the start. The contracts should be in clear and simple language, and they should be thoroughly explained before signing. The organization would have a duty to ask its volunteers and clients if they understood the terms and had any questions about them. In a more general way, it would also behoove volunteer driving programs to discuss the hazards and safety precautions of the service arrangement with a prospective client in advance. This action would be less done for exculpation than for simple safety purposes, and to avoid misunderstandings and ill will later.

\section{A SPECIAL CONTRACT ISSUE: EXCULPATORY CLAUSES IN PROGRAM/RIDER CONTRACTS}

One option for reducing the liability of volunteer driving programs in relation to riders would involve the use of exculpatory clauses in contracts between the program and the rider. Sometimes these are termed "waivers or releases of liability." Under this approach, a non-profit organization might ask a prospective client to sign a contract that would free the organization, and sometimes the volunteer, from liability if the volunteer caused the client negligent injury in the course of service. This might be a quid pro quo for receiving the ride. Such provisos are founded on the legal "right to contract," and courts uphold them under some circumstances. (See, e.g., Merten v. Nathan, 108 Wis.2d 205, 210, 321 N.W.2d 173, 176 (1982), cited by Alexander T. Pendleton, "Enforceable Exculpatory Agreements," 70 WIS. LAW. 10, 18 [Nov. 1997].) In recent Florida cases not involving volunteer driving, district courts of appeals have sometimes upheld exculpatory clauses (e.g., Shaw v. Premier Health and Fitness Ctr., Inc., 937 So. 2d 1204 [Fla. $1^{\text {st }}$ DCA 2006]; Hopkins v. The Boat Club, Inc., 866 So. 2d 108 [Fla. 1st DCA 2004]), and sometimes invalidated them (e.g., Cain v. Banka, 932 So.2d 575 [Fla. $5^{\text {th }}$ DCA 2006]).

However, exculpatory clauses are generally troubling, and they may be unjustified in the context of a volunteer driving program. Arguably, waivers may shift the policy "scales" too far in the direction of protecting the programs and volunteers, and against protecting the interests of the elderly clients. In any case, they may not be an effective defense in court, since judges tend to be suspicious of such waivers, and usually construe them strictly against the organizations that try to invoke them. (See, e.g., 70 WIS. LAW., at 10; 32 AKRON L. REV., at fn. 59.) In Tunkl v. Regents of the Univ. of Calif., 383 P.2d 441, 445-46 (Cal. 1963), the California Supreme Court enunciated several criteria for invalidating liability waivers, and some of these appear to apply here. (See also 32 AKRON L. REV., at fns. 59, 63).

The theory behind exculpatory contracts is that the signor fully and subjectively understands the risk involved. In return for receiving the desired service, the signor voluntarily assumes that risk, giving up his or her right to sue for future negligence. However, this raises a number of legal concerns in the present context. First, courts will ask if there was an unequal bargaining position between the parties, and many seniors desperately seeking transportation might have been unable to refuse any terms imposed on them. In addition, the mental status of many potential riders may raise questions about their capacity to understand what rights they were signing away. Further, the senior riders put themselves under the full control of the drivers during the trip, utterly relying on their skillful driving, and courts will weigh this fact heavily in their decisions. Ultimately, remarked one commentator (70 WIS. LAW, at 66), "[t]he first thing that attorneys should tell clients who want to rely upon exculpatory 
agreements is 'don't bet the farm' on ... [their] enforceability." In the end, releases of liability are arguably inappropriate in a volunteer driving program context.

\section{INSURANCE REFORMS}

Volunteers and charities/non-profits have legitimate concerns about their insurance to cover any future costs. This study did not find direct evidence that individuals and programs have difficulty finding insurance due to volunteer status and the nature of the service. However, the literature review on volunteer driving programs reports that some insurance carriers have denied coverage to charities/non-profits and their volunteers on those grounds. Historically, some insurance companies have been concerned about non-profit organizations that make extensive use of volunteers, particularly when the provided services involve extensive driving. In the eyes of these firms, there might seem to be a risk of limitless, or at least unpredictable, liability. On the public record, few lawsuits against volunteer driving organizations and their volunteers have actually reached the courts, but this does not rule out a larger number that might have been settled out of court. Moreover, the perception of extensive liability could be even more important than the reality of it. Some insurance carriers have responded by discriminating against charities/non-profits and their volunteers, denying them coverage, refusing to renew their policies, or raising their premiums. For the sake of charities/non-profits, their volunteers, and the services they provide to society's needy, this situation needs remedy.

\section{FLORIDA'S NEW STATUTE BARS INSURERS FROM PENALIZING VOLUNTEER DRIVER STATUS}

On June 15, 2007, Governor Crist signed HB 359 (2007 Fl. ALS 150) into law, aiming to address this problem. Section 5 of the new act amended Fla. Stats. Ann. s 627.7261 to provide, in pertinent part, that

An insurer may not deny an application for automobile liability insurance or impose a surcharge or otherwise increase the premium rate for an automobile liability policy solely on the basis that the applicant [or another regular user of the vehicle] ... is a volunteer driver. Sec. 627.7261(2)(a)

Florida's new law goes some distance to protecting volunteer drivers in the state from insurance penalization, but it does leave some lingering concerns. First, the new statute also includes a provision stating that:

[t]his section does not prohibit an insurer from refusing to renew, imposing a surcharge on, or otherwise increasing the premium rate for an automobile liability insurance policy based upon factors other than volunteer status of the persons named in this subsection. Sec. (2)(c) (emphasis added).

In practice, this phrasing might be a loophole in some cases. It is not clear how much an insurance carrier needs to prove that it was not discriminating against drivers on grounds of their volunteer status. Some alternative pretexts could be found. It would be especially problematic for volunteer drivers who actually did get into accidents while doing their charitable work. At that juncture, regardless of fault, their insurers might openly raise their rates or drop them from coverage because those accidents were "factors other than [mere] volunteer status."

Another concern relates to other insurance company practices that may adversely impinge on volunteer drivers. Many insurance carriers adjust their premiums based on the approximate number 
of miles driven per year by their policyholders or by other drivers in their households. In the course of driving seniors in their own cars, especially helpful volunteers might rack up high mileage each year. By its terms, the new statute prohibits insurers from dropping such drivers or imposing surcharges on them "solely on the basis of" their volunteer status, but it would not seem to preclude the carriers from raising their rates strictly based on miles driven per year. There would be some question if the new law would provide adequate protection to volunteer drivers in such cases. At least, individual volunteers would likely have to show affirmatively that they were incurring the mileage in the course of service in a protected status.

The limited background data on HB 359 did not indicate whether the legislators considered the above points. In any event, HB 359 does not, in itself, obviate the arguable need to accord volunteer drivers a degree of statutory protection under the FL-VPA from liability for simple negligence.

\section{LIABILITY REFORMS}

At a later "stage" of the liability process are the "liability reforms," which address the question of how much legal liability should be imposed on volunteer drivers if, despite the above pre-event precautions, they do get into accidents. In exchange for mandating certain administrative and operational protections to clients, as discussed above, the policy "scales" could be further balanced somewhat by amending state and/or federal Volunteer Protection Act statutes to reduce the liability burden on volunteer drivers in senior volunteer driving programs.

One approach may be to revise Florida's existing FL-VPA (Fla. Stats. s 768.1355) so that it finally has real protective meaning. The wording in Section 768.1355(1) should simply state that volunteers (including senior rideshare drivers) will be protected from civil liability if they were acting in good faith within the scope of their official duties, and not performing those duties in a manner of wanton or willful misconduct. In other words, legislators should expunge the "ordinary reasonably prudent person" requirement from Section (1)(a).

Would such a state legislative remedy square with the requirements of federal law? By its own terms, the federal statute preempts and invalidates any state laws that are less protective of volunteers than it is, but it allows the states to enact laws that are more protective of volunteers. 42 U.S.C. s 14502(a). The above proposal would make Florida's VPA as protective of volunteers as the FED-VPA with regard to the ordinary negligence standard while continuing to extend coverage to volunteer drivers as well as to other volunteers. This would make the current FL-VPA more protective than the current FEDVPA. The federal statute would, in principle, permit Florida to change its law as recommended here. In fact, it could be argued that this remedy would correct current Florida law, whose harsher tort liability standards should actually be preempted by the FED-VPA's standards.

An alternative legislative remedy might be accomplished at the federal level. The curious gap in protection that Congress placed around volunteer drivers in the FED-VPA (42 U.S.C. s 14503(a)(4)) should reasonably be removed. Specifically, this would require taking out the word "not" in the FEDVPA language contained in 42 USC. Sec. 14503(a)(4), as shown below.

Liability protection for volunteers

...no volunteer of a nonprofit organization or governmental entity shall be liable for harm caused by an act or omission of the volunteer on behalf of the organization or entity if - ...the harm was caused by the volunteer operating a motor vehicle...for which the state requires the operator...to

(A) possess an operator's license; or

(B) maintain insurance. 
This would better address the explicit Congressional concern, found in the law's own preamble, over the high cost of insurance policies that may be burdening volunteer drivers and the volunteer driving programs that have hired them. (See, e.g., 42 U.S.C. s 14501(a)(6).) Of course, Congressional amendment of the federal VPA would no doubt be slower and harder than state action. Representative John Porter of Illinois submitted a proposed FED-VPA bill every year for ten years before Congress passed the final version in 1997. Still, this federal statutory remedy might be preferable, since it could offer protection for volunteer drivers across states.

A remaining issue concerns the relationship between the tortfeasor volunteer and the nonprofit or agency that employed him. Under the FED-VPA, the organization could still sue the volunteer. 42 U.S.C. s 14503(b). (See also Kenneth W. Biedzynski, "The Federal Volunteer Protection Act: Does Congress Want to Play Ball?" 23 SETON HALL LEGIS. J. 319, 345 [1999].) It may be questioned whether this situation would be desirable public policy, in the absence of special culpability by the volunteer.

In addition, the current FED-VPA explicitly excludes the charities/non-profits themselves from any liability protection. ("Nothing in this section [of the FED-VPA] shall be construed to affect the liability of any nonprofit organization or governmental entity with respect to harm caused to any person." 42 U.S.C. s 14503(c).) Arguably, this may leave small, underfunded volunteer driving programs at high risk. Perhaps in return for taking administrative and operational measures to avert accidents, as proposed above, the organizations themselves should be entitled to a limited measure of protection, such as a cap on liability damages, discussed below.

\section{REFORMS TO PAYMENT OF DAMAGES}

Thus far, recommendations have been made with respect to administrative and operational reforms, use of contracts, and liability reforms. The next set of options presented is those relating to the issue of damages. These do not address the basic questions of volunteer or program risk management, insurance coverage, or their degree of liability in an accident (i.e., basic duty of care to other parties). They do address the issue of remedies, assuming that an accident has actually happened and costs have been allocated to the volunteer or the program. Which defendants would pay? How much would they pay? How would they avoid ruinous losses? Several mechanisms have been proposed for addressing the issue of damages, mainly to take the load off the "thin pockets" of small organizations.

\section{"CAPS" ON DAMAGES}

One method used in some settings is to place a "cap" or "ceiling" on the amounts of damages that organizations must pay when they are found liable. This would keep a poorly funded and socially useful organization from bearing a hugely burdensome financial loss for a single event. However, the use of a cap on an organization's liability is controversial. Some would argue that it continues the failings of the old charitable immunity doctrine and the "sovereign immunity" doctrine, denying an accident victim his or her right to full redress of damages, as determined by a jury, and therefore weighing the public policy "balance" too heavily on the side of the organization. At least one volunteer driving case involved a major dispute over the implementation of such a cap on a defendant's damage obligations.

In the Wisconsin case of Manor v. Hanson, 123 Wis. 524, 368 N.W.2d 41 (1985), Anna Hanson, a volunteer driver for the Trempealeau County Volunteer Transportation Program struck another car while driving a senior to the doctor. The collision killed the other motorist, Neil Manor. His widow sued Ms. Hanson and Trempealeau County for "wrongful death." Among other things, the plaintiff argued that the county was vicariously liable for Ms. Hanson's act for two reasons. First, she was 
acting as its "servant" when she hit the Manor car, which would subject the county to liability of up to a cap of $\$ 25,000-$ but no more (under Wis. Stats. Ann. 893.80(3) (1979-80). Second, the county was also "renting" the use of her car at the time, which would make it liable for additional damages under another state statute that waived a local government's immunity when it owned or rented the vehicle involved (Wisc. Stats. Ann. s 345.05(2)).

After the jury found Ms. Hanson 100 percent liable, it awarded the plaintiff $\$ 296,550.50$ in damages. The trial court determined that Trempealeau County had to share $\$ 25,000$ of liability with the luckless volunteer and it also had to pay the full balance of $\$ 271,558.50$ that the jury had awarded, since the county was indeed "renting" Ms. Hanson's car at the time of the accident. Both Trempealeau County and plaintiff Manor appealed. A local appellate court determined that the county was not actually "renting" the Hanson car under the terms of the law, which would limit its liability to $\$ 25,000$ (shared with the volunteer). However, Manor v. Hanson eventually reached the Wisconsin Supreme Court, which upheld the trial court's conclusions, and levied the additional $\$ 271,558.50$ on Trempealeau County.

\section{A “CHARITABLE REDRESS SYSTEM"}

Commentator Charles Robert Tremper proposed one approach to the problem of expenses for volunteer and charity liability, advancing a system he called the "Charitable Redress System" ("CRS") (76 CORNELL L. REV., at 444-476). In general terms, this system would operate somewhat like a combination of Workers' Compensation programs and the National Childhood Vaccine Injury Act compensation program (42 U.S.C. ss 300aa-10 to 300aa-34 [Supp. 1988]). Simply put, Tremper's CRS proposal would involve the following components:

- A first-party insurance would cover charities for most injuries to third parties. The insurer would make relatively quick payment offers to the latter that would apply only to economic losses, including medical expenses, expenses for adjustment to disability, and property damages.

- Replacements of lost earnings and loss-of-life compensation would be treated differently from the standard tort law system.

- Noneconomic losses, such as injuries to dignity, would not be compensated, and plaintiffs could only get punitive damages under a high standard of proof establishing that the harm was caused deliberately.

- If the accident victim was compensated by other sources, these would reduce his or her recoveries under the CRS, as in Workers' Compensation cases.

- As a separate matter, joint-and-several liability would not be permitted.

- Finally, if the charity did not make the accident victim a CRS offer, the accident victim would have a last resort opportunity to file a lawsuit, with potential recovery being a multiple (perhaps $1 \frac{1}{2}$ ) of his or her CRS entitlement, plus attorney fees.

As Tremper saw it, his CRS would better serve the goals of social policy and serve the interests of all parties in the event of a volunteer-caused accident, than does the current tort system. For the injured claimant/client, the proposed system would provide relatively certain and rapid payment of medical bills and collateral bills. For its part, the nonprofit or charity would benefit by having more predictable and limited costs, which could enable it to obtain better insurance in the market. Moreover, Tremper believed that his CRS would efficiently spread the losses incurred in an accident, not leaving them to the accident victim. $\underline{I d}$, at $444-45$.

Tremper also sought to protect the volunteers themselves from overwhelming loss when their charity employers could not cover them for simple negligence. He recommended that, in such cases, the 
volunteers' losses be statutorily limited to the extent of their own liability insurance coverage, if any. Id., at 457-58.

POOLING OF COSTS

In a related approach, volunteer driving programs might band together and spread the risks across their larger numbers. Either they would "self-insure" or they would get a commercial carrier to insure them collectively. This concept in some ways resembles the concept of "risk pooling," and it shares some of its features. It would be beneficial in providing larger capitalization for paying premiums and better negotiation power with insurers. On the other hand, it might be logistically difficult to manage, considering the heterogeneity and varying interests of the volunteer driving organizations. Appendix $E$ provides an example of an insurance risk pool for volunteers of nonprofit organizations.

FEDERAL PAYER

A similar, but alternative approach would tap one of the "deepest pockets" of all, the federal government. Perhaps as a concrete expression of national appreciation for charitable service, the government might cover the liability costs of nonprofit organizations. This consideration already exists in the form of federal income tax exemptions for certain nonprofits. For example, the Swine Flu Immunization Act of 1976 (Pub. L. No. 94-380) was passed to encourage skittish pharmaceutical companies to perform the vital social act of making vaccines. In this Act, Congress agreed to cover their lawsuit costs for vaccine-related injuries. The Swine Flu Immunization Act could be a model for federal coverage of lawsuits involving nonprofit organizations. If this payment method is adopted, it should probably be tied to a mandate for adequate pre-accident risk-management efforts by the charities/non-profits, as discussed above.

\section{LIABILITY OF PUBLIC SECTOR PROGRAMS ENGAGING VOLUNTEERS}

A special class of organization that provides volunteer driving options for senior citizens in some localities is the public sector agency. This is not a common volunteer driver provider in Florida, but some agencies in the state that might, in some ways, fit this description. These include the City of Jacksonville Transit Authority, which provides special transit pick-ups for seniors in its metropolitan area and the Sarasota County Area Transit, which provides paratransit services to persons who cannot use fixed-route transportation. It might also include the Manatee County Advisory Board on Senior Supplemental Transportation Programs, which was planning to outsource senior transportation services to a nonprofit organization. Although some general rules apply to both public sector volunteer driving programs and private sector nonprofits, including vicarious liability, public sector providers are subject to some distinctive legal doctrines as well.

\section{THE DOCTRINE OF "SOVEREIGN IMMUNITY"}

Most importantly, public agencies have been historically covered by the doctrine of sovereign immunity. This ancient doctrine goes back to the English common law, which asserted that the English monarch could not be held legally liable in the courts of the realm (under the legal fiction that "the king could do no wrong"). Later, sovereign immunity crossed the Atlantic, and it survived the American Revolution in judge-made law and legislative statutes. It had a number of practical underpinnings, including a concern that policy makers and administrators might be beset by a myriad of frivolous lawsuits for their public actions, which would impede governance in the common interest. The federal government and virtually all of the states and territories retain some degree of sovereign immunity in their codebooks, explicitly or implicitly. 
Over the years, however, it began to appear that the principle might cause unfair outcomes in some specific circumstances. At a pragmatic level, it also seemed that the public authority would frequently have a better capacity to insure against risks and to spread out its costs than would victims of agency torts. Thus, the federal government passed statutes, including notably the Federal Tort Claims Act, 28 U.S.C. ss 1346,2671 , et seq., that waived its sovereign immunity in some narrowly limited contexts. A number of states and territories have done likewise, waiving their own sovereign immunity from certain tort liabilities, and waiving immunity for their legal subdivisions, such as counties, parishes, and incorporated towns. In 1973, for example, the State of Florida passed a law waiving its own sovereign immunity and allowing itself to be sued in court under circumscribed conditions. Fl. Stats. Ann. ss 768.28 , et seq. This statute will be discussed further below.

Sometimes, the old tort doctrine of sovereign immunity can become an important issue in volunteer driving arrangements, when injured passengers or third parties sue quasi-governmental rideshare entities, and courts must decide if they are sufficiently governmental in character to come under this doctrine.

In 2000, an Illinois court addressed a relevant case, Niehaus v. Rural Peoria Co. Coun. on Aging, Inc., 314 III. App. 3d 665, 732 N.E. 2d 132, 247 III. Dec. 416. Plaintiff Niehaus, an elderly woman, sustained injuries while being transported to the local YWCA in a van run by the Rural Peoria County Council on Aging (RPCCA), a non-profit charitable organization. Ms. Niehaus sued RPCCA. She claimed that it was not a governmental organization exempted from liability under Illinois's Local Governmental and Governmental Employees Tort Immunity (LGGETI) Act. The circuit court threw out her case, concluding that the RPCCA was protected by law as a de facto governmental entity. However, the Third District Appellate Court disagreed, concluding that the charity was not a public sector agency entitled to protection under the LGGETI Act, and it reinstated the plaintiff's right to sue the charity.

FLORIDA'S WAIVER OF SOVEREIGN IMMUNITY LAW

For present purposes, Florida's waiver of sovereign immunity law (FL-WSIL) has three important features.

- First, the act states that an injured party could sue the state or its subdivisions for a negligent or wrongful act or omission by an employee in the line of duty "... if a private person, would be liable to the claimant, in accordance with the general laws of this state." Sec. 768.28(1).

- However, the statute bars any recoveries for punitive damages, and it caps all state and subdivision liability to one plaintiff at $\$ 100,000$ and to all plaintiffs in an action at $\$ 200,000$, unless the Legislature elects to pay a larger judgment. Sec. 768.28(5). Separately, the law does permit agencies to insure themselves or to purchase liability coverage, and to settle claims for more than the $\$ 100,000 / \$ 200,000$ amounts within their insurance coverage. Id.

- Finally, the FL-WSIL exempts the state's employees or agents, including certain volunteers, from personal liability for their actions or omissions within the scope of their duties, so long as they had not acted "in bad faith or with malicious purpose or in a manner exhibiting wanton and willful disregard of human rights, safety, or property." Sec. 768.28(9)(a). On the other hand, the causative employee or agent would "be considered an adverse witness in a tort action" against the state or its subdivision. Id. 
LIABILITY PERSPECTIVE OF VOLUNTEERS

It is not entirely clear whether the FL-WSIL would cover volunteer drivers who work for a state or local agency. By itself, the waiver statute only defines "employee" of the state or its subdivision as including "volunteer firefighters." Sec. 768.28(9)(b)1. Under some principles of statutory construction, this might seem to exclude silently other sorts of public sector volunteers, since they are not explicitly mentioned. On the other hand, another Florida statute covering a variety of state agency volunteers defines them as "any person[s] who ... provide ... services ... to any state department or agency, or nonprofit organization, with no monetary or material compensation." Fla. Stat. Ann. s 110.501(1). The latter act goes on to state, in another provision, that such "[v]olunteers shall be covered by state liability protection in accordance with the definition of a volunteer and the provisions of $s$ 768.28." Sec. 110.504(4). Thus, the statutory wording of Sec. 110.504 does not fully indicate whether it refers to the narrow definition of "volunteer" in Section 768.28(9)(b)1, which appears to only include volunteer firefighters, or whether it refers to the broader provision of Section 110.501(1), which encompasses all types of volunteers for state agencies, local agencies, or even private nonprofit agencies. The statutory context of Sec. 110.504(4) appears to apply to many different kinds of agency volunteers, so this meaning may have been intended, but its reference to Sec. 768.28 is still ambiguous. If this issue came up in litigation, a court would have to decide which meaning to adopt.

This seeming minor statutory distinction may have some significant implications for volunteers. Since it has been pointed out elsewhere in this analysis that the FL-VPA currently gives only limited liability protection to volunteers in general, it is possible that volunteer drivers who serve in a state-sponsored senior driving program will be in a special protection class under Secs. 110.504(4) and 768.28(9)(a). If this reading were correct, such public sector volunteer drivers would only need to avoid "act[ing] in bad faith or with malicious purpose or in a manner exhibiting wanton and willful disregard of human rights, safety, or property." By contrast, the FL-VPA states that volunteers in general must avoid even acts or omissions of simple negligence.

\section{LIABILITY PERSPECTIVE OF STATE AND LOCAL AGENCIES}

From the perspective of any county, public transit agency or municipal senior volunteer driving programs, it is important to know if they would come under the protective "umbrella" of sovereign immunity. If so, they would be intrinsically protected from liability in case one of their drivers negligently caused injuries or property damage.

Unfortunately, it is difficult to give the agencies a clear answer. The exceptions and applications that pertain to the doctrine of sovereign immunity at the federal and state levels are highly complex. The statutes themselves have often been written in difficult language, further burdened by complicating amendments added over the years. Courts have further confused matters by developing elaborate interpretive doctrines, and applying them differently to the sovereign immunity-waiver statutes from case to case. The Florida judiciary has certainly done this. (See, e.g., William N. Drake, Jr. \& Thomas A. Bustin, "Governmental Tort Liability in Florida: A Tangled Web," 77-FEB. FLA. B. J. 8 (2003).) This can make it very difficult for agencies and their agents to predict how the law will apply to them and shape their practices accordingly.

Without detailing the complex evolution of judicial interpretations of Florida's statutes in the last three decades, it can be said that the state's Supreme Court has gradually widened the public sector's liability over time. This has been especially true for local government agencies, including counties and municipalities, which may sometimes be the providers of volunteer driving services. (See the discussion by Drake \& Bustin, above.) In a 1979 case, Commercial Carrier corp. v. Indian River Co., 371 So. $2 \mathrm{~d} 1010$, the Florida Supreme Court first interpreted the FL-WSIL, and directed lower courts to be 
"sensitive" to whether or not the state agency's particular act, omission, or decision involved "discretion," which would make it protected by sovereign immunity. Six years later, the same court developed very different criteria in another FL-WSIL sovereign immunity case, Trianon Park Condominium Ass'n v. City of Hialeah, 468 So. $2 \mathrm{~d} 912$. At this juncture, the court distinguished between agency functions that involved the following.

(1) Legislative, permitting, licensing, and executive officer functions (always covered by sovereign immunity)

(2) Law-enforcement and public protection (generally covered by sovereign immunity)

(3) Capital improvements and property control functions (same duties as private persons)

(4) Provision of professional, educational, and general services (not covered by sovereign immunity)

Presumably, volunteer driving services would fall under the last class of governmental functions, so they would theoretically not be protected from liability under this Trianon Park standard, but the issue has not been explicitly addressed.

In a 1989 case, the Florida Supreme Court came up with yet another interpretation of the FL-WSIL, this time asserting that " $[w]$ here a defendant's conduct creates a foreseeable zone of risk, the law generally will recognize a duty placed upon the defendant to lessen the risk or see that sufficient precautions are taken to protect others from the harm that the risk poses." Kaisner v. Kolb, 543 So. $2 d$ 732. As Drake \& Bustin remarked, this "foreseeable zone of risk" approach in Kaisner led the court usually to find that agencies had a duty to injured persons, and thus were subject to suit. 77-FEB. FLA. B. J., at 14.

In their analysis, Drake \& Bustin urged the Florida high court to clarify Florida sovereign immunity law. "Lower appellate courts are struggling to apply the incomprehensible law in this area. There are few activities which state and local government can have confidence will not be subject to court scrutiny and potential liability." Id., at 15 . These authors recommended that Florida law follow the law in federal sovereign immunity cases, which focused on whether a state agency would have had a duty to the injured person if it had been a private entity. Barring such court action, they wrote, the Legislature should revise the law to better define the bounds of sovereign immunity in Florida.

Given the current state of sovereign immunity law in Florida, and given the judiciary's apparent philosophical dislike for this old doctrine, it would probably be prudent for state and local agencies to assume that it will give them little or no liability protection if one of their volunteer or paid drivers causes an accident. 


\section{APPENDIX F}

EXAMPLES OF STATE SAFETY REQUIREMENTS FOR TRANSPORTATION FOR VULNERABLE POPULATIONS

Many states currently impose an assortment of these measures on for-profit liveried or subsidized transportation companies and agencies, especially when they work with day-care toddlers, schoolchildren, or the disabled. To cite some examples:

FLORIDA

Florida requires that drivers for day-care facilities have a valid state driver's license, insurance, an annual physical examination, and certification in first aid and CPR. They must maintain appropriate logbooks; and their vehicles must be inspected annually. 65 FL ADC 65C-22.008(3)(s).

\section{TENNESSEE}

Tennessee mandates that day-care center vehicles carrying over fifteen passengers be driven by commercially licensed operators. They must carry emergency reflective devices, first-aid kits, and blood-borne pathogen clean-up kits. Staff must periodically practice emergency exiting procedures, although volunteers providing occasional rides need not do so. Paid and volunteer drivers must keep records of operation. TN ADC 0520-12-1-.06.

\section{WISCONSIN}

Wisconsin directs that drivers for youth residential care facilities-including paid staff and volunteersbe at least 18 years old, with at least one year of licensed driving experience and no convictions for reckless driving or DUls within the previous year. Also, the facilities' vehicles must be registered, insured, and equipped with Red Cross-approved first-aid kits and emergency telephone numbers; they must also be kept clean, uncluttered, and enclosed while driven, with doors blocked and seat belts worn by all passengers. WI ADC s HFS 52.47.

\section{MISSOURI}

Missouri's detailed regulatory code states that, at least, transporters of the aged or the handicapped must, if they receive federal funds, maintain documentation of driver health, livery or common carrier licensing or demonstrated DUl-free records for three years, in-service training (including defensivedriving, handling wheelchairs and other assistive devices, using fire extinguishers, first-aid training, CPR training, Heimlich training, and knowledge of universal precautions for handling bodily fluids). The vehicles also must carry safety equipment that includes, among other things, extra electric fuses, ice-scrapers, a flashlight, spare tires and jacks or two-way radios for assistance, and emergency roadside warning devices. 19 Mo. Code of St. Regs. 15-7.040.

\section{PENNSYLVANIA}

Pennsylvania's Administrative Code orders staffers and volunteers of "personal care home" transport services to be 18 or older, with valid driver's licenses. The drivers cannot be residents of the home themselves. Operationally, they may be accompanied by trained assistants; they must use appropriate passenger restraints (such as seatbelts); and they may use only hands-free cellular phones. 55 Pa. Code s 2600.171(b). 